\title{
The interaction of flavonoids within the NO-system
}

Citation for published version (APA):

Beerens - Heijnen, C. G. M. (2004). The interaction of flavonoids within the NO-system. [Doctoral Thesis, Maastricht University]. Universiteit Maastricht. https://doi.org/10.26481/dis.20040923cb

Document status and date:

Published: 01/01/2004

DOI:

10.26481/dis.20040923cb

Document Version:

Publisher's PDF, also known as Version of record

\section{Please check the document version of this publication:}

- A submitted manuscript is the version of the article upon submission and before peer-review. There can be important differences between the submitted version and the official published version of record.

People interested in the research are advised to contact the author for the final version of the publication, or visit the DOI to the publisher's website.

- The final author version and the galley proof are versions of the publication after peer review.

- The final published version features the final layout of the paper including the volume, issue and page numbers.

Link to publication

\footnotetext{
General rights rights.

- You may freely distribute the URL identifying the publication in the public portal. please follow below link for the End User Agreement:

www.umlib.nl/taverne-license

Take down policy

If you believe that this document breaches copyright please contact us at:

repository@maastrichtuniversity.nl

providing details and we will investigate your claim.
}

Copyright and moral rights for the publications made accessible in the public portal are retained by the authors and/or other copyright owners and it is a condition of accessing publications that users recognise and abide by the legal requirements associated with these

- Users may download and print one copy of any publication from the public portal for the purpose of private study or research.

- You may not further distribute the material or use it for any profit-making activity or commercial gain

If the publication is distributed under the terms of Article $25 \mathrm{fa}$ of the Dutch Copyright Act, indicated by the "Taverne" license above, 
The interaction of flavonoids with the $\mathrm{NO}^{\circ}$-system

Chantal G.M. Beerens - Heijnen 
(C) Chantal G.M. Beerens - Heijnen, Maastricht 2004

ISBN 90 - $9018-397-3$

Printed by: Febodruk BV Enschede

Cover design: Esther van Hinsberg

Lay-out: $\quad$ Esther van Hinsberg

NOTOX Financial support by NOTOX Safety \& Environmental Research for the publication of this thesis is gratefully acknowledged.

Additional support to this thesis has kindly been provided by the Dr. Ir. van de Laar Stichting and Numico Research.

The study presented in this thesis was performed at the Cardiovascular Research Institute Maastricht (CARIM) and at the Nutrition and Toxicology Research Institute Maastricht (NUTRIM) which participates in the Graduate School VLAG (Food Technology, Agrobiotechnology, Nutrition and Health Sciences), accredited by the Royal Netherlands Academy of Arts and Sciences. 


\title{
The interaction of flavonoids with the $\mathrm{NO}^{\circ}$-system
}

\author{
PROEFSCHRIFT
}

ter verkrijging van de graad van doctor aan de Universiteit Maastricht, op gezag van de Rector Magnificus, Prof. mr. G.P.M.F. Mols volgens het besluit van het College van Decanen, in het openbaar te verdedigen op donderdag 23 september 2004 om 14.00 uur

door

Chantal Gerarda Maria Beerens - Heijnen

Geboren te Utrecht, 15 oktober 1974 


\section{Promotor:}

Prof. dr. A. Bast

\section{Co-promotor:}

Dr. G.R.M.M. Haenen

\section{Beoordelingscommissie}

Prof. dr. E.C.M. Mariman (voorzitter)

Prof. dr. R.J. Brummer

Prof. dr. I.M.C.M. Rietjens (Wageningen Universiteit)

Prof. dr. H.A.J. Struijker Boudier

Dr. S. Wiseman (Unilever Health Institute) 
"De waarde van een mens herkent men aan wat hij met zijn vrije tijd weet te doen."

(M. Waggerl) 



\section{Contents}

1 Introduction 1

$1.1 \quad$ Flavonoids.............................. 3

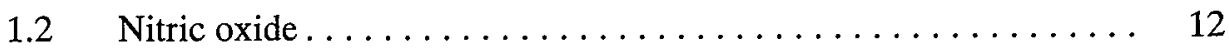

1.3 The interaction of flavonoids with the $\mathrm{NO}^{\circ}$-system $\ldots \ldots \ldots \ldots 17$

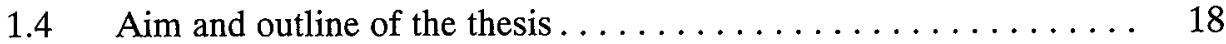

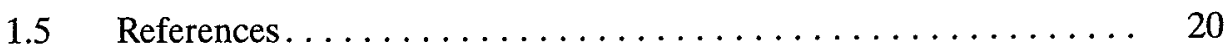

2 The interaction of tea flavonoids with the $\mathrm{NO}^{\circ}$-system: discrimination between good and bad $\mathrm{NO}^{\circ} 29$

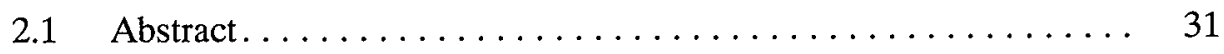

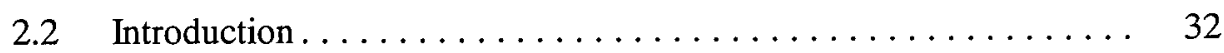

2.3 Materials and methods.................... 34

2.4 Results.......................... 36

2.5 Discussion......................... 40

2.6 References............................. 44

3 Flavonoids as peroxynitrite scavengers:

The role of the hydroxyl groups $\quad 47$

$3.1 \quad$ Abstract........................... 49

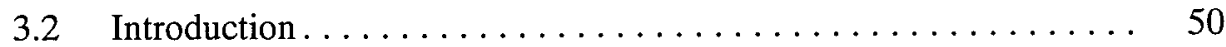

3.3 Materials and methods .................. 50

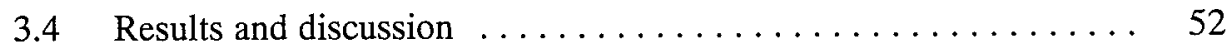

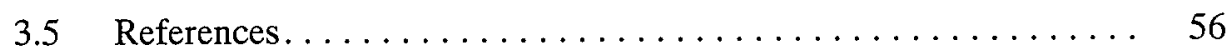


4 Peroxynitrite scavenging of flavonoids:

Structure activity relationship $\quad \mathbf{5 9}$

$\begin{array}{lll}4.1 & \text { Abstract } & 61\end{array}$

4.2 Introduction $\quad 62$

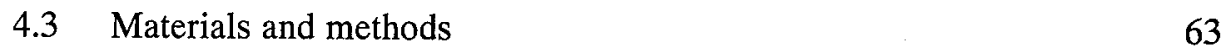

$\begin{array}{lll}4.4 & \text { Results and discussion } & 65\end{array}$

$\begin{array}{lll}4.5 & \text { References } & 78\end{array}$

5 Protection of flavonoids against lipid peroxidation:

$\begin{array}{ll}\text { The structure activity relationship revisited } & \mathbf{8 1}\end{array}$

$\begin{array}{lll}5.1 \text { Abstract } & 83\end{array}$

$\begin{array}{lll}5.2 & \text { Introduction } & 84\end{array}$

5.3 Materials and methods $\quad 85$

$\begin{array}{lll}5.4 & \text { Results } & 87\end{array}$

$\begin{array}{lll}5.5 & \text { Discussion } & 92\end{array}$

$\begin{array}{lll}5.6 & \text { References } & 99\end{array}$

6 The effect of flavonol-enriched tomato paste on blood pressure in spontaneously hypertensive rats $\quad 103$

$\begin{array}{lll}6.1 \text { Abstract } & 105\end{array}$

$\begin{array}{lll}6.2 \text { Introduction } & 106\end{array}$

$\begin{array}{ll}\text { 6.3 Materials and methods } & 107\end{array}$

6.4 Results 111

$\begin{array}{lll}6.5 & \text { Discussion } & 111\end{array}$

$\begin{array}{lll}6.6 & \text { References } & 118\end{array}$

$7 \quad$ Summary and general discussion $\quad 123$

$\begin{array}{lll}7.1 & \text { Summary and general discussion } & 125\end{array}$

$\begin{array}{lll}7.2 & \text { Conclusions } & 129\end{array}$

$\begin{array}{lll}7.3 & \text { Implications } & 129\end{array}$

$\begin{array}{lll}7.4 & \text { References } & 131\end{array}$ 
$8 \quad$ Samenvatting en algemene discussie 133

8.1 Samenvatting en algemene discussie $\quad 135$

$\begin{array}{lll}8.2 \text { Conclusies } & 139\end{array}$

$\begin{array}{lll}8.3 \text { Implicaties } & 140\end{array}$

$\begin{array}{lll}8.4 & \text { Referenties } & 142\end{array}$

Dankwoord 144

$\begin{array}{ll}\text { Curriculum Vitae } & 147\end{array}$

$\begin{array}{ll}\text { List of publications } & 148\end{array}$ 



\section{Chapter 1}

Introduction 



\subsection{Flavonoids}

The consumption of food is vital since it provides us with proteins, fats, carbohydrates, minerals, vitamins and other established nutrients. In addition, natural foods contain countless other compounds besides those established nutrients (Beecher, 1999). Many of these compounds have the capacity to modify enzymatic and chemical reactions and their impact on human health might be either positive or negative (Thompson, 1993) depending on, for example, the type and dose of the compound, and the combination with other elements. The health promoting compounds have become known as phytochemicals, phytonutrients and non-traditional nutrients. One very large group of phytonutrients that has gained much attention is the group of flavonoids.

\section{a) Chemical heterogeneity}

Flavonoids are a heterogeneous group of natural benzo-gamma-pyrone derivatives that are abundantly formed in fruits and vegetables used in our diet. To date more than 4000 different structures have been identified within this group, and even an additional variety of flavonoids is chemically synthesized. Despite this huge diversity, all flavonoids can be recognized by their structural properties. Most flavonoids contain three rings, referred to, as ring $\mathrm{A}, \mathrm{B}$, or $\mathrm{C}$. Ring $\mathrm{A}$ and $\mathrm{B}$ are aromatic and ring $\mathrm{C}$ is a heterocyclic ring. According to their backbone, the flavonoids are categorized in subclasses: flavones, flavonols, flavanones, flavanols (or catechins), anthocyanidins, chalcones and isoflavonoids depicted in figure 1 . The two latter subgroups belong to the flavonoid family, however their backbone is different. The chalcones have an opened C-ring, and in the subgroup of isoflavonoids the phenyl group (B-ring) is attached to the $\mathrm{C}$-ring to $\mathrm{C} 3$ instead of $\mathrm{C} 2$. Substitution of all these flavonoids can be hydrogenation, hydroxylation, methylation, malonylation, sulfation, and glycosylation (Harborne, 1988). Many flavonoids occur naturally as flavonoid glycosides including D-glucose, L-rhamnose, glucorhamnose, galactose, lignin and arabinose (Havsteen, 1983). The flavonoids mentioned in this thesis are given in table 1. The chemical structure and relative orientation of moieties on the molecule are responsible for the difference in biochemical activity between different flavonoids. 
Figure 1 Subclasses of flavonoid

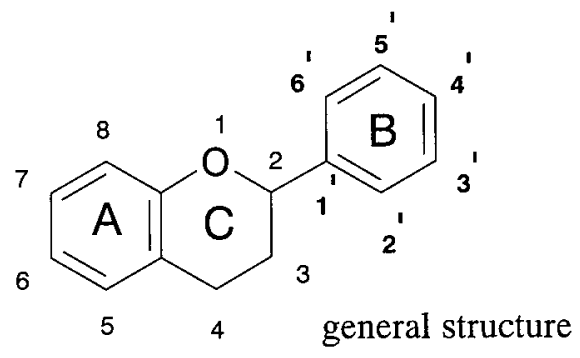<smiles>O=c1cc(-c2ccccc2)oc2ccccc12</smiles><smiles>O=c1c(O)c(-c2ccccc2)oc2ccccc12</smiles><smiles>O=C1CC(c2ccccc2)Oc2ccccc21</smiles><smiles>OC1Cc2ccccc2OC1c1ccccc1</smiles><smiles>Oc1cc2ccccc2[o+]c1-c1ccccc1</smiles>

flavanol

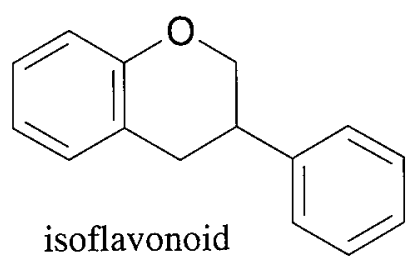
anthocyanidin<smiles>Oc1ccccc1CC=Cc1ccccc1</smiles> 

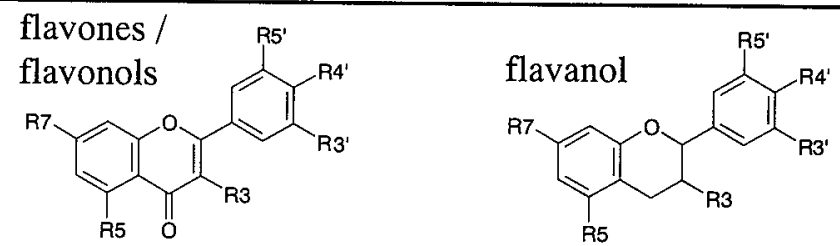

\section{Compound}

Substituents

\begin{tabular}{lllllll}
\cline { 2 - 6 } & $\mathbf{R 3}$ & $\mathbf{R 5}$ & $\mathbf{R 7}$ & $\mathbf{R 3}^{\prime}$ & $\mathbf{R 4}^{\prime}$ & $\mathbf{R 5}^{\prime}$ \\
\hline flavones & & & & & & \\
5-hydroxy-flavone & $\mathrm{H}$ & $\mathrm{OH}$ & $\mathrm{H}$ & $\mathrm{H}$ & $\mathrm{H}$ & $\mathrm{H}$ \\
7-hydroxy-flavone & $\mathrm{H}$ & $\mathrm{H}$ & $\mathrm{OH}$ & $\mathrm{H}$ & $\mathrm{H}$ & $\mathrm{H}$ \\
chrysin & $\mathrm{H}$ & $\mathrm{OH}$ & $\mathrm{OH}$ & $\mathrm{H}$ & $\mathrm{H}$ & $\mathrm{H}$ \\
apigenin & $\mathrm{H}$ & $\mathrm{OH}$ & $\mathrm{OH}$ & $\mathrm{H}$ & $\mathrm{OH}$ & $\mathrm{H}$ \\
\hline
\end{tabular}

\section{flavonols}

\begin{tabular}{|c|c|c|c|c|c|}
\hline 3-hydroxy-flavone & $\mathrm{OH}$ & $\mathrm{H}$ & $\mathrm{H}$ & $\mathrm{H}$ & $\mathrm{H}$ \\
\hline TUM 9761 & $\mathrm{OH}$ & $\mathrm{H}$ & $\mathrm{H}$ & $\mathrm{OBn}$ & $\mathrm{OBn}$ \\
\hline galangin & $\mathrm{OH}$ & $\mathrm{OH}$ & $\mathrm{OH}$ & $\mathrm{H}$ & $\mathrm{H}$ \\
\hline kaempferol & $\mathrm{OH}$ & $\mathrm{OH}$ & $\mathrm{OH}$ & $\mathrm{H}$ & $\mathrm{OH}$ \\
\hline quercetin & $\mathrm{OH}$ & $\mathrm{OH}$ & $\mathrm{OH}$ & $\mathrm{OH}$ & $\mathrm{OH}$ \\
\hline tri HEQ & $\mathrm{OH}$ & $\mathrm{OH}$ & OEtOH & OEtOH & OEtOH \\
\hline rutin & $\mathrm{O}-\mathrm{Ru}$ & $\mathrm{OH}$ & $\mathrm{OH}$ & $\mathrm{OH}$ & $\mathrm{OH}$ \\
\hline monoHER & $\mathrm{O}-\mathrm{Ru}$ & $\mathrm{OH}$ & OEtOH & $\mathrm{OH}$ & $\mathrm{OH}$ \\
\hline diHER & $\mathrm{O}-\mathrm{Ru}$ & $\mathrm{OH}$ & OEtOH & $\mathrm{OH}$ & OEtOH \\
\hline triHER & $\mathrm{O}-\mathrm{Ru}$ & $\mathrm{OH}$ & OEtOH & OEtOH & OEtOH \\
\hline penta-O-methyl-quercetin & $\mathrm{OCH}_{3}$ & $\mathrm{OCH}_{3}$ & $\mathrm{OCH}_{3}$ & $\mathrm{OCH}_{3}$ & $\mathrm{OCH}_{3}$ \\
\hline tetra-O-methyl-quercetin & $\mathrm{OH}$ & $\mathrm{OCH}_{3}$ & $\mathrm{OCH}_{3}$ & $\mathrm{OCH}_{3}$ & $\mathrm{OCH}_{3}$ \\
\hline
\end{tabular}

\section{flavanol}

catechin

$\mathrm{OH} \quad \mathrm{OH} \quad \mathrm{OH}$

$\mathrm{OH} \quad \mathrm{OH} \quad \mathrm{H}$

epicatechin

$\mathrm{OH} \quad \mathrm{OH} \quad \mathrm{OH}$

$\mathrm{OH} \quad \mathrm{OH} \quad \mathrm{H}$

epicatechin-gallate

O-gallate $\mathrm{OH} \quad \mathrm{OH}$

$\mathrm{OH} \quad \mathrm{OH} \quad \mathrm{H}$

epigallocatechin

$\mathrm{OH} \quad \mathrm{OH} \quad \mathrm{OH}$

$\mathrm{OH} \quad \mathrm{OH}$

$\mathrm{OH}$

epigallocatechin-gallate O-gallate $\mathrm{OH} \quad \mathrm{OH}$

$\mathrm{OH} \quad \mathrm{OH} \quad \mathrm{OH}$

$\mathrm{Ru}=$ Rutinose (=Glu-Rha), $\mathrm{Et}=\mathrm{CH}_{2} \mathrm{CH}_{2}, \mathrm{Bn}=$ Benzyl 
Figure 2 Scheme of the biosynthetic pathway of flavonoids in tomato (Verhoeyen, et al., 2002). Included are the structures of the major flavonol glycosides in tomato, rutin and its precursor isoquercitrin and kaempferol-3-rutinoside.

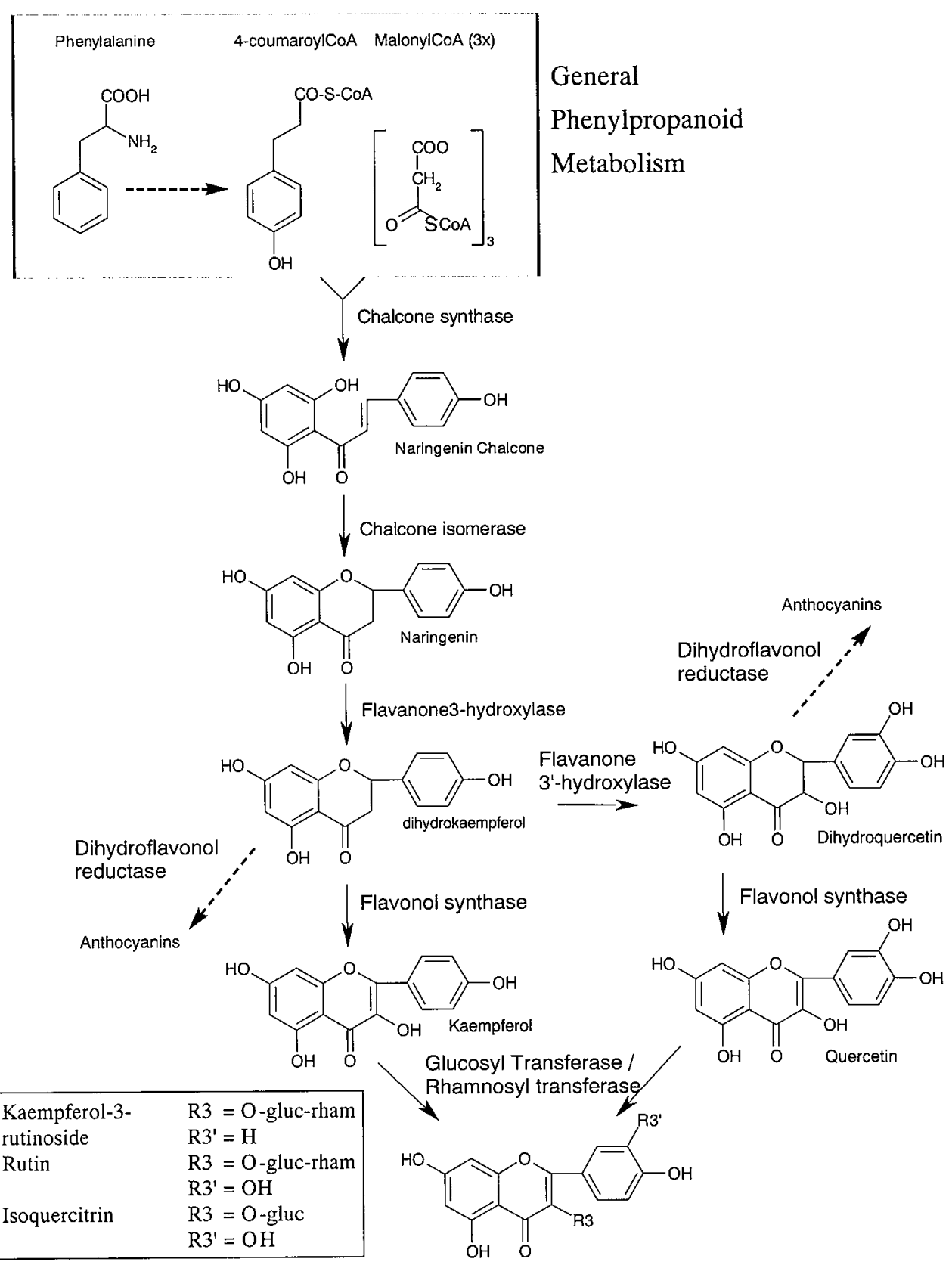


In most fruits and vegetables the flavonoids are synthesized and commonly deposited in the upper epidermal layers of leaves (Harborne and Williams, 2000, Stewart, et al., 2000). However, disposition also occurs in other parts of the plants such as fruits, roots, nuts, seeds, and flowers. In plants, the flavonoids are thought to have various functions including the protection against UV-B radiation, the defence against pathogens, the attraction of pollinating insects, and the use as signal compounds for the initiation of symbiotic relationships (Parr and Bolwell, 2000). The research of biosynthesis of the flavonoids in plant physiology is mainly aimed at alteration of anthocyanidin pigmentation (Mol, et al., 1998, Stewart, et al., 2000). From a health perspective, the biosynthesis of flavonoids is further investigated with emphasis on the flavones and flavonols (Verhoeyen, et al., 2002). The biosynthetic pathway is generally identical in many fruits and vegetables. The biosynthetic pathway depicted in figure 2 is present in the tomato, a fruit frequently used in our diet.

\section{b) Intake}

Authorities have not defined any recommended intake level for flavonoids. This is partly due to the fact that the average intake of flavonoids is difficult to estimate. Large variation exists in the composition of diets between different countries and subsequently also in the amount of flavonoids (or subgroup of flavonoids) that is consumed. In table 2 several sources of flavonoids are described (US Department of Agriculture, 2003). In some countries flavonoids from tea form a major part, $61 \%$, of the flavonoids ingested (Hertog, et al., 1993a).

The reported intake of flavonoids differs from $23 \mathrm{mg}$ (only flavones and flavonols) up to more than $1 \mathrm{~g}$ flavonoids per day. The highest average intake of total flavonoids reported is $1-1.1 \mathrm{~g}$ per day in the USA (Kuhnau, 1976). This is probably a too high estimate because of the outdated analytical method that has been used. Recently, the mean flavonol and flavone intake in US health professionals was determined at approximately 20 to $22 \mathrm{mg}$ per day (Sampson, et al., 2002). Of the flavonols and flavones studied, quercetin contributed $73 \%$ in the intake of women and $76 \%$ in the intake of men. In the Netherlands the intake of flavones and flavonols is determined as 23-34 mg per day (Hertog, et al., 1993b, Vries, et al., 1997) and $70 \%$ of this amount is quercetin. Hertog et al. (1993b) estimated a total 
amount of flavonoids of several hundreds of $\mathrm{mg}$ per day for the Dutch population. In Denmark an average intake of $28 \mathrm{mg}$ flavones + flavonols + flavanones per day (Justesen, et al., 1997) has been determined. Because of a higher consumption of fruits and vegetables, vegetarians have a $40 \%$ higher flavonoid intake than nonvegetarians (Moline, et al., 2000).

Table 2 flavonoid occurrence in foods (US Department of Agriculture, 2003)

\begin{tabular}{|lll|}
\hline selected food & subgroup & $\begin{array}{l}\text { amount } \\
\text { (mg/ 100g edible portion) }\end{array}$ \\
\hline apples (raw, with skin) & flavanols & 9.1 \\
& flavonols & 4.4 \\
\hline onions (red, raw) & anthocyanidins & 13.1 \\
& flavonols & 38.8 \\
\hline onions (white, raw) & flavonols & 5.52 \\
\hline tea (black, brewed) & flavanols & 113.8 \\
& flavonols & 3.9 \\
\hline tea (green, brewed) & flavanols & 133.3 \\
& flavonols & 5.21 \\
\hline tomato products (canned, puree) & flavonols & 4.2 \\
\hline wine (red) & anthocyanidins & 9.2 \\
& flavanols & 11.9 \\
& flavonols & 1.6 \\
\hline wine (white) & anthocyanidins & 0.06 \\
& flavanols & 1.4 \\
& flavonols & 0.06 \\
\hline
\end{tabular}


c) Absorption and metabolism

Except for a direct effect in the gastro-intestinal tract, absorption of the flavonoids from the diet is a prerequisite for a causal relation between the dietary flavonoids and their health effects. The absorption and subsequent distribution, metabolism, and excretion of flavonoids in humans are not known to the full extent.

Initially, flavonoids without a sugar molecule, the so-called aglycones, were regarded as the only form able to pass the gut wall. In the diet the flavonoids occur predominantly as beta-glycosides. Hydrolysis of these glycosides was considered not to take place in the gastro-intestinal tract (Hollman and Katan, 1998). This process was found in the colon by microorganisms that at the same time degrade the aglycones extensively (Kuhnau, 1976). Therefore, a limited absorption of dietary flavonoids was expected at that time. In 1995 Holman et al. published a study on the absorption of glycosides and aglycones in ileostomy subjects. They found that the absorption of orally administered quercetin aglycone and quercetin-rutinoside in the small intestine was respectively $24 \%$ and $17 \%$. The absorption of quercetin glucosides from onions was much higher, i.e. $52 \%$. These data demonstrate that the absorption of flavonoid-glycosides in the small gut does take place. The uptake of flavonoid-glucosides is suggested to occur via an active glucoside transport, which is suggested to be the $\mathrm{Na}^{+}$-glucose co-transporter (Gee, et al., 2000, Gee, et al., 1998, Mizuma and Awazu, 1998, Mizuma, et al., 1992, Walgren, et al., 2000). Contrary to the prior believes that only aglycons are absorbed, flavonoid glycosides can be absorbed as well, without prior hydrolysis.

Flavonoids can be metabolized in the colon or in other organs, such as small intestine, liver or kidney, (Hollman and Katan, 1998). As mentioned above, microorganisms in the colon can hydrolyse flavonoid-glucosides, after which the aglycone is either absorbed, metabolized or excreted. The absorbed flavonoids and their metabolites can be metabolized in the liver by biotransformation enzymes (e.g. glucuronidation, sulfation, or O-methylation) (Day, et al., 2000, Hollman and Katan, 1997, Zhu, et al., 1994). Other organs, as the kidney and small intestine, also contain enzymes that might be capable of biotransformation of flavonoids (Shargel and Yu, 1992). 


\section{Chapter 1}

d) Associations with diseases

When the flavonoids are consumed, the flavonoids or their metabolites finally reach an organ where a biological effect might be induced. Dietary flavonoids are associated with beneficial effects in inflammation, cancer, osteoporosis, virus-infections and cardiovascular disease (Formica and Regelson, 1995, Hegarty, et al., 2000, Kim, et al., 1998, Nijveldt, et al., 2001). Epidemiological studies suggest a cardio protective role of flavonoids against coronary heart disease (Arai, et al., 2000, Mojzisova and Kuchta, 2001). These studies indicate that flavonoids might reduce mortality from coronary heart disease (Hertog, et al., 1993b). The molecular mechanisms underlying these health effects of flavonoids still have to be elucidated. Many processes, which play a role in cardiovascular diseases, have been studied in vitro and will be discussed in paragraph 2 .

\section{e) Screening: structure - activity}

Because of the wide heterogeneity in the molecular structures of flavonoids (paragraph 1a) and the range of processes flavonoids are supposed to be involved in, the study on the health effects of flavonoids is complex. In in vivo studies many aspects have to be taken into account including bioavailability, metabolism, and distribution. One approach is to investigate the activity of flavonoids first at a fundamental level (in vitro) and determine the structural elements and activities that are important. The activity of flavonoids depends upon the substitution pattern in the flavonoid-backbone. In order to find the most optimal structure, both the model used to study the activity and the structures that are studied have to be chosen carefully.

There are two approaches to find the most optimal structure. One can compare (i) the activity of interesting and readily available structures or (ii) the activity of a series of components with a comparable backbone and distinct and diverse moieties, according to a preconceived plan and determine the characteristics needed for a high activity, as originally suggested by Topliss (Topliss, 1972). The Topliss approach is based on an assumption that a particular substituent modifies the activity relative to the parent compound by virtue of changes in hydrophobic, electronic and steric effects (figure 3). The latter approach is more efficient than the first one. The final goal is to obtain a structure-activity relationship. The optimal characteristics of the 
structure, resulting in the highest activity can be determined. Furthermore a structureactivity relationship gives information of the molecular mechanism of the tested activity.

Figure 3 Topliss approach: operational scheme of aromatic substitution (Topliss, 1972) The Topliss approach is based on the assumption that a particular substituent modifies the activity relative to a parent compound (at the top of the approach) by virtue of changes in hydrophobic, electronic, and steric parameters. The activity of the non-substituted compound (substitution is $H$ ) is compared to that of the para-chloro substituted $(4 \mathrm{Cl})$ compound. When the para-chloro substituted compound is less active than the non-substituted compound, the dotted line has to be followed, the bold line has to be followed when it is more active. Subsequently, the activity of the compound with the next substituent is compared to that of the para-chloro substituted compound and the substituent that has to be evaluated next is obtained. The hydrophobic, electronic or steric parameters can be discriminated in this approach. For example, when hydrophobicity is important, the active compounds are located in the branch at the right side. In the left branch the electron donating effect plays an important role in the activity of the substituted compounds.

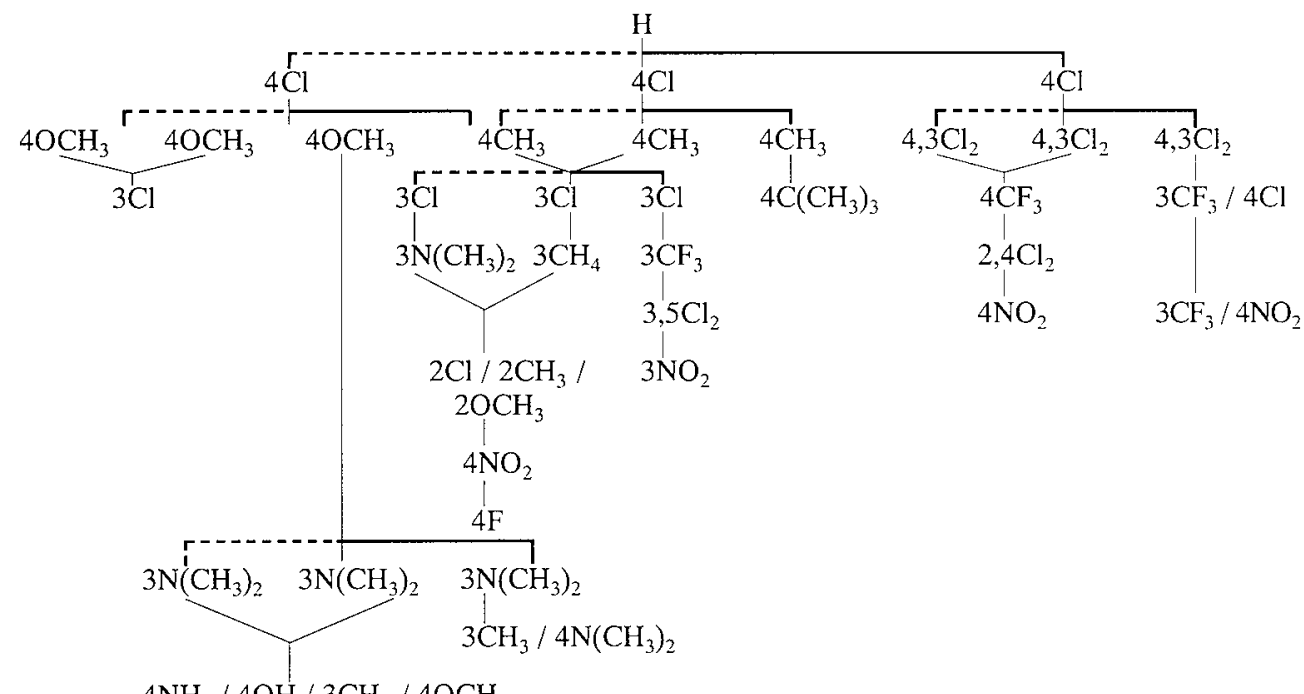

$4 \mathrm{NH}_{2} / 4 \mathrm{OH} / 3 \mathrm{CH}_{3} / 4 \mathrm{OCH}_{3}$ 


\subsection{Nitric oxide}

The discovery of the endogenous formation of nitric oxide (NO) has boosted the research directed to various biological processes in which $\mathrm{NO}^{\circ}$ plays a role.

Surprisingly, this diatomic free radical is involved in numerous regulatory functions ranging from manipulating the cardiovascular system to modulating neuron function (Christopherson and Bredt, 1997, Knowles and Moncada, 1992, Moncada, et al., 1991). In addition $\mathrm{NO}^{\circ}$ has been shown to play a role in antitumor activity and in the immune system by virtue of involvement in anti-pathogen host response (Wink and Mitchell, 1998). Next to all these beneficial properties, $\mathrm{NO}^{\circ}$ is also found to be a highly reactive and potentially toxic compound that plays a role in patho-physiological conditions. The commonly reported aspects are given in figure 4 (Wink and Mitchell, 1998).

Figure $4 \quad$ Several beneficial and deleterious aspects of $N \mathrm{O}^{\circ}$

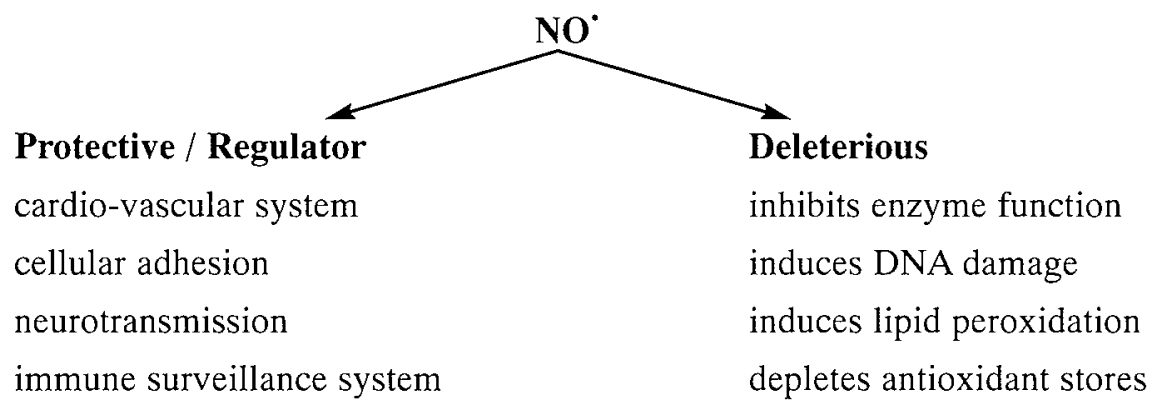

bronchodilatation

protects against TNF toxicity

a) Formation of nitric oxide

$\mathrm{NO}^{\circ}$ is produced by the enzyme NO-synthase (NOS). This enzyme converts L-arginine to L-citruline and $\mathrm{NO}^{\circ}$. This reaction requires molecular oxygen and cofactors, such as NADPH and tetrabiopterin. A number of NOS isoforms has been purified 
from the different tissues. The subtypes of NOS are based on location, cofactor requirement, amino acid sequence and post-translational modifications (Cattell and Mosley, 1998, Smith and Titheradge, 1998) The iso-enzymes are divided in three main groups: nNOS, eNOS, and iNOS. Neuronal NOS (nNOS) and endothelial NOS (eNOS) are constitutively expressed and located in respectively neuronal and endothelial cells. These two isoforms are activated in the presence of calcium. Calcium catalyses the binding of calmodulin to NOS, and thereby activates the enzyme (Michel and Feron, 1997). The factors that increase intracellular calcium concentration stimulate the $\mathrm{NO}^{\circ}$ production by nNOS and eNOS (Michel, et al., 1997). Inducible NOS, iNOS, is characterized from macrophages and does not depend on $\mathrm{Ca}^{2+} /$ calmoduline. This isoform is present in macrophages, heart muscle, astroglia, liver and smooth muscle cells, and is activated by endotoxin and cytokines (e.g. IL-1, TNF-alpha) as a part of the inflammatory response against pathogens This stimulation leads to an acute NO release, in high concentrations (Mayer and Hemmens, 1997). Recent studies indicate a fourth NOS isoform, which is suggested to be a distinct mitochondrial NOS, although this is still extensively discussed (Lacza, et al., 2003).

\section{b) $\mathrm{NO}^{\circ}, \mathrm{O}^{*}$ and $\mathrm{ONOO}^{-}$}

Nitric oxide is a highly reactive compound with a half-life close to the diffusion time in biological systems. It can react with several biomolecules as second messenger in physiological processes. But it can also react with other radicals, as the superoxide radical $\left(\mathrm{O} 2^{\circ}\right)$ (reaction 1$)$. This reaction takes place in vivo and is very fast $\left(0.7-1.9 \times 10^{10} \mathrm{M}^{-1} \mathrm{~s}^{-1}\right)$ (Huie and Padmaja, 1993). The reaction rate of SOD with $\mathrm{O} 2{ }^{\circ}$ is $5-10$ times slower compared to the reaction of $\mathrm{NO}^{\circ}$ with $\mathrm{O} 2{ }^{\circ}$. (Koppenol, 2001, Rotilio, et al., 1972). The reaction of $\mathrm{O}^{*}{ }^{-}$with $\mathrm{NO}^{\circ}$ leads to a loss of the messenger molecule $\mathrm{NO}^{\circ}$ and in addition peroxynitrite (ONOO ${ }^{\circ}$ ) is formed, which plays a pivotal role in $\mathrm{NO}^{\circ}$-toxicity.

$\mathrm{NO}^{\circ}+\mathrm{O}^{-} \rightarrow \mathrm{ONOO}^{-}$

Peroxynitrite anion itself is not a free radical and is relatively stable, however, the protonated form (peroxynitrous acid) rearranges rapidly to form nitrate. The half-life 
of peroxynitrite is dependent of the $\mathrm{pH}$ of the environment. In an alkaline environment peroxynitrite is not protonated and stable, in contrast to an acidic environment. Under physiological conditions at $\mathrm{pH} 7.420 \%$ of the peroxynitrite is protonated and the half-life is approximately 1.9 seconds. Also the configuration of the protonated molecule plays a role in the stability (figure 5). The relative stability of peroxynitrite is believed to result from the anion being folded in the cis- configuration (Beckman, et al., 1992). In cis-peroxynitrite the terminal peroxide oxygen cannot directly approach the nitrogen to transform to nitrate, this would require large rearrangements of the other oxygen atoms, which are not needed in trans-peroxynitrite. After protonation of cis-peroxynitite the isomer trans-peroxynitrous acid is formed. The protonated and the deprotonated form in trans-configuration can rearrange to nitrate.

Figure $5 \quad$ configuration of peroxynitrite and decomposition to nitrate

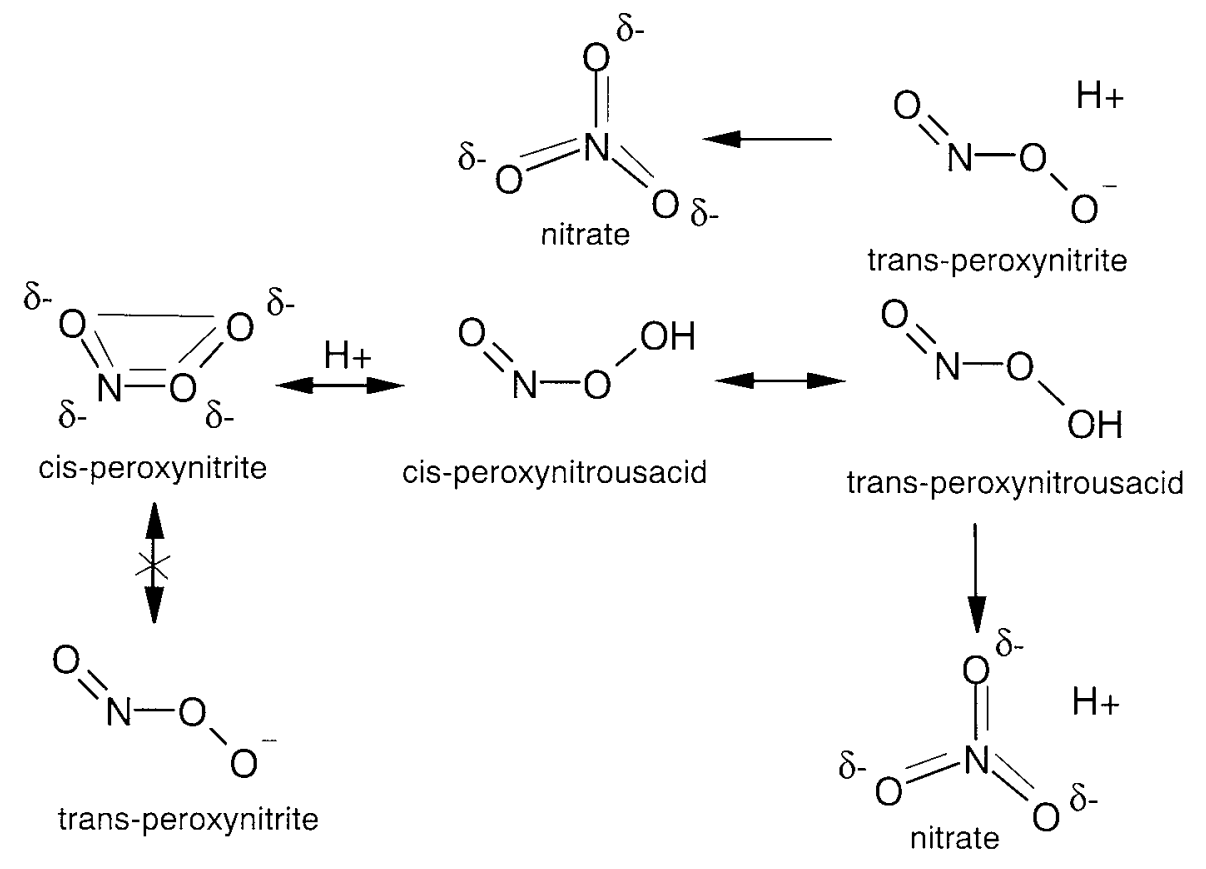


Because of its reactivity, the reaction between peroxynitrite and biomolecules depends on the formation of peroxynitrite near the particular target molecules. Carbon dioxide is ubiquitous in vivo; it is continuously produced by cells and is a part of the bicarbonate buffering system in the tissues. The reaction of peroxynitrite with $\mathrm{CO}_{2}$ is of enormous importance, because this reaction (reaction 2) is very fast (Denicola, et al., 1996, Meli, et al., 2002, Squadrito and Pryor, 1998). The nitrosoperoxycarbonate anion is formed, which subsequently rearranges to form the nitrocarbonate anion. The nitrocarbonate anion is postulated to be the oxidant of peroxynitrite mediated reactions in biological environments. It can undergo hydrolysis, oxidise biomolecules via one or two electron transfers and it can nitrosylate substrates (Koppenol, 1999).

\section{$\mathrm{ONOO}^{-}+\mathrm{CO}_{2} \rightarrow \mathrm{ONOOCO}_{2} \rightarrow \mathrm{O}_{2} \mathrm{NOCO}_{2}$}

(reaction 2)

c) Role of nitric oxide in vascular tissue

$\mathrm{NO}^{\circ}$ was first discovered in the endothelium as EDRF, endothelium-derived relaxing factor (Furchgott and Zawadzki, 1980). Many studies now indicate an important regulatory role of $\mathrm{NO}^{\circ}$ in the cardiovascular system (Patel, et al., 2000, Tomasian, et al., 2000). In cardiovascular tissue eNOS is constitutively expressed in the endothelial cells. The factors that increase intracellular calcium concentration stimulate the NO production by eNOS (Michel, et al., 1997). These factors include the receptor-dependent agonists like acetylcholine, bradykinin, serotonin, and thrombin, and the physical stimuli as shear stress. Vasodilatation by the produced $\mathrm{NO}^{\circ}$ is a result of the reaction of NO' with the heme group of cytosolic guanylate cyclase in vascular smooth muscle cells. This increases the concentration of cyclic-3', 5'-guanosine monophasphate (cGMP) in the cell (Arnold, et al., 1977), which activates cGMP-dependent protein kinase that decreases cytosolic calcium concentration. This causes modulation of the ion channels leading to relaxation of vascular smooth muscle cells. A direct effect of $\mathrm{NO}^{\circ}$ on relaxation may occur via activation of calcium-dependent potassium channels in smooth muscle cells, producing hyperpolarization (Bolotina, et al., 1994). $\mathrm{NO}^{\circ}$ reacts also with guanylate cyclase in platelets, which causes inhibition of platelet aggregation and adhesion. (Broekman, et al., 1991, Radomski, et al., 1987). 
This inhibition can have a positive influence on atheroslerosis.

A part of the amount of $\mathrm{NO}^{\circ}$ in the vascular system is produced by iNOS, as an element of the inflammatory response against pathogens. This production occurs not continuously, but high amounts are released when iNOS is activated. When all NO formed after inflammation would cause vasodilatation, a severe hypotension would occur in inflammatory conditions. This is indeed observed in septic shock. However, $\mathrm{NO}^{-}$-induced hypotension normally does not occur as a consequence of inflammation, because $\mathrm{NO}^{\circ}$ reacts fast with biomolecules. NO ${ }^{\circ}$ itself can damage DNA, RNA and proteins, which can inhibit enzyme functions. $\mathrm{NO}^{\circ}$ can also initiate lipid peroxidation (Patel, et al., 2000). As mentioned in par. 1.2.b NO can compete with superoxide dismutase (SOD) for $\mathrm{O}_{2}{ }^{*}$ (Koppenol, 2001, Rotilio, et al., 1972).

In small amounts $\mathrm{O}_{2}{ }^{--}$is produced in all cells as a consequence of normal oxidative metabolism. It is suggested that $\mathrm{O}_{2}{ }^{-*}$ at this low, physiological level acts as a modulator of the bioactivity of endothelial derived NO' (Ignarro, et al., 1988). However excessive amounts of $\mathrm{O}_{2}{ }^{-}$are toxic. As a part of the inflammatory response of granulocytes and macrophages against pathogens, high amounts of $\mathrm{O}_{2}{ }^{--}$are produced (Muijsers, et al., 1997). Sources of $\mathrm{O}_{2}{ }^{-}$include NAD(P)H-dependent oxidases (Cai, et al., 2003, Franco Mdo, et al., 2003), xanthine oxidase (White, et al., 1996) and cyclooxygenase (Armstead, 2001). Also eNOS itself may produce $\mathrm{O}_{2}{ }_{2}^{-*}$ under certain conditions. Recent studies suggest that the reduced availability of arginine or of the cofactor tetrahydrobiopterin may result in uncoupling of eNOS, resulting in $\mathrm{O}_{2}{ }^{--}$production (Vasquez-Vivar, et al., 2003, Vasquez-Vivar, et al., 1998). The excessive vascular $\mathrm{O}_{2}{ }^{--}$production is associated with vascular diseases, including hypertension, atherosclerosis or coronary artery disease (Cai, et al., 2003, Guzik, et al., 2000). The reaction of $\mathrm{NO}^{*}$ with $\mathrm{O}_{2}{ }^{*}$ does not only cause the inhibition of the biological activity of $\mathrm{NO}^{\circ}$, it also causes the formation of a cytotoxic compound, peroxynitrite. This is a more powerful oxidizing and nitrating agent than NO ${ }^{\circ}$ itself (Radi, et al., 2001). Peroxynitrite oxidizes and nitrates several biomolecules, such as DNA, RNA, proteins and lipids. In this way enzymes are inhibited and LDL-oxidation (lipid peroxidation) is started. Peroxynitrite and the damage by this molecule are associated in several diseases. Nitration of tyrosine residues is linked with atherosclerosis, Alzheimer's disease, amyotrophic lateral sclerosis, and other diseases (Squadrito and 
Pryor, 1998). And the oxidation of lipoproteins by peroxynitrite, i.e. LDL-oxidation, is suggested to be important in the onset of atherosclerose (White, et al., 1994).

\subsection{The interaction of flavonoids with the $\mathrm{NO}^{\circ}$-system}

An inverse association has been found of the dietary flavonoid intake and mortality of coronary heart disease and a weaker inverse relation of the dietary flavonoid intake with incidence of myocardial infarction, as described above (Hertog, et al., 1997, Hertog, et al., 1995, Hertog, et al., 1993b, Knekt, et al., 1996).

An impaired $\mathrm{NO}^{\circ}$-system, induced by an excessive $\mathrm{O}_{2}{ }^{*}$ production, peroxynitrite formation, oxidative stress and nitration, is associated with the cardiovascular diseases, as in atherosclerosis. The molecular basis for the protective effect of flavonoids on cardiovascular diseases may be found in the interaction of several flavonoids with the $\mathrm{NO}^{-}$-system. The hypothesis that atherosclerosis has a viral or bacterial trigger suggests a possible early intervention by flavonoids (Paquay, et al., 2000). Inflammation causes up-regulation of adhesion molecules, cytokine, iNOS, and also NADPH-oxidase. The combined formation of $\mathrm{NO}^{\circ}$ and $\mathrm{O}_{2}{ }^{--}$from iNOS and NADPH-oxidase, results in the formation of peroxynitrite. Several flavonoids are proposed to have an interaction with the $\mathrm{NO}^{\circ}$-system at several levels. From in vivo animal studies and from ex vivo and in vitro studies more insights in this interaction are gathered.

Flavonoids can influence the NO' synthesis. Inducible NOS, which causes an acute and high release of $\mathrm{NO}^{\circ}$, may be inhibited by several flavonoids (Chan, et al., 1997, Lin and Lin, 1997, Paquay, et al., 2000, Raso, et al., 2001). This would prevent the high $\mathrm{NO}^{\circ}$ burst, and thereby inhibits damage to DNA or lipids by $\mathrm{NO}^{\circ}$ and formation of peroxynitrite. Besides inhibiting the high release of $\mathrm{NO}^{\circ}$, flavonoids are also shown to be good scavengers of $\mathrm{NO}^{\circ}$ (Nakagawa and Yokozawa, 2002, Paquay, et al., 2000, van Acker, et al., 1995). The synthesis of NO by endothelium NOS can also be influenced by several flavonoids (Benito, et al., 2002, Chiesi and Schwaller, 1995, Lemos, et al., 1999). A mild enhancement of the NO synthesis is suggested, causing vasorelaxation. An enhanced endothelium-dependent relaxation by 
flavonoids is also shown in ex vivo experiments in aorta (Benito, et al., 2002, Duarte, et al., 1993). This may be a result of the enhanced $\mathrm{NO}^{\circ}$ production, or a result of a higher bioavailability of $\mathrm{NO}^{\circ}$. Flavonoids can protect the availability of $\mathrm{NO}^{\circ}$ by scavening $\mathrm{O}_{2}{ }^{--}$(Girard, et al., 1995, Taubert, et al., 2003). Decreasing the amount of $\mathrm{O}_{2}{ }^{-}$is important in three ways; to inhibit the damage caused by $\mathrm{O}_{2}{ }^{-\cdots}$, increase the $\mathrm{NO}^{\circ}$ availability, and also inhibiting the production of peroxynitrite. Peroxynitrite is a strong cytotoxic compound and the damage caused by peroxynitrite can be prevented by scavenging the precurors of peroxynitrite or scavenging peroxynitrite itself. The latter is also shown by flavonoids (Haenen, et al., 1997, Ketsawatsakul, et al., 2000). All the reactive oxygen species in the $\mathrm{NO}^{\circ}$-system can cause lipid peroxidation, this plays a role in LDL-oxidation and damage of cellmembranes (Hogg and Kalyanaraman, 1999, Radi, et al., 1991). Flavonoids can inhibit the onset of this lipid peroxidation by scavenging the reactive oxygen species or terminate this chain-process (Abu Amsha Caccetta, et al., 2001, Grinberg, et al., 1997, Heller, et al., 1998).

As described here, the interactions between flavonoids and $\mathrm{NO}^{\circ}$ and processes related to $\mathrm{NO}^{\circ}$ ( $\mathrm{NO}^{\circ}$-system) is very complex. Much evidence has been published for an interaction of flavonoids with the $\mathrm{NO}^{\circ}$-system. These interactions with the NO system are linked to several diseases, including cardiovascular diseases. However the molecular mechanism involved in the beneficial effect of flavonoids on cardiovascular diseases still needs to be elucidated.

\subsection{Aim and outline of the thesis}

As indicated in this chapter there is strong indication that high flavonoid-intake has a protective effect on cardiovascular disease. The $\mathrm{NO}^{-}$-system plays a pivotal role in the cardiovascular system, in both a beneficial and a deleterious way. The interaction between several flavonoids and the $\mathrm{NO}^{-}$-system is studied in this thesis.

As tea is found to be the largest contributor to the flavonoid-intake of the western population, the interaction of tea flavonoids with the $\mathrm{NO}^{\circ}$-system was investigated in the first article (Chapter 2). The activity to scavenge reactive compounds of the NO'- 
system, namely $\mathrm{NO}^{\circ}$ itself and peroxynitrite by the catechins and theaflavines is determined. Also the effect of black and green tea on functioning of the vessel was investigated ex vivo.

Flavonoids include chemically varying structures. Within the subgroups, the flavones and flavonols, the peroxynitrite scavenging activity differs. A new structural element in peroxynitrite scavenging activity by flavones and flavonols is defined in chapter 3 . The suggested structure-activity relationship is further investigated in chapter 4 . In this study a series of substituted simple phenols, according to the Topliss approach, is used to identify the most favourable substitution for peroxynitrite scavenging. It was possible to translate the structure-activity relationship of peroxynitrite scavenging by simple phenols to the flavones/flavonols. The next step was to extrapolate the structure-activity relationship to another antioxidant activity, i.e. inhibition of lipid peroxidation (chapter 5).

From chapter 4 and 5 it is concluded that flavonols such as quercetin and kaempferol, are very potent antioxidants. These flavonols and their glycosides are produced in moderate amounts in the fruits of the tomato plant. By the technique of genetically modification the production of these flavonoids is extensively enhanced in the tomato-strain used in an in vivo experiment (Chapter 6). As described above, a high flavonoid intake is linked to a positive effect on cardiovascular diseases by epidemiological studies. The blood pressure lowering effect of flavonoid-intake via foodmatrix is studied in an animal model for essential hypertension, i.e. the spontaneously hypertensive rat (Chapter 6).

In the last chapter, the results described in this thesis are summarized and discussed (Chapter 7). 


\section{$1.5 \quad$ References}

Abu Amsha Caccetta, R., Burke, V., Mori, T.A., Beilin, L.J., Puddey, I.B. and Croft, K.D., (2001) Red wine polyphenols, in the absence of alcohol, reduce lipid peroxidative stress in smoking subjects.

Free Radical Biology and Medicine 30 (6), 636-642.

Arai, Y., Watanabe, S., Kimira, M., Shimoi, K., Mochizuki, R. and Kinae, N., (2000) Dietary intakes of flavonols, flavones and isoflavones by Japanese women and the inverse correlation between quercetin intake and plasma LDL cholesterol concentration.

Journal of Nutrition 130 (9), 2243-2250.

Armstead, W.M., (2001) Endothelin-Induced cyclooxygenase-dependent superoxide generation contributes to $\mathrm{K}+$ channel functional impairment after brain injury. Journal of Neurotraumatology 18 (10), 1039-1048.

Arnold, W.P., Mittal, C.K., Katsuki, S. and Murad, F., (1977) Nitric oxide activates guanylate cyclase and increases guanosine 3':5'-cyclic monophosphate levels in various tissue preparations. Proceedings of the National Academy of Sciences of the United States of America 74 (8), 3203-3207.

Beckman, J.S., Ischiropoulos, H., Zhu, L., van der Woerd, M., Smith, C., Chen, J., Harrison, J., Martin, J.C. and Tsai, M., (1992) Kinetics of superoxide dismutase- and iron-catalyzed nitration of phenolics by peroxynitrite. Archives of Biochemistry and Biophysics 298 (2), 438-445.

Beecher, G.R., (1999) Phytonutrients' role in metabolism: effects on resistance to degenerative processes.

Nutrition Reviews 57 (9 Pt 2), S3-6.

Benito, S., Lopez, D., Saiz, M.P., Buxaderas, S., Sanchez, J., Puig-Parellada, P. and Mitjavila, M.T., (2002) A flavonoid-rich diet increases nitric oxide production in rat aorta.

British Journal of Pharmacology 135 (4), 910-916.

Bolotina, V.M., Najibi, S., Palacino, J.J., Pagano, P.J. and Cohen, R.A., (1994) Nitric oxide directly activates calcium-dependent potassium channels in vascular smooth muscle. Nature 368 (6474), 850-853. 
Broekman, M.J., Eiroa, A.M. and Marcus, A.J., (1991) Inhibition of human platelet reactivity by endothelium-derived relaxing factor from human umbilical vein endothelial cells in suspension: blockade of aggregation and secretion by an aspirin-insensitive mechanism. Blood 78 (4), 1033-1040.

Cai, H., Griendling, K.K. and Harrison, D.G., (2003) The vascular NAD(P)H oxidases as therapeutic targets in cardiovascular diseases.

Trends in Pharmacological Science 24 (9), 471-478.

Cattell, V. and Mosley, K., (1998) Immunohistochemical localization of NOS isoforms. Methods in Molecular Biolology 100 181-189.

Chan, M., Fong, D., Ho, C.T. and Huang, H.I., (1997) Inhibition of inducible nitric oxide synthase gen expression and enzyme activity by epigallocatechin gallate, a natural product from green tea. Biochemical Pharmacology 54 1281-1286.

Chiesi, M. and Schwaller, R., (1995) Inhibition of constitutive endothelial NO-synthase activity by tannin and Quercetin. Biochemical Pharmacology 49 (4), 495-501.

Christopherson, K.S. and Bredt, D.S., (1997) nitric oxide in excitable tissues:

physiological roles and diseases.

Journal of Clinical Investigations 100 (10), 2424-2429.

Day, A.J., Bao, Y., Morgan, M.R. and Williamson, G., (2000) Conjugation position of quercetin glucuronides and effect on biological activity.

Free Radical Biology and Medicine 29 (12), 1234-1243.

Denicola, A., Freeman, B.A., Trujillo, M. and Radi, R., (1996) peroxynitrite reaction with carbon dioxide/bicarbonate: kinetics and influence on peroxynitritemediated oxidations. Archives of Biochemistry and Biophysics 333 (1), 49-58.

Duarte, J., Perez-Vizcaino, F., Zarzuelo, A., Jimenez, J. and Tamargo, J., (1993)

Vasodilator effects of quercetin in isolated rat vascular smooth muscle.

European Journal of Pharmacology 239 (1-3), 1-7.

Formica, J.V. and Regelson, W., (1995) Review of the biology of Quercetin and related bioflavonoids. Food and Chemical Toxicology 33 (12), 1061-1080.

Franco Mdo, C., Akamine, E.H., Di Marco, G.S., Casarini, D.E., Fortes, Z.B., Tostes, R.C., Carvalho, M.H. and Nigro, D., (2003) NADPH oxidase and enhanced superoxide generation in intrauterine undernourished rats: involvement of the renin-angiotensin system. Cardiovascular Research 59 (3), 767-775. 
Furchgott, R.F. and Zawadzki, J.V., (1980) The obligatory role of endothelial cells in the relaxation of arterial smooth muscle by acetylcholine.

Nature 288 (5789), 373-376.

Gee, J.M., DuPont, M.S., Day, A.J., Plumb, G.W., Williamson, G. and Johnson, I.T., (2000) Intestinal transport of quercetin glycosides in rats involves both deglycosylation and interaction with the hexose transport pathway. Journal of Nutrition 130 (11), 2765-2771.

Gee, J.M., DuPont, M.S., Rhodes, M.J. and Johnson, I.T., (1998) Quercetin glucosides interact with the intestinal glucose transport pathway.

Free Radical Biology and Medicine 25 (1), 19-25.

Girard, P., Sercombe, R., Sercombe, C., LeLem, G., Seylam, J. and Potier, P., (1995) A new synthetic flavonoid protects endothelium-derived relaxing factorinduced relaxation in rabbit arteries in vitro: evidence for superoxide scavenging. Biochemical Pharmacology 49 (10), 1533-1539.

Grinberg, L., Newmark, H., Kitrossky, N., Rahamim, E., Chevion, M. and Rachmilewitz, E., (1997) protective effects of tea polyphenols against oxidative damage to red blood cells. Biochemical Pharmacology 54 973-978.

Guzik, T.J., West, N.E., Black, E., McDonald, D., Ratnatunga, C., Pillai, R. and Channon, K.M., (2000) Vascular superoxide production by NAD(P)H oxidase: association with endothelial dysfunction and clinical risk factors. Circulation Research 86 (9), E85-90.

Haenen, G.R.M.M., Paquay, J.B.G., Korthouwer, R.E.M. and Bast, A., (1997) Peroxynitrite scavenging by flavonoids.

Biochemical and Biophysical Research Communications 236 591-593.

Harborne, J.B., (1988) Flavonoids in the environment: structure-activity relationships. Progressions in Clinical Biological Research 280 17-27.

Harborne, J.B. and Williams, C.A., (2000) Advances in flavonoid research since 1992. Phytochemistry 55 (6), 481-504.

Havsteen, B., (1983) Flavonoids, a class of natural products of high pharmacological potency. Biochemical Pharmacology 32 (7), 1141-1148.

Hegarty, V.M., May, H.M. and Khaw, K.T., (2000) Tea drinking and bone mineral density in older women. American Journal of Clinical Nutrition 71 (1003-1007), 
Heller, F.R., Descamps, O. and Hondekijn, J.-C., (1998) LDL oxidation: therapeutic perspectives. Atherosclerosis 137 Suppl S25-31.

Hertog, M.G., Feskens, E.J. and Kromhout, D., (1997) Antioxidant flavonols and coronary heart disease risk. Lancet 349 (9053), 699.

Hertog, M.G., Hollman, P.C., Katan, M.B. and Kromhout, D., (1993a) Intake of potentially anticarcinogenic flavonoids and their determinants in adults in The Netherlands. Nutrition Cancer 20 (1), 21-29.

Hertog, M.G., Kromhout, D., Aravanis, C., Blackburn, H., Buzina, R., Fidanza, F., Giampaoli, S., Jansen, A., Menotti, A., Nedeljkovic, S. and et al., (1995) Flavonoid intake and long-term risk of coronary heart disease and cancer in the seven countries study.

Archives of Internal Medicin 155 (4), 381-386.

Hertog, M.G.L., Feskens, E.J.M., Hollman, P.C.H., Katan, M.B. and Kromhout, D., (1993b) Dietary antioxidant flavonoids and risk of coronary heart disease: the Zutphen Elderly Study. Lancet 342 1007-1011.

Hogg, N. and Kalyanaraman, B., (1999) Nitric oxide and lipid peroxidation.

Biochimica et Biophysica Acta 1411 378-384.

Hollman, P. and Katan, M.B., (1998) Absorption, metabolism, and bioavailability of flavonoids. In: Flavonoids in health and disease Rice Evans, C.A. and Packer, L. Marcel Dekker Inc. New York 483-522.

Hollman, P.C., de Vries, J.H., van Leeuwen, S.D., Mengelers, M.J. and Katan, M.B., (1995) Absorption of dietary quercetin glycosides and quercetin in healthy ileostomy volunteers. American Journal of Clinical Nutrition 62 (6), 1276-1282.

Hollman, P.C. and Katan, M.B., (1997) Absorption, metabolism and health effects of dietary flavonoids in man. Biomedical Pharmacotherapy 51 (8), 305-310.

Huie, R.E. and Padmaja, S., (1993) The reaction of no with superoxide.

Free Radical Research Communications 18 (4), 195-199.

Ignarro, L.J., Byrns, R.E., Buga, G.M., Wood, K.S. and Chaudhuri, G., (1988)

Pharmacological evidence that endothelium-derived relaxing factor is nitric oxide: use of pyrogallol and superoxide dismutase to study endotheliumdependent and nitric oxide-elicited vascular smooth muscle relaxation. Journal of Pharmacology and Experimental Therapeutics 244 (1), 181-189. 
Justesen, U., Knuthsen, P. and Leth, T., (1997) Determination of plant polyphenols in Danish foodstuffs by HPLC-UV and LC-MS detection.

Cancer Letters 114 (l-2), 165-167.

Ketsawatsakul, U., Whiteman, M. and Halliwell, B., (2000) A reevaluation of the peroxynitrite scavenging activity of some dietary phenolics.

Biochemical and Biophysical Research Communications 279 (2), 692-699.

Kim, H.P., Mani, I., Iversen, L. and Ziboh, V.A., (1998) Effects of naturally-occurring flavonoids and biflavonoids on epidermal cyclooxygenase and lipoxygenase from guinea-pigs.

Prostaglandins Leukotrines Essential Fatty Acids 58 (1), 17-24.

Knekt, P., Jarvinen, R., Reunanen, A. and Maatela, J., (1996) Flavonoid intake and coronary mortality in Finland: a cohort study.

British Medical Journal 312 (7029), 478-481.

Knowles, R. and Moncada, S., (1992) Nitric oxide as a signal in blood vessels. Trends in Biochemical Sciences 17 (10), 399-402.

Koppenol, W., (1999) Chemistry of peroxynitrite and its relevance to biological systems. Metal Ions in Biological Systems 36 597-619.

Koppenol, W.H., (2001) 100 years of peroxynitrite chemistry and 11 years of peroxynitrite biochemistry. Redox report 6 (6), 339-341.

Kuhnau, J., (1976) The flavonoids. A class of semi-essential food components: their role in human nutrition. World Reviews of Nutrition and Diet 24 117-191.

Lacza, Z., Snipes, J.A., Zhang, J., Horvath, E.M., Figueroa, J.P., Szabo, C. and Busija, D.W., (2003) Mitochondrial nitric oxide synthase is not eNOS, nNOS or iNOS. Free Radical Biology and Medicine 35 (10), 1217-1228.

Lemos, V.S., Freitas, M.R., Muller, B., Lino, Y.D., Queiroga, C.E. and Cortes, S.F., (1999) Dioclein, a new nitric oxide- and endothelium-dependent vasodilator flavonoid. European Journal of Pharmacology 386 (1), 41-46.

Lin, Y. and Lin, J., (1997) (-)epigallocatechin-3-gallate blocks the induction of nitric oxide synthase by down regulating lipopolysaccharide-induced activity of transcription factor nuclear factor-kappaB. Molecular Pharmacology 52 465-472.

Mayer, B. and Hemmens, B., (1997) biosynthesis and action of nitric oxide in mammalian cells. Biochimica et Biophysica Acta 22 (12), 477-481. 
Meli, R., Nauser, T., Latal, P. and Koppenol, W.H., (2002) Reaction of peroxynitrite with carbon dioxide: intermediates and determination of the yield of CO3'- and NO2'. Journal of Biological Inorganic Chemistry 7 31-36.

Michel, J.B., Feron, O., Sase, K., Prabhakar, P. and Michel, T., (1997) Caveolin versus calmodulin. Counterbalancing allosteric modulators of endothelial nitric oxide synthase. Journal of Biological Chemistry 272 (41), 25907-25912.

Michel, T. and Feron, O., (1997) Nitric oxide synthases: which, where, how, and why? Journal of Clinical Investigations 100 (9), 2146-2152.

Mizuma, T. and Awazu, S., (1998) Intestinal Nat/glucose cotransporter-mediated transport of glucose conjugate formed from disaccharide conjugate. Biochimica et Biophysica Acta 1379 (1), 1-6.

Mizuma, T., Ohta, K., Hayashi, M. and Awazu, S., (1992) Intestinal active absorption of sugar-conjugated compounds by glucose transport system: implication of improvement of poorly absorbable drugs. Biochemical Pharmacology 43 (9), 2037-2039.

Mojzisova, G. and Kuchta, M., (2001) Dietary flavonoids and risk of coronary heart disease. Physiological Research 50 (6), 529-535.

Mol, J., Grotewold, E. and Koes, R., (1998) How genes paint flowers and seeds. Trends in Plant Science 3 212-217.

Moline, J., Bukharovich, I.F., Wolff, M.S. and Phillips, R., (2000) Dietary flavonoids and hypertension: is there a link? Medical Hypotheses 55 (4), 306-309.

Moncada, S., Palmer, R.M.J. and Higgs, E.A., (1991) Nitric oxide:Physiology, Pathophsiology, and pharmacology. Pharmacological Reviews 43 109-142.

Muijsers, R.B., Folkerts, G., Henricks, P.A., Sadeghi Hashjin, G. and Nijkamp, F.P., (1997) Peroxynitrite: a two-faced metabolite of nitric oxide.

Life Sciences 60 (21), 1833-1845.

Nakagawa, T. and Yokozawa, T., (2002) Direct scavenging of nitric oxide and superoxide by green tea. Food and Chemical Toxicology 40 (12), 1745-1750.

Nijveldt, R.J., van Nood, E., van Hoorn, D.E., Boelens, P.G., van Norren, K. and van Leeuwen, P.A., (2001) Flavonoids: a review of probable mechanisms of action and potential applications.

American Journal of Clinical Nutrition 74 (4), 418-425. 
Paquay, J.B.G., Haenen, G.R.M.M., Stender, G., Wiseman, S.A., Tijburg, L.B.M. and Bast, A., (2000) Protection against nitric oxide toxicity by tea. Journal of Agricultural and Food Chemistry 48 (11), 5768-5772.

Parr, A.J. and Bolwell, G.P., (2000) Phenols in the plant and in man. The potential for possible nutritional enhancement of the diet by modifying the phenols content or profile.

Journal of the Science of Food and Agriculture 80 985-1012.

Patel, R.P., Levonen, A.L., Crawford, J.H. and Darley Usmar, V.M., (2000)

Mechanisms of the pro- and anti-oxidant actions of nitric oxide in atherosclerosis. Cardiovascular Research 47 (3)), 465-474.

Radi, R., Beckman, J.S., Bush, K.M. and Freeman, B.A., (1991) Peroxynitrite-induced membrane lipid peroxidation: the cytotoxic potential of superoxide and nitric oxide. Archives of Biochemistry and Biophysics 288 481-487.

Radi, R., Peluffo, G., Alvarez, M.N., Naviliat, M. and Cayota, A., (2001) Unraveling peroxynitrite formation in biological systems.

Free Radical Biology and Medicine 30 (5), 463-488.

Radomski, M.W., Palmer, R.M. and Moncada, S., (1987) The anti-aggregating properties of vascular endothelium: interactions between prostacyclin and nitric oxide. British Journal of Pharmacology 92 (3), 639-646.

Raso, G.M., Meli, R., Di Carlo, G., Pacilio, M. and Di Carlo, R., (2001) Inhibition of inducible nitric oxide synthase and cyclooxygenase- 2 expression by flavonoids in macrophage J774A.1. Life Sciences 68 (8), 921-931.

Rotilio, G., Bray, R.C. and Fielden, E.M., (1972) A pulse radiolysis study of superoxide dismutase.

Biochimica et Biophysica Acta 268 (2), 605-609.

Sampson, L., Rimm, E., Hollman, P.C., de Vries, J.H. and Katan, M.B., (2002)

Flavonol and flavone intakes in US health professionals.

Journal of the American Diet Association 102 (10), 1414-1420.

Shargel, L. and Yu, A.B.C., (1992) Applied biopharmaceutics and Pharmacokinetics 3d ed. London Prentice Hall International (UK) Limited

Smith, F.S. and Titheradge, M.A., (1998) Detection of NOS isoforms by western-blot analysis. Methods in Molecular Biolology 100 171-180. 
Squadrito, G.L. and Pryor, W.A., (1998) Oxidative chemistry of nitric oxide: the roles of superoxide, peroxynitrite, and carbon dioxide.

Free Radical Biology and Medicine 25 (4/5), 392-403.

Stewart, A.J., Bozonnet, S., Mullen, W., Jenkins, G.I., Lean, M.E. and Crozier, A., (2000) Occurrence of flavonols in tomatoes and tomato-based products. Journal of Agricultural and Food Chemistry 48 (7), 2663-2669.

Taubert, D., Breitenbach, T., Lazar, A., Censarek, P., Harlfinger, S., Berkels, R., Klaus, W. and Roesen, R., (2003) Reaction rate constants of superoxide scavenging by plant antioxidants.

Free Radical Biology and Medicine 35 (12), 1599-1607.

Thompson, L.U., (1993) Potential health benefits and problems associated with antinutrients in foods.

Food Research International 26 131-149.

Tomasian, D., Keaney, J.F. and Vita, J.A., (2000) Antioxidants and the bioactivity of endothelium-derived nitric oxide.

Cardiovascular Research 47 (3)), 426-435.

Topliss, J.G., (1972) Utilization of operational schemes for analog synthesis in drug design. Journal of Medicinal Chemistry 15 (10), 1006-1011.

US Department of Agriculture, (2003) USDA Database for the flavonoid content of selected foods.

van Acker, S.A., Tromp, M.N., Haenen, G.R., van der Vijgh, W.J. and Bast, A., (1995) Flavonoids as scavengers of nitric oxide radical.

Biochemical and Biophysical Research Communications 214 (3), 755-759.

Vasquez-Vivar, J., Kalyanaraman, B. and Martasek, P., (2003) The role of tetrahydrobiopterin in superoxide generation from eNOS: enzymology and physiological implications.

Free Radical Research 37 (2), 121-127.

Vasquez-Vivar, J., Kalyanaraman, B., Martasek, P., Hogg, N., Masters, B.S., Karoui, H., Tordo, P. and Pritchard, K.A., Jr., (1998) Superoxide generation by endothelial nitric oxide synthase: the influence of cofactors. Proceedings of the National Academy of Sciences of the United States of America 95 (16), 9220-9225. 
Verhoeyen, M.E., Bovy, A., Collins, G., Muir, S., Robinson, S., de Vos, C.H.R. and Colliver, S., (2002) Increasing antioxidant levels in tomatoes through modification of the flavonoid biosynthetic pathway.

Journal of Experimental Botany 53 (377), 1-8.

Vries, J.H.d., Janssen, P.L., Hollman, P.C., van Staveren, W.A. and Katan, M.B., (1997) Consumption of quercetin and kaempferol in free-living subjects eating a variety of diets. Cancer Letters 114 (1-2), 141-144.

Walgren, R.A., Lin, J.T., Kinne, R.K. and Walle, T., (2000) Cellular uptake of dietary flavonoid quercetin 4'-beta-glucoside by sodium-dependent glucose transporter SGLT1. J Pharmacol Exp Ther 294 (3), 837-843.

White, C.R., Brock, T.A., Chang, L.Y., Crapo, J., Briscoe, P., Ku, D., Bradley, W.A., Gianturco, S.H., Gore, J., Freeman, B.A. and et al., (1994) Superoxide and peroxynitrite in atherosclerosis. Proceedings of the National Academy of Sciences of the United States of America 91 (3), 1044-1048.

White, C.R., Darley-Usmar, V., Berrington, W.R., McAdams, M., Gore, J.Z., Thompson, J.A., Parks, D.A., Tarpey, M.M. and Freeman, B.A., (1996) Circulating plasma xanthine oxidase contributes to vascular dysfunction in hypercholesterolemic rabbits. Proceedings of the National Academy of Sciences of the United States of America 93 (16), 8745-8749.

Wink, D. and Mitchell, J., (1998) Chemical biology of nitric oxide: insights into regulatory, cytotoxic, and protective mechanisms of nitric oxide. Free Radical Biology and Medicine 25 (4/5), 434-456.

Zhu, B.T., Ezell, E.L. and Liehr, J.G., (1994) Catechol-O-methyltransferase-catalyzed rapid O-methylation of mutagenic flavonoids. Metabolic inactivation as a possible reason for their lack of carcinogenicity in vivo.

Journal of Biological Chemistry 269 (1), 292-299. 


\section{Chapter 2}

\section{The interaction of tea flavonoids with the $\mathrm{NO}^{\bullet}$-system: discrimination between good and bad $\mathrm{NO}^{\circ}$}

Chantal G.M. Heijnen, Guido R.M.M. Haenen, Sheila A. Wiseman', Lilian B.M. Tijburg;, Aalt Bast

- Unilever Research, P.O. Box 114, 3130 AC Vlaardingen, The Netherlands.

Food Chemistry 70 (2000) 365-370 



\subsection{Abstract}

The effect of black and green tea on the $\mathrm{NO}^{\bullet}$ system was tested. Beside a general effect i.e. $\mathrm{NO}^{\bullet}$ scavenging, the teas interacted with good, i.e. relaxation of the aorta, and bad effects, i.e. peroxynitrite scavenging, of $\mathrm{NO}^{\bullet}$. Green tea was a better $\mathrm{NO}^{\bullet}$ and peroxynitrite scavenger than black tea. Epigallocatechin gallate was the major identified contributor to both the peroxynitrite and $\mathrm{NO}^{\bullet}$ scavenging. The theaflavins, only present in black tea, also had a substantial contribution to the $\mathrm{NO}^{\bullet}$ scavenging of black tea. The teas were found to have only a minor and nonspecific effect on the $\mathrm{NO}^{\bullet}$ mediated vasorelaxation. Based on these results it is concluded that tea discriminates between the good and bad effects of $\mathrm{NO}^{\bullet}$; tea is likely to prevent $\mathrm{NO}^{\bullet}$ toxicity primarily. 


\subsection{Introduction}

Nitric oxide (nitrogen monoxide, $\mathrm{NO}^{\bullet}$ ) plays an ambiguous role in physiology. On the one hand $\mathrm{NO}^{\bullet}$ is involved in various regulatory processes as second messenger. For example, the acetylcholine-induced relaxation in aorta is $\mathrm{NO}^{\circ}$-mediated. Upon stimulation of the acetylcholine-receptor, the constitutive $\mathrm{NO}^{\circ}$-synthase (NOS) produces $\mathrm{NO}^{\bullet}$. $\mathrm{NO}^{\bullet}$ activates guanylate cyclase, which leads to the production of cyclic GMP, and ultimately to vasorelaxation. On the other hand $\mathrm{NO}^{\bullet}$ is toxic, predominantly due to the formation of peroxynitrite formed in the reaction with superoxide radicals (Radi, et al., 1991, Rubbo, et al., 1996).

Previously, it has been shown that flavonoids, i.e. a group of polyphenolic antioxidants (Miller, et al., 1996, Salah, et al., 1995), interact with the NO system. For example, it has been found that flavonoids are efficient scavengers of the nitric oxide radical (Haenen and Bast, 1999, Verhagen, et al., 1996). In their effect on the $\mathrm{NO}^{*}$-system, e.g. $\mathrm{NO}^{\bullet}$ scavenging, the flavonoids do not distinguish between good and bad $\mathrm{NO}^{\circ}$. It has been reported that flavonoids accumulate in vascular tissue between the endothelial layer and the vascular smooth muscle cells (Neumann, et al., 1992). Interestingly at this site both beneficial (vasorelaxation) and detrimental (atherosclerosis) processes with $\mathrm{NO}^{\bullet}$ as a protagonist take place.

A major source of flavonoids in the western diet is tea (Camellia sinensis). The most frequently consumed teas are black and green tea. In the production of green tea, steaming and drying of the tealeaves prevent oxidation of the polyphenols in the leaves. The major polyphenols of green tea are catechins, mainly epicatechin (EC), epigallocatechin (EGC), epicatechin gallate (ECG), and epigallocatechin gallate (EGCG). In the production of black tea fermentation, i.e. enzymatic, aerobic oxidation of leaf polyphenols, and subsequent condensation, takes place.

Due to this process, the total catechin content is reduced to approximately $20 \%$ of the total catechin content of green tea, and new products, such as theaflavins, are formed. The theaflavins comprise approximately $1 \%$ of the total flavonoids of black tea. The major ones are theaflavin, theaflavin 3-gallate, theaflavin 3'-gallate and theaflavin 3,3'-digallate. The most important catechins and theaflavins are depicted in figure 1. 
In the present study, the interaction of tea with the $\mathrm{NO}^{\bullet}$ system was determined. Beside a general effect ( $\mathrm{NO}^{\bullet}$ scavenging), the interaction with good (the acetyl choline-dependent relaxation of the aorta) and bad $\mathrm{NO}^{\bullet}$ (peroxynitrite scavenging) was measured. Both black and green tea were investigated.

Figure $1 \quad$ Structures of the catechins and theaflavins. For the catechins: epicatechin $R_{I}=H$ and $R_{2}=O H ;$ for epigallocatechin $R_{I}=O H$ and $R_{2}=O H ;$ for epicatechin gallate $R_{1}=H$ and $R_{2}=$ gallate; for epigallocatechin gallate $R_{1}=O H$ and $R_{2}=$ gallate. For the theaflavins: theaflavin, $R_{3}=R_{4}=O H$; for theaflavin-3-monogallate $R_{3}=$ gallate and $R_{4}=O H ;$ for theaflavin-3'-monogallate $R_{3}=O H$ and $R_{4}=$ gallate; for theaflavin 3,3'-digallate $R_{3}=R_{4}=$ gallate (Pannala, et al. 1997).<smiles>[R]c1cc(C2Oc3cc(O)cc(O)c3CC2[R2])cc(O)c1O</smiles>

Catechins<smiles>O=C(O)c1cc(O)c(O)c(O)c1</smiles>

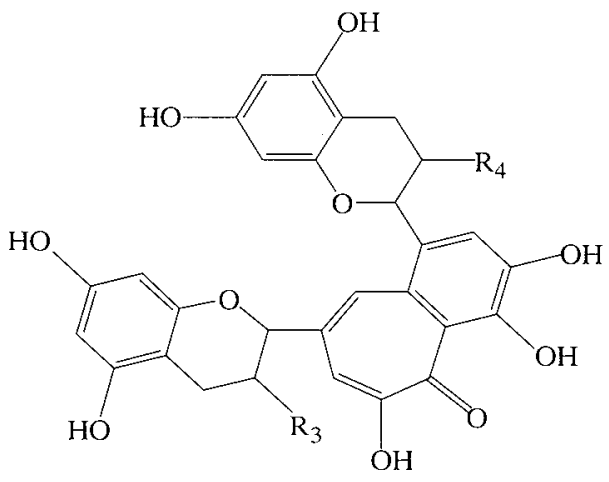

Teaflavins 


\subsection{Materials and methods}

\section{Chemicals}

The flavonoids and green and black tea powder were gifts from Lipton (Englewood Cliffs, New Jersey USA). The composition of the tea powders is given in Table 1. The amount of solids obtained from tea is variable, depending e.g. on brewing time and agitation. The average amount of solids obtained from an average English cup is 2-5 g/l. For calculation of the activity of tea, $3 \mathrm{~g}$ solids per litre was used.

Peroxynitrite was synthesised in a quenched flow reactor, as previously described by Radi et al. (1991). Excess hydrogen peroxide was removed by $\mathrm{MnO}_{2}$ treatment. All other chemicals were of analytical purity grade.

Table 1 Composition of the teas.

\begin{tabular}{lll}
\hline & Green Tea & Black Tea \\
\hline Catechins & 32.8 & 6.80 \\
(+)-catechin & 1.3 & 0.32 \\
(+)-gallocatechin & 1.4 & 0.28 \\
(+)-gallocatechin gallate & 0.39 & $<$ LLOQ \\
EC & 4.2 & 0.79 \\
EGC & 7.9 & 1.2 \\
ECG & 5.8 & 1.4 \\
EGCG & 11.8 & 2.8 \\
& & \\
Theaflavins & & 1.18 \\
theaflavin & $<$ LLOQ & 0.36 \\
theaflavin-3-gallate & $<$ LLOQ & 0.36 \\
theaflavin-3'-gallate & $<$ LLOQ & 0.19 \\
theaflavin-3,3'-digallate & $<$ LLOQ & 0.27 \\
gallic acid & 0.15 & 0.80 \\
caffeine & 6.4 & 6.6 \\
theobromine & 0.25 & 0.25 \\
unknown material & 60.5 & 84.4 \\
\hline
\end{tabular}

Results are represented as percentage (w/w)

$<L L O Q=$ below the lower limit of quantification i.e.0.1\% 
$N O^{\bullet}$ scavenging

$\mathrm{NO}^{\bullet}$ scavenging was determined according to Vriesman (Vriesman, et al., 1997). In short, deoxygenated water was purged with $\mathrm{NO}^{\bullet}$ gas for about $1 \mathrm{~min}$. Two $\mu \mathrm{l}$ of the $\mathrm{NO}^{\circ}$ spiked water was added to $20 \mathrm{ml}$ of $50 \mathrm{mM}$ phosphate buffer (pH 7.4) in a thermostatted test vessel $\left(37^{\circ} \mathrm{C}\right)$. During measurements the test vessel was kept under a $\mathrm{N}_{2}$ atmosphere. The $\mathrm{NO}^{\bullet}$ concentration was monitored with an Iso-NO meter (World Precision Instruments, Sarasota, USA) which was coupled to a MacLab ${ }^{\mathrm{TM}}$ interface (ML020 MacLab/8, ADInstruments, London, U.K.). The decrease in NO concentration was followed in time in the presence or absence of the test compound in solution. The stock solution of the test compound was incubated at $37^{\circ} \mathrm{C}$ for 10 minutes before being used. The second order reaction constant $(k)$ was calculated.

\section{Peroxynitrite scavenging}

Peroxynitrite scavenging was measured by the oxidation of dihydrorhodamine 123 , as described by Kooy et al. (1994). Fluorescence measurements were performed on a Shimadzu RF-5001 PC fluorimeter with excitation and emission wavelengths of 500 $\mathrm{nm}$ and $536 \mathrm{~nm}$ respectively at $37^{\circ} \mathrm{C}$. The effects are expressed as the concentration giving 50\% inhibition of the oxidation of dihydrorhodamine $123\left(\mathrm{IC}_{50}\right)$.

\section{The isolated aorta.}

Male Wistar rats (200-220 g, Harlan Olac, Horst, The Netherlands) were used. After decapitation, the aorta was rapidly excised, and small rings (app. $1 \mathrm{~mm}$ thick) were mounted in a thermostated organ bath $\left(37^{\circ} \mathrm{C}\right)$ containing Krebs buffer gassed with a mixture of $95 \% \mathrm{O}_{2}$ and $5 \% \mathrm{CO}_{2} ; \mathrm{pH} 7.4$ and fixed to a isotonic transducer. The composition of the Krebs buffer was (mM): $\mathrm{NaCl}(117.5), \mathrm{KCl}(5.6), \mathrm{MgSO}_{4}(1,18)$, $\mathrm{CaCl}_{2}$ (2.5), $\mathrm{NaHPO}_{4}(1.28), \mathrm{NaHCO}_{3}(25)$ and glucose (5.5). The tension was adjusted to $0.1 \mathrm{~g}$. The concentration and relaxation of the aorta was determined isotonically. To determine the acetylcholine-receptor mediated relaxation, the aorta rings were first pre-contracted using phenylephrine (PE) (Kenakin, T.P., 1987). A dose-response curve was constructed. Subsequently, the dose-dependent relaxation mediated by the acetylcholine-receptor was determined. Metacholine (MCh), 
a chemically more stable receptor agonist than acetylcholine, was used for this purpose.

Firstly, a reference curve of both PE and MCh was constructed in each organ. Subsequently, the organs were incubated for $30 \mathrm{~min}$ with tea at several concentrations. After this period, a second dose-response curve of $\mathrm{PE}$ and $\mathrm{MCh}$ was constructed. The $\mathrm{pD}_{2}$ values (-log of the molar concentration that produces half maximal effect) of the compounds were calculated. The maximal effect produced by the compounds in the second dose-response curve was related to that of PE in the first dose-response curve. The reversibility of the effect of tea was examined by washing 3 times for 5 minutes with $20 \mathrm{ml}$ of fresh Krebs buffer.

\section{Statistics}

The results were expressed as mean $+/$ - SEM and statistical analysis were performed with a non-parametric Man-Whitney-U-test.

\subsection{Results}

The ability of tea to scavenge the $\mathrm{NO}^{\bullet}$ radical was tested. Green tea (the rate constant, $\mathrm{k}=0.101 \pm 0.016 \mathrm{ml} \mathrm{mg}^{-1} \mathrm{~s}^{-1}, \mathrm{n}=3$ ) was more effective than black tea $\left(\mathrm{k}=0.019 \pm 0.009 \mathrm{mg}^{-1} \mathrm{~s}^{-1}, \mathrm{n}=3\right)$. The contribution of various polyphenols to the $\mathrm{NO}^{\bullet}$ scavenging, calculated from their own activity and their content in tea, is given in figure 3. In this calculation it is assumed that only additive and not synergistic effects occur. The ability of tea to scavenge peroxynitrite was also tested. Again green tea $\left(\mathrm{IC}_{51)}=0.380 \pm 0.037 \mu \mathrm{g} \mathrm{ml}^{-1}\right)$ appeared to be a better scavenger than black tea, $\mathrm{p}<0.05\left(\mathrm{IC}_{50}=0.882 \pm 0.036 \mu \mathrm{g} \mathrm{ml}^{-1}\right)$. The contribution of the various polyphenols to the peroxynitrite scavenging is also quantified (figure 4).

The effect of tea on the NO mediated vasorelaxation was examined in isolated aorta rings. Addition of $\mathrm{PE}$ and $\mathrm{MCh}$ to the aorta rings resulted respectively in a contraction and relaxation (figure 2). The $\mathrm{pD}_{2}$ values of $\mathrm{PE}$ and $\mathrm{MCh}$ in the reference curve were respectively 7.27 and 6.98 (table II). The maximal relaxation by MCh was $69 \%$ of the contraction induced by PE. Neither black nor green tea had an effect on the 
tonus of the aorta in the concentrations studied $(1 \mu \mathrm{g} / \mathrm{ml}-0.1 \mathrm{mg} / \mathrm{ml})$ (data not shown). To test the effect of tea on the $\mathrm{NO}^{\bullet}$ mediated relaxation of the aorta, the aorta was incubated 30 min with tea. Then dose-response curves for PE and MCh were constructed. The $\mathrm{pD}_{2}$ of $\mathrm{PE}$ was not affected by a $30 \mathrm{~min}$ incubation period with $0.1 \mathrm{mg} / \mathrm{ml}$ black tea. Green tea $(0.1 \mathrm{mg} / \mathrm{ml})$ induced a small reduction of the $\mathrm{pD}_{2}$ value. Incubation with either black or green tea in a concentration of $0.1 \mathrm{mg} / \mathrm{ml}$ reduced the maximal effect induced by PE slightly. The effect of green tea on the maximal PE induced contraction was absent when a concentration of $1 \mu \mathrm{g} / \mathrm{ml}$ was applied (data not shown). After incubation with either black or green tea at a concentration of $0.1 \mathrm{mg} / \mathrm{ml}$, no $\mathrm{MCh}$ response was obtained.

Figure 2 Typical traces of the dose response curves of PE and MCh in a control aorta ring (trace $A$ ) and an aorta incubated with $0.1 \mathrm{mg} / \mathrm{ml}$ green tea (trace B). The concentrations of PE and MCh are depicted as - log of the molar concentration.

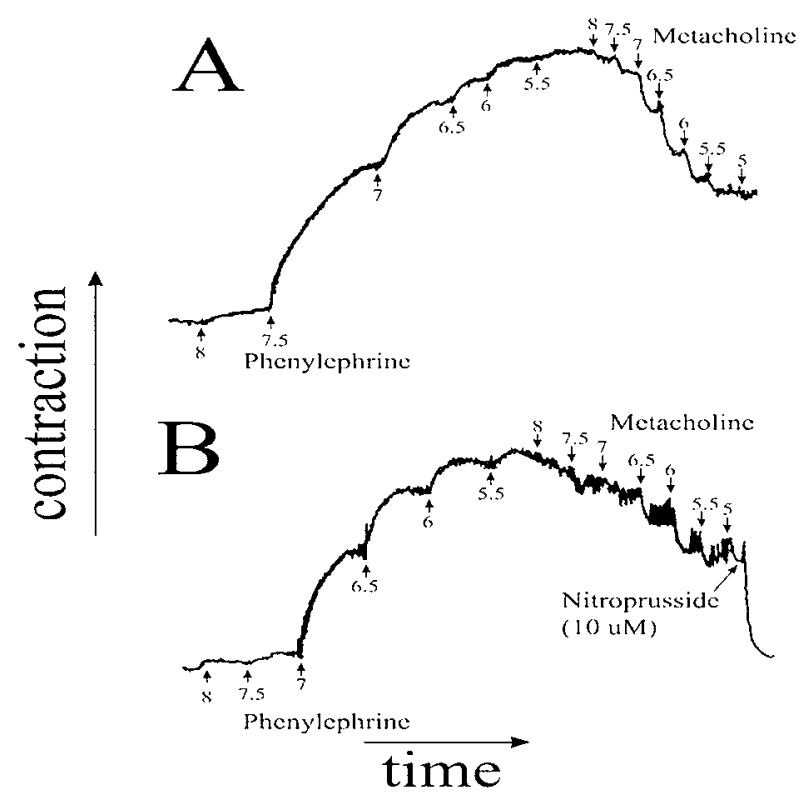


In contrast, when nitroprusside $(10 \mu \mathrm{M})$, a direct $\mathrm{NO}^{\circ}$-donor, was added to the organ bath containing either black or green tea extract a full relaxation of the aorta was observed. Incubation with either black or green tea in a concentration of $0.1 \mathrm{mg} / \mathrm{ml}$ and subsequent washing, restored the MCh response from $0 \%$ to approximately $50 \%$ of the MCh response of the reference curve.

In an additional experiment, the aorta rings were contracted with PE, and MCh was added to give maximal relaxation. Subsequently, i.e. after the $\mathrm{MCh}$ induced relaxation, tea was added. It was found that tea in a concentration of $0.1 \mathrm{mg} / \mathrm{ml}$ induced a slow contraction of the aorta. Surprisingly, the effect was small compared to the complete inhibition of the MCh response when tea was added 30 min before the MCh was added.

Figure 3 Relative contribution of mixed theaflavins (MTF), epicatechin (EC), epigallocatechin $(E G C)$, epicatechin gallate ( $E C G)$, and epigallocatechin gallate (EGCG) to the $N \mathrm{O}^{\circ}$ scavenging by black and green tea.
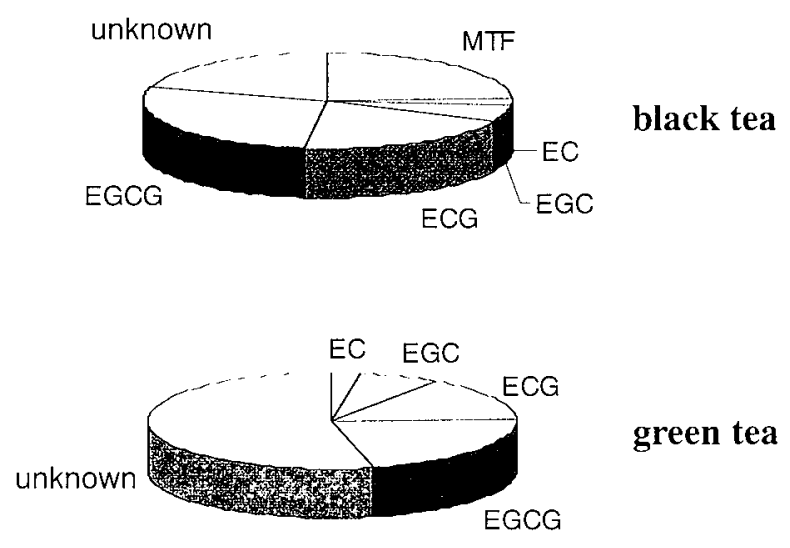
Figure 4

Relative contribution of mixed theaflavins (MTF), epicatechin (EC), epigallocatechin (EGC), epicatechin gallate (ECG), and epigallocatechin gallate (EGCG) to the peroxynitrite scavenging by black and green tea
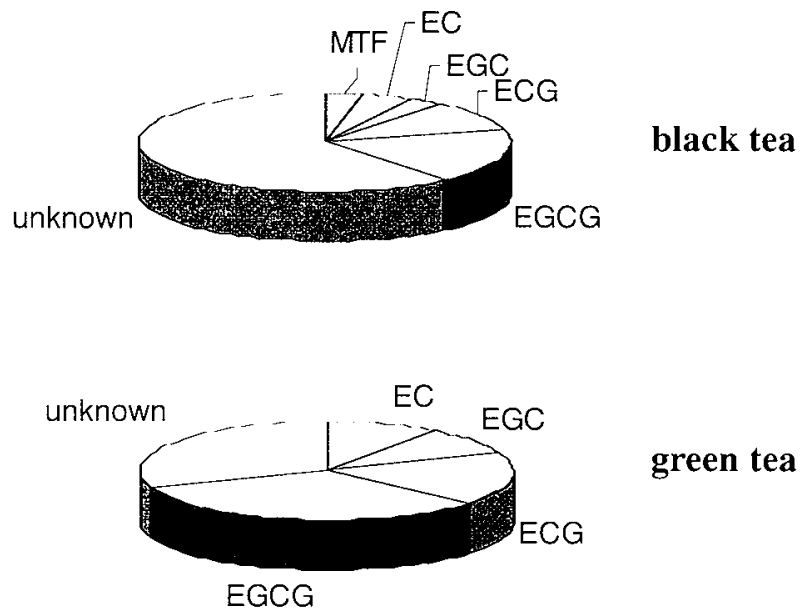

Table 2 The effect of black and green tea on the dose response curves of PE and $M C h$ in aorta rings. The aorta ring was incubated $30 \mathrm{~min}$ with the tea in the given concentration before the dose response curves were constructed.

\begin{tabular}{|c|c|c|c|c|}
\hline & & \multirow{3}{*}{ Control $(n=16)$} & \multicolumn{2}{|c|}{ Treatment } \\
\hline & & & black tea & green tea \\
\hline & & & $100 \mu \mathrm{g} / \mathrm{ml}(\mathrm{n}=4)$ & $100 \mu \mathrm{g} / \mathrm{ml}(\mathrm{n}=4)$ \\
\hline \multirow{2}{*}{$\mathrm{PE}$} & $\mathrm{pD}_{2}$ & $7.24 \pm 0.15$ & $7.32 \pm 0.19$ & $6.63 \pm 0.17$ \\
\hline & $\mathrm{E}_{\max }(\%)$ & $100^{*}$ & $87 \pm 7$ & $79 \pm 9$ \\
\hline \multirow{2}{*}{$\mathrm{MCh}$} & $\mathrm{pD}_{2}$ & $6.98+0.13$ & N.R." & N.R." \\
\hline & $\mathrm{E}_{\max }(\%)$ & $69 \pm 12$ & 0 & 0 \\
\hline
\end{tabular}

The maximal effect $\left(\mathrm{E}_{\text {max }}\right)$ of PE in the control curve was used as reference and set at $100 \%$.

* N.R. = no response. 


\subsection{Discussion}

The effect of tea on the $\mathrm{NO}^{\bullet}$ system was determined in the present study. It was found that tea is a scavenger of $\mathrm{NO}^{\circ}$. Green tea was found to be a more efficient scavenger of $\mathrm{NO}^{\bullet}$ than black tea; green tea powder was approximately 5 times more potent than black tea powder. Taking an average tea concentration as $3 \mathrm{~g} / \mathrm{l}$ tea solids, it can be calculated that green tea has an activity comparable to white wine and is approximately 50 times less active than red wine (Verhagen, et al., 1996).

The ability of flavonoids to protect against $\mathrm{NO}^{\bullet}$ toxicity was monitored by the peroxynitrite scavenging activity. Previously, it has been shown that the catechins and theaflavins present in tea are peroxynitrite scavengers (Pannala, et al., 1997). In the present study it appeared that green tea was the better peroxynitrite scavenger; green tea powder has more than twice the activity of black tea powder. It was calculated that green tea had a slightly higher activity than red wine, and was approximately 20 times more potent than white wine.

As shown in figure 3 and 4 , a substantial part of the $\mathrm{NO}^{\bullet}$ scavenging activity as well as the peroxynitrite scavenging resides in the flavonoid fraction of both green and black tea. In black tea, theaflavins - that comprise only $1.2 \%(\mathrm{w} / \mathrm{w})$ of the weight are responsible for $25 \%$ of the $\mathrm{NO}^{\bullet}$ scavenging of black tea powder. EGCG also accounts for $25 \%$ of the $\mathrm{NO}^{\circ}$ scavenging, while its content is more than twice that of the theaflavins. The other major contributor $(20 \%)$ to the NO ${ }^{\bullet}$ scavenging of black tea is ECG $(1.4 \% \mathrm{w} / \mathrm{w})$. In green tea ECG and EGCG are the two major contributors that are identified. Theaflavins are not present in green tea.

Theaflavins appear to be better $\mathrm{NO}^{\bullet}$ scavengers than peroxynitrite scavengers. The major reason for the lower peroxynitrite scavenging of black tea compared to green tea can be found in the lower catechin content, due to the enzymic oxidation process in the production of black tea. ECG and EGCG were found to be the major identified contributors in both black and green tea. In green tea EGCG $(11.8 \% \mathrm{w} / \mathrm{w})$ and ECG $(5.8 \% \mathrm{w} / \mathrm{w})$ are responsible for respectively $33 \%$ and $18 \%$ of the total peroxynitrite scavenging. 
The effect of tea on a major physiological role of $\mathrm{NO}^{\bullet}$ was tested in vitro, i.e. the $\mathrm{NO}^{\bullet}$ mediated relaxation of the aorta. It was found that tea is able to block the MChinduced relaxation of aorta rings at a concentration that only slightly affects the PE response. These results are consistent with the observed $\mathrm{NO}^{\bullet}$ scavenging activity of tea. Moreover, they are in line with the reduction of the acetylcholine response in rabbit aorta by red wine (Cishek, et al., 1997). The effect of tea may be explained by a reduction of $\mathrm{NO}^{\bullet}$ production, by $\mathrm{NO}^{\bullet}$ scavenging or by reducing the $\mathrm{NO}^{\bullet}$ response. Since tea did not affect the nitroprusside response, $\mathrm{NO}^{\bullet}$ scavenging and reduction of the $\mathrm{NO}^{\bullet}$ response seem less likely. The $\mathrm{NO}^{\circ}$ scavenging effect of black tea was $20 \%$ of that of green tea. The effect on the MCh response of $30 \mu \mathrm{g} / \mathrm{ml}$ green tea (data not shown) was less than that of $100 \mu \mathrm{g} / \mathrm{ml}$ black tea. This indicates that $\mathrm{NO}^{\bullet}$ scavenging is at its most only partly involved in the effect of black tea.

Tea in a concentration of $0.1 \mathrm{mg} / \mathrm{ml}$ that was added to the aorta $30 \mathrm{~min}$ before $\mathrm{MCh}$ was added completely blocked the MCh response. Surprisingly, tea $(0.1 \mathrm{mg} / \mathrm{ml})$ added after $\mathrm{MCh}$, only slightly reduced the MCh response. This indicates that the onset of the effect of tea is relatively slow. Since $\mathrm{NO}^{\bullet}$ scavenging is expected to give a rapid onset of the effect, this again indicates that the effect of tea is not mediated by $\mathrm{NO}^{\bullet}$ scavenging. Duarte (Duarte, et al., 1993) reported that the vasodilatory effect of various flavonoids might be due to protein kinase $\mathrm{C}$ inhibition, phosphodiesterase inhibition or decreased calcium uptake. Chiesi and Schwaller (Chiesi, and Schwaller, 1995) found that the polyphenols tannin and quercetin are efficient inhibitors of the endothelial NOS (eNOS). Possibly, these effects of flavonoids are involved in the effect of tea on the MCh response reported in the present study. However, according to Cishek et al. (Cishek, et al., 1997) catechin and epicatechin had no effect on the response to acetylcholine. Girard et al. (Girard, et al., 1995) reported that a new synthetic flavonoid induced vasorelaxation by scavenging superoxide. Superoxide was supposed to inactivate $\mathrm{NO}^{\circ}$. Scavenging of superoxide by the flavonoid should prolong the half-life of $\mathrm{NO}^{\circ}$, resulting in the observed relaxation. Given the $\mathrm{NO}^{\bullet}$ scavenging capacity of tea, preservation of $\mathrm{NO}^{\bullet}$ by tea does not seem probable.

Various studies report on a vasorelaxing activity of flavonoids and flavonoid 
containing products like tea and wine. Although these studies are partly contradictory and non-conclusive, most of them seem to point at an enhanced $\mathrm{NO}^{\bullet}$ production induced by the flavonoids. This is however not in line with the reported inhibition of eNOS (Chiesi, and Schwaller, 1995), the reduction of the acetylcholine receptormediated vasorelaxation by wine (Cishek, et al., 1997) and tea (this study), and the observation that mechanical removal of the endothelium did not modify the relaxant effect of the flavonoids. The simultaneous induction of vasorelaxing and contracting factors by a single compound (Russel, and Rohrbach, 1989) may hamper a straightforward interpretation of the results. This becomes even more complicated when products that contain a mixture of flavonoids, such as wine and tea, are studied. This may be one of the reasons for the conflicting results and variation in the molecular mechanisms that have been proposed. In addition, it should be kept in mind that the flavonoids comprise approximately 5,000 different compounds of natural origin. The chemical heterogeneity is even increased by the processing of flavonoid containing products, like the fermentation of tea. Due to this immense heterogeneity, a uniform mechanism for all flavonoids cannot be expected. The interaction of different flavonoids with the $\mathrm{NO}^{\bullet}$ system may be different or even opposite. The relative high concentration needed to reduce the $\mathrm{NO}^{\circ}$-mediated relaxation points at a rather unspecific and less relevant effect of tea on the beneficial effect of $\mathrm{NO}^{\circ}$.

A beneficial effect of high flavonoid intake on the occurrence of cardiovascular heart diseases has been demonstrated in various studies (Frankel, et al., 1993, Hertog, et al., 1993). Previously, it has been speculated that the molecular mechanism for this effect may be found in the protection by the flavonoids against $\mathrm{NO}^{\bullet}$ toxicity. Tea is a major dietary source of flavonoids. However, the exact knowledge on digestion, absorption and metabolism is scarce. In the present in vitro study the potency of green tea relative to black tea to reduce either the good or bad effects of $\mathrm{NO}^{\bullet}$ is higher. The $\mathrm{NO}^{\bullet}$ scavenging of the teas studied is of limited importance; it is at its most only partly involved in the nonspecific inhibition by the teas of the MCh induced relaxation of the aorta. The scavenging activity of the undesirable form of $\mathrm{NO}^{\circ}$, peroxynitrite, by both black and green tea is superior to the effect the teas have on the beneficial vasorelaxation effect of $\mathrm{NO}^{\circ}$. Besides peroxynitrite scavenging, tea 
might prevent $\mathrm{NO}^{\bullet}$ toxicity also in other ways. It has been reported that EGCG is able to inhibit the formation of bad $\mathrm{NO}^{\circ}$ by inhibition of the inducible form of NOS (iNOS) and suppression of the expression of iNOS. Apparently, in its effect on the $\mathrm{NO}^{\bullet}$ system, tea discriminates between good and bad $\mathrm{NO}^{\bullet}$; tea is likely to prevent NO ${ }^{\bullet}$ toxicity primarily. 


\subsection{References}

Chiesi, M. and Schwaller, R., (1995) Inhibition of constitutive endothelial NO-synthase activity by tannin and Quercetin.

Biochemical Pharmacology 49 (4), 495-501.

Cishek, M.B., Galloway, M.T., Karim, M., German, J.B. and Kappagoda, C.T., (1997) Effect of red wine on endothelium-dependent relaxation in rabbits. Clinical Science 93 507-511.

Duarte, J., Perez-Vizcaino, F., Utrilla, P., Jiménez, J., Tamargo, J. and Zarzuelo, A., (1993) Vasodilatory effects of flavonoids in rat aortic smooth muscle.

Structure-activity relationships.

General Pharmacology 24 (4), 857-862.

Frankel, E.N., Kanner, J., German, J.B., Parks, E. and Kinsella, J.E., (1993) Inhibition of oxidation of human low-density lipoprotein by phenolic substances in red wine. Lancet 341 454-457.

Girard, P., Sercombe, R., Sercombe, C., LeLem, G., Seylam, J. and Potier, P., (1995) A new synthetic flavonoid protects endothelium-derived relaxing factor-induced relaxation in rabbit arteries in vitro: evidence for superoxide scavenging.

Biochemical Pharmacology 49 (10), 1533-1539.

Haenen, G.R.M.M. and Bast, A., (1999) Nitric oxide radical scavenging of flavonoids.

Methods in Enzymology Acedemic Press San Diego 490-503.

Hertog, M.G.L., Feskens, E.J.M., Hollman, P.C.H., Katan, M.B. and Kromhout, D., (1993) Dietary antioxidant flavonoids and risk of coronary heart disease: the Zutphen Elderly Study. Lancet 342 1007-1011.

Kenakin, T.P., (1987) Chapter 3: Isolated-tissue response system.

Pharmacologic analysis of drug-receptor interaction

Raven Press New York 52-84.

Kooy, N.W., Royall, J.A., Ischiropoulos, H. and Beckman, J.S., (1994)

Peroxynitrite-mediated oxidation of dihydrorhodamine 123.

Free Radical Biology and Medicine 16 (2), 149-156. 
Miller, N., Castelluccio, C., Tijburg, L. and Rice-Evans, C., (1996) The antioxidant properties of theaflavins and their gallate esters - radical scavengers or metal chelators? FEBS Letters 392 40-44.

Neumann, H., Carlsson, K. and Brom, G., (1992) Uptake and localisation of $\mathrm{O}$-(beta-hydroxyethyl)-rutosides in the venous wall, measured by laser scanning microscopy. European Journal of Clinical Pharmacology 43 423-426.

Pannala, A.S., Rice-Evans, C.A., Halliwell, B. and Singh, S., (1997) Inhibition of peroxynitrite-mediated tyrosine nitration by catechin polyphenols. Biochemical and Biophysical Research Communications 232 164-168.

Radi, R., Beckman, J.S., Bush, K.M. and Freeman, B.A., (1991) Peroxynitrite-induced membrane lipid peroxidation: the cytotoxic potential of superoxide and nitric oxide. Archives of Biochemistry and Biophysics 288 481-487.

Rubbo, H., Darley-Usmar, V. and Freeman, B.A., (1996) Nitric oxide regulation of tissue free radical injury. Chemical Research in Toxicology 9 809-820.

Russel, J.A. and Rohrbach, M.S., (1989) Tannin induces endothelium-dependent contraction and relaxation of rabbit pulmonary artery. American Review of Respiratory Disease 139 498-503.

Salah, N., Miller, N.J., Paganga, G., Tijburg, L., Bolwell, G.P. and Rice-Evans, C., (1995) Polyphenolic flavanols as scavengers of aqueous phase radicals and as chain-breaking antioxidants. Arch. Biochem. Biophys. 322 (2), 339-346.

Verhagen, J.V., Haenen, G.R.M.M. and Bast, A., (1996) Nitric oxide radical scavenging by wines.

Journal of Agricultural and Food Chemistry 44 3733-3734.

Vriesman, M.F., Haenen, G.R.M.M., Westerveld, G.J., Paquay, J.B.G., Voss, H.P. and Bast, A., (1997) A method for measuring nitric oxide radical scavenging activity. Scavening properties of sulfer-containung compounds.

Pharmacy World and Science 19 (6), 283-286. 



\section{Chapter 3}

\section{Flavonoids as peroxynitrite scavengers: The role of the hydroxyl groups}

C.G.M. Heijnen, G.R.M.M. Haenen, F.A.A. van Acker', W.J.F. van der Vijgh', A. Bast.

- Department of Medical Oncology, University Hospital, Vrije Universiteit, De Boelelaan 1117, 1081 HV Amsterdam, The Netherlands.

Toxicology in Vitro 15 (2001) 3-6 



\subsection{Abstract}

It has been reported that flavonoids efficiently protect against peroxynitrite toxicity. Two pharmacophores have been identified in flavonoids, namely the catechol group in ring $\mathrm{B}$ and the hydroxyl $(\mathrm{OH})$ group at the 3-position. In this study, this structure activity relationship was further examined. It was found that catechol (1,2-dihydroxybenzene) is a potent peroxynitrite scavenger, whereas phenol (hydroxybenzene) is not. Of the flavonols tested without a catechol group in ring $\mathrm{B}$, kaempferol $(\mathrm{OH}$ groups at positions $\left.3,5,7,4^{\prime}\right)$ and galangin ( $\mathrm{OH}$ groups at positions $\left.3,5,7\right)$ are also potent scavengers, whereas apigenin ( $\mathrm{OH}$ groups at positions $\left.5,7,4^{\prime}\right)$ and chrysin (OH groups at positions 5,7) are not. This confirms the importance of the $\mathrm{OH}$ group at the 3-position. However the synthetic flavonol TUM 9761 and 3-hydroxyflavone (OH group only at position 3 ) are poor scavengers. Based on these results, the structure-activity relationship on the peroxynitrite scavenging activity of flavonols was refined. The catechol in ring $\mathrm{B}$ remains important. Also the 3-OH group remains important, but the activity of this pharmacophore is influenced by the substituents at position 5 and at position 7 . 


\subsection{Introduction}

Flavonoids are a group of naturally occurring compounds abundantly present in our diet. Some of these flavonoids possess a strong antioxidant effect (Diplock, et al., 1998, Pannala, et al., 1997). It has been reported that flavonoids have a protective effect against several diseases, for example, atherosclerosis (Duarte, et al., 1993, Hertog, et al., 1993). This effect is linked to their antioxidant property. In general it is considered that a higher number of $\mathrm{OH}$ substituents in a flavonoid results in a higher antioxidant activity. Recently, their ability to protect against peroxynitrite [oxoperoxonitrate (1)] toxicity has gained much interest. Peroxynitrite toxicity is associated with several diseases for instance airway diseases (Sadeghi Hashjin, et al., 1998), cardiovascular (Digerness, et al., 1999, Wattanapitayakul, et al., 2000) and neurological diseases (e.g. amyotrophic lateral sclerosis) (Beckman, 1996, Estévez, et al., 1999). Two pharmacophores have been identified in flavonols, a subgroup of the flavonoids that can be held responsible for this effect, that is, a catechol group in ring $\mathrm{B}$ and the $\mathrm{OH}$ group at position 3 (Haenen, et al., 1997). The aim of the present

study was to further examine this structure-activity relationship with a selected group of natural occurring compounds and a flavonoid that was designed according to the structure-activity relationship.

\subsection{Materials and methods}

\section{Chemicals}

Kaempferol and apigenin were purchased from Fluka. Galangin and chrysin were purchased from Sigma Aldrich. All other chemicals were of analytical grade.

\section{Synthesis of peroxynitrite}

ONOOK was produced from the reaction of solid $\mathrm{KO}_{2}$ with $\mathrm{NO}^{\circ}$-gas as described by Koppenol et al. (Koppenol, et al., 1996). 
Synthesis of 3'4'-dibenzyloxy-3-hydroxyflavone, TUM 9761

A suspension of $31.4 \mathrm{mmol}$ 3,4-dibenzyloxybenzaldehyde and $31.4 \mathrm{mmol}$ 2-hydroxyacetophenone in $80 \mathrm{ml}$ ethanol and $50 \mathrm{ml}$ dioxane was cooled to $10^{\circ} \mathrm{C}$ and $25 \mathrm{ml}$ $40 \%$ (w/v) KOH solution was added dropwise. The reaction mixture was stirred for $66 \mathrm{~h}$ at room temperature. Four hundred millilitres $\mathrm{CH}_{2} \mathrm{Cl}_{2}$ was added and the organic layer was washed with $\mathrm{H}_{2} \mathrm{O}(3 \times 50 \mathrm{ml})$, dried over sodium sulfate and concentrated in vacuo.

The oily residue was dissolved in $110 \mathrm{ml}$ dioxane and $300 \mathrm{ml}$ ethanol and $100 \mathrm{ml}$ $5.4 \%(\mathrm{w} / \mathrm{v}) \mathrm{NaOH}$ solution. $11.4 \mathrm{ml} 35 \% \mathrm{H}_{2} \mathrm{O}_{2}$ was added dropwise. The reaction mixture was stirred on ice for $2 \mathrm{~h}$ and subsequently at room temperature overnight, resulting in a yellow suspension. After acidification with $100 \mathrm{ml} 2 \mathrm{M} \mathrm{HCl}$ the precipitate was filtered and washed with $500 \mathrm{ml} \mathrm{H}_{2} \mathrm{O}$. The product, TUM 9761, was recrystallized from ethanol to give $7.0 \mathrm{~g}(49 \%)$ of a light yellow solid; H NMR $\left(\mathrm{CDCl}_{3}\right): 85.22\left(\mathrm{~s}, 2 \mathrm{H}, \mathrm{OCH}_{2} \mathrm{Ph}\right), 5.25\left(\mathrm{~s}, 2 \mathrm{H}, \mathrm{OCH}_{2} \mathrm{Ph}\right), 7.01\left(\mathrm{~d}, \mathrm{~J}=8 \mathrm{~Hz}, \mathrm{C} 5{ }^{\prime} \mathrm{H}\right), 7.08$ (br s, $1 \mathrm{H}, \mathrm{C} 3 \mathrm{OH}), 7.3-7.5\left(\mathrm{~m}, 12 \mathrm{H}, \mathrm{OCH}_{2} \mathrm{Ph} \times 2+\mathrm{C} 6 \mathrm{H}+\mathrm{C} 8 \mathrm{H}\right) 7.64(\mathrm{dt}, 1 \mathrm{H}, \mathrm{J}=7 \mathrm{~Hz}$, $1.5 \mathrm{~Hz}, \mathrm{C} 7 \mathrm{H}), 7.82$ (dd, $\left.1 \mathrm{H}, \mathrm{J}=9 \mathrm{~Hz}, 2 \mathrm{~Hz}, \mathrm{C}{ }^{\prime} \mathrm{H}\right), 7.92$ (d, $\left.1 \mathrm{H}, \mathrm{J}=2 \mathrm{~Hz}, \mathrm{C} 2^{\prime} \mathrm{H}\right), 8.20$ (dd, $1 \mathrm{H}, \mathrm{J}=8 \mathrm{~Hz}, \mathrm{C} 5 \mathrm{H}$ ).

\section{Peroxynitrite scavenging}

Peroxynitrite scavenging was measured by the oxidation of dihydrorhodamine-123, as described by Kooy et al. (1994). Fluorescence measurements were performed at $37^{\circ} \mathrm{C}$ on a SPF-500C $\mathrm{C}^{\mathrm{TM}}$ spectrofluorometer (SLM AMINCO) with excitation and emission wavelengths of 500 and $536 \mathrm{~nm}$, respectively. The effects are expressed as the concentration giving $50 \%$ inhibition of the oxidation of dihydrorhodamine- 123 $\left(\mathrm{IC}_{50}\right)$. 


\subsection{Results and discussion}

It was found that catechol (1,2-dihydroxybenzene) is a potent scavenger in our assay, whereas phenol (hydroxybenzene) is not (Table 1), indicating that the catechol in ring $\mathrm{B}$ is indeed important for the peroxynitrite scavenging of flavonoids.

Hydroquinone also proved to be a potent peroxynitrite scavenger.

Table 1

Values of $I C_{50}(\mu M)$ in peroxynitrite scavenging

(mean value \pm S.D. $n=3-6$ ) of the tested phenols.

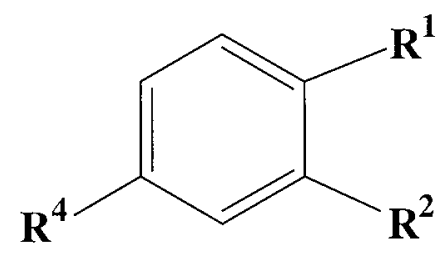

$\mathrm{R}^{1} \quad \mathrm{R}^{2} \quad \mathrm{R}^{4} \quad \mathrm{IC}_{50}(\mu \mathrm{M})$

$\begin{array}{lllll}\text { Phenol } & \mathrm{OH} & \mathrm{H} & \mathrm{H} & 263 \pm 31 \\ \text { Catechol } & \mathrm{OH} & \mathrm{OH} & \mathrm{H} & 2.8 \pm 0.5 \\ \text { Hydroquinone } & \mathrm{OH} & \mathrm{H} & \mathrm{OH} & 1.9 \pm 0.2\end{array}$

Kaempferol and galangin, flavonoids that lack the catechol but do contain the 3-OH group, were also potent scavengers of peroxynitrite (Table 2). Apigenin and chrysin, flavonoids that contains neither a catechol group nor a 3-OH group, had a poor activity in our assay (Table 2). Also the flavones with only a 5-OH group or only a $7-\mathrm{OH}$ group were poor scavengers of peroxynitrite. This would suggest an important role for the 3-OH group. We also tested a synthetic flavonoid (TUM 9761) and 3-hydroxyflavone, compounds that only contain an $\mathrm{OH}$ group at the 3-position. Surprisingly, both compounds were poor scavengers of peroxynitrite (Table 2). 
The results obtained with apigenin and kaempferol and with chrysin and galangin demonstrate the importance of the 3-OH group. The only difference in chemical structure between apigenin and kaempferol and between chrysin and galangin is that apigenin and chrysin lack the $3-\mathrm{OH}$ group. This difference drastically reduced the activity of apigenin and chrysin compared to kaempferol and galangin.

A similar observation on the importance of the 3-OH group has been made previously with trihydroxyethylquercetin and trihydroxyethylrutoside (Haenen, et al., 1997). Neither compounds contain a free catechol group in ring B.

Table 2 Values of $I C_{50}$ in peroxynitrite scavenging (mean value $\pm S . D$., $n=3-6$ ) of the tested flavonoids.

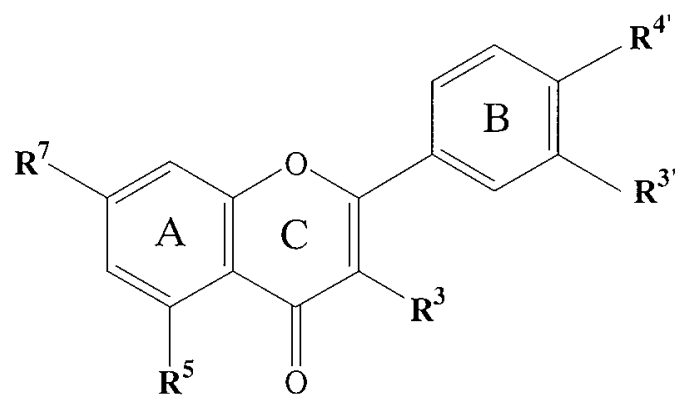

$$
\begin{array}{llllll}
\mathrm{R}^{3} & \mathrm{R}^{5} & \mathrm{R}^{7} & \mathrm{R}^{3} & \mathrm{R}^{4} & \mathrm{IC}_{50}(\mu \mathrm{M})
\end{array}
$$

TUM 9761

$\mathrm{OH} \quad \mathrm{H} \quad \mathrm{H} \quad \mathrm{OBn}^{\circ} \mathrm{OBn}^{\circ}>200$

3-Hydroxyflavone

$\mathrm{OH} \quad \mathrm{H} \quad \mathrm{H}$

$\mathrm{H}$

5-Hydroxyflavone

$\mathrm{H} \quad \mathrm{OH} \quad \mathrm{H}$

$\mathrm{H}$

$\mathrm{H}>200$

7-Hydroxyflavone

$\mathrm{H} \quad \mathrm{H}$

$\mathrm{OH}$

$\mathrm{H}$

$\mathrm{H}>300$

Apigenin

$\mathrm{H} \quad \mathrm{OH}$

$\mathrm{OH}$

$\mathrm{H}$

$\mathrm{H}>300$

Kaempferol

$\mathrm{OH} \quad \mathrm{OH}$

$\mathrm{OH}$

$\mathrm{H}$

$\mathrm{OH}$

$189 \pm 3$

Chrysin

$\mathrm{H} \quad \mathrm{OH}$

$\mathrm{OH}$

$\mathrm{H}$

$\mathrm{OH}$

$0.35 \pm 0.05$

Galangin

$\mathrm{OH} \quad \mathrm{OH} \quad \mathrm{OH} \quad \mathrm{H}$

$\mathrm{H}$

$295 \pm 26$

'Bn = benzyl 
Trihydroxyethylrutoside has rutinose as substituent on the 3-position and has a relatively poor activity in the peroxynitrite scavenging assay compared to trihydroxyethylquercetin, which lacks the rutinose and contains a free $\mathrm{OH}$ group at the 3 position.

When kaempferol and galangin are compared to the synthetic flavonoid TUM 9761 and 3-hydroxyflavone, compounds that all possess a 3-OH group, a remarkable difference in activity was observed. TUM 9761 and 3-hydroxyflavone, compounds that only contain an $\mathrm{OH}$ group at the 3-position, were hardly active in the peroxynitrite scavenging assay.

This illustrates that although the 3-OH group is important, the presence of a 3-OH group is not sufficient for an efficient protection against peroxynitrite. Apparently, the substituents at position 5 and at position 7 drastically affect the reactivity of the 3-OH group.

Deduced from the poor activity of apigenin and chrysin, the $\mathrm{OH}$ groups at the position 5 and 7 are not directly involved in peroxynitrite scavenging. Also the flavones with only a $5-\mathrm{OH}$ or a $7-\mathrm{OH}$ group were poor peroxynitrite scavengers. However, by influencing the reactivity of the $3-\mathrm{OH}$ group, they indirectly modulate peroxynitrite scavenging, which explains the high activity of kaempferol and galangin. Intramolecular rearrangement may take place when the $5-\mathrm{OH}$ group is present, giving a catechol like structure in ring $C$ (Figure 1). As catechols are excellent peroxynitrite scavengers, this would point to a major contribution of the 5-hydroxy group. It would suggest that the tautomer with the catechol like structure in ring $\mathrm{C}$ would be the active form. The high activity of hydroquinone shows that the $\mathrm{OH}$ group does not have to be in the ortho position for an efficient peroxynitrite scavenging. Apparently, an electronic effect of the parasubstituted $\mathrm{OH}$ group over the aromatic ring also promotes peroxynitrite scavenging of hydroquinone. This indicates that also the tautomer (e.g. of galangin), not having the catechol like structure in ring $\mathrm{C}$, may have high activity, and an electronic effect of the 7-OH group probably also enhances the peroxynitrite scavenging.

In previous structure-activity relationships only the number or the presence of $\mathrm{OH}$ groups at certain positions was taken into account (Cao, et al., 1997, Rice-Evans, et al., 1997) and the interaction between the groups was not considered. 
The present study demonstrates that this is incorrect. In the $\mathrm{AC}$ ring the $\mathrm{OH}$ group at position 3 is of primary importance in peroxynitrite scavenging and its activity is enhanced by the hydroxyl groups at position 5 and 7 . This insight is of major importance for the design of flavonoid structures with optimal peroxynitrite scavenging activity.

Figure $1 \quad$ Tautomers of galangin<smiles></smiles>

Acknowledgement: We thank Sonja Tibi for her helpful comments on the peroxynitrite synthesis. 


\subsection{References}

Beckman, J.S., (1996) Oxidative damage and tyrosine nitration from peroxynitrite. Chemical Research in Toxicology 9 (5), 836-844.

Cao, G., Sofic, E. and Prior, R.L., (1997) Antioxidant and prooxidant behavior of flavonoids: structure-activity relationships.

Free Radical Biology and Medicine 22 (5), 749-760.

Digerness, S.B., Harris, K.D., Kirklin, J.W., Urthaler, F., Viera, L., Beckman, J.S. and Darley Usmar, V., (1999) Peroxynitrite irreversibly decreases diastolic and systolic function in cardiac muscle.

Free Radical Biology and Medicine 27 (11-12), 1386-1392.

Diplock, A.T., Charleux, J.L., Crozier-Willi, G., Kok, F.J., Rice-Evans, C.,

Roberfroid, M., Stahl, W. and Vina-Ribes, J., (1998) Functional food science and defence against reactive oxidative species.

British Journal of Nutrition 80 (Suppl 1), S77-S112.

Duarte, J., Perez-Vizcaino, F., Utrilla, P., Jiménez, J., Tamargo, J. and Zarzuelo, A., (1993) Vasodilatory effects of flavonoids in rat aortic smooth muscle.

Structure-activity relationships.

General Pharmacology 24 (4), 857-862.

Estévez, A.G., Crow, J.P., Sampson, J.B., Reiter, C., Zhuang, Y., Richardson, G.J., Tarpey, M.M., Barbeito, L. and Beckman, J.S., (1999) Induction of nitric oxide-dependent apoptosis in motor neurons by zinc-deficient superoxide dismutase. Science 286 2498-2500.

Haenen, G.R.M.M., Paquay, J.B.G., Korthouwer, R.E.M. and Bast, A., (1997) Peroxynitrite scavenging by flavonoids.

Biochemical and Biophysical Research Communications 236 591-593.

Hertog, M.G.L., Feskens, E.J.M., Hollman, P.C.H., Katan, M.B. and Kromhout, D., (1993) Dietary antioxidant flavonoids and risk of coronary heart disease: the Zutphen Elderly Study. Lancet 342 1007-1011.

Kooy, N.W., Royall, J.A., Ischiropoulos, H. and Beckman, J.S., (1994)

Peroxynitrite-mediated oxidation of dihydrorhodamine 123.

Free Radical Biology and Medicine 16 (2), 149-156. 
Koppenol, W.H., Kissner, R. and Beckman, J.S., (1996) Syntheses of peroxynitrite: To go with the flow or on solid grounds?

Methods of Enzymology 269 296-302.

Pannala, A.S., Rice-Evans, C.A., Halliwell, B. and Singh, S., (1997) Inhibition of peroxynitrite-mediated tyrosine nitration by catechin polyphenols.

Biochemical and Biophysic al Research Communications 232 164-168.

Rice-Evans, C.A., Miller, N.J. and Paganga, G., (1997) Antioxidant properties of phenolic compounds. Trends in plant science: reviews 2 (4), 152-159.

Sadeghi Hashjin, G., Folkerts, G., Henricks, P.A., Muijsers, R.B. and Nijkamp, F.P., (1998) Peroxynitrite in airway diseases.

Clinical and Experimental Allergy 28 (12), 1464-1473.

Wattanapitayakul, S.K., Weinstein, D.M., Holycross, B.J. and Bauer, J.A., (2000)

Endothelial dysfunction and peroxynitrite formation are early events in angiotensin-induced cardiovascular disorders.

FASEB Journal 14 (2), 271-278. 



\section{Chapter 4}

\section{Peroxynitrite scavenging of flavonoids: Structure activity relationship}

Chantal G.M. Heijnen, Guido R.M.M. Haenen, Jef A.J.M. Vekemans', Aalt Bast

- Laboratory of Macromolecular and Organic Chemistry, Eindhoven University of Technology, P.O. Box 5135600 MB Eindhoven The Netherlands

Environmental Toxicology and Pharmacology 10 (2001) 199-206 



\subsection{Abstract}

Peroxynitrite can oxidize and nitrosylate biomolecules and is associated with several diseases. The peroxynitrite scavenging of substituted phenols and several flavonoids was studied. The activity of phenol (poor scavenger) is positively influenced by electron donating substituents. A good correlation was found between the peroxynitrite scavenging activity of the substituted phenols and the Hammett $\sigma$ or the

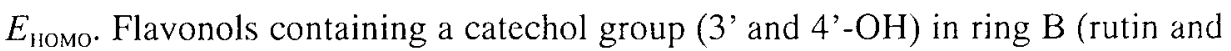
monohydroxyethyl rutoside) or an $\mathrm{AC}$-ring with three $\mathrm{OH}$ groups $(3,5$ and $7-\mathrm{OH}$ ) were potent scavengers. Evidence has been produced that in the $\mathrm{AC}$-ring the $3-\mathrm{OH}$ group was the reactive centre and that the reactivity of this group was positively influenced by electron donating groups at the 5 and / or 7 position (galangin, kaempferol, trihydroxyethyl quercetin). 


\subsection{Introduction}

Flavonoids are abundantly present in our diet, e.g. in vegetables, fruits and beverages such as tea and red wine. This group of compounds is intensively investigated because of their positive health effects (Diplock, et al., 1998). To study these beneficial effects several attempts have been made to establish a structure activity relationship (SAR) for the effects of flavonoids. However, no unambiguous SAR has been obtained for these general effects. When all aspects are considered, there are difficulties to be encountered in the search for a generally applicable SAR for the effects of flavonoids. Firstly, pathologies where flavonoids have been claimed to have positive effects, such as cardiovascular disease and cancer (Duarte, et al., 1993, Hertog, et al., 1993) are diverse, and differ in their respective aetiologies. Secondly, the point of action of different flavonoids in a certain disease is not necessarily the same. For example, the interaction of a flavonoid with the nitric oxide $\left(\mathrm{NO}^{\circ}\right)$ system can be achieved either by inhibition of nitric oxide synthase, scavenging of $\mathrm{NO}^{\bullet}$ or blocking of nitric oxide synthase expression (Heijnen, et al., 2000, Paquay, et al., 2000). Thirdly, the chemical heterogeneity of the flavonoids is immense; indeed, this group comprises more than 5000 compounds and includes diverse pharmacophores. Evidence has been generated that even within a single compound more than one pharmacophore can be found (Haenen, et al., 1997, Heijnen, et al., 2001).

Due to this variation in biological effects, points of action and pharmacophores it is somewhat utopian to expect to find a general applicable SAR accounting for the effects of all flavonoids. A SAR can only be expected for a well-defined mode of action within a chemically homogeneous group. In this study we concentrate on the SAR of peroxynitrite scavenging by flavonols. Flavonols were chosen because they form a subgroup of well-studied flavonoids present in a relatively large amount in our diet, displaying a potent antioxidant activity (Rice-Evans, et al., 1996, van Acker, et al., 1996a, van Acker, et al., 1996b).

$\mathrm{NO}^{*}$, a free radical species produced by several mammalian cell types, plays a role in regulation of vascular, neurological and immunological signal transduction and function. $\mathrm{NO}^{\circ}$ toxicity is for the greater part mediated by peroxynitrite (ONOO${ }^{-}$). formed in the reaction of $\mathrm{NO}^{\bullet}$ with $\mathrm{O}_{2}^{-\bullet}$ (Rubbo, et al., 1996). Peroxynitrite plays an 
important role in various diseases, c.g. cardiovascular, neurological and airway diseases (Beckman, 1996, Digerness, et al., 1999, Estévez, et al., 1999, Sadeghi Hashjin, et al., 1998, Wattanapitayakul, et al., 2000). It is a potent oxidant that is able to oxidize and nitrosylate a large variety of biomolecules. Various toxic effects of peroxynitrite have been described e.g. oxidation and nitration of proteins (Crow, et al., 1997, Ischiropoulos, and Al-Mehdi, 1995).

In existing SARs on the antioxidant activity of flavonoids, both the presence of aromatic $\mathrm{OH}$ groups and their number per molecule are considered to play a pivotal role (Cao, et al., 1997). However, these studies do not take the position of the $\mathrm{OH}$ groups into account. The aim of this work is to refine the SAR of a specific antioxidant effect, that is, peroxynitrite scavenging by flavonols. However, even within the structurally restricted group of these flavonols, the interactions are extremely complex. Therefore we began by studying the SAR of peroxynitrite scavenging by simple substituted phenols, thus casting light on the fundamentals of the SAR of the peroxynitrite scavenging by flavonols.

\subsection{Materials and methods}

\section{Chemicals}

Dihydrorhodamine-123 was obtained from Sigma and $\mathrm{KO}_{2}$ was obtained from Fluka (Buchs, Switzerland). Nitrogen monoxide was obtained from AGA (Hamburg, Germany). All other chemicals were of the highest grade of purity available.

\section{Peroxynitrite synthesis (potassium oxoperoxonitrate(1-))}

ONOOK was produced from the reaction of solid $\mathrm{KO}_{2}$ with $\mathrm{NO}^{\circ}$-gas as described by Koppenol et al. (1996). In short the $\mathrm{NO}^{*}$-gas slowly flowed over the mixture of $\mathrm{KO}_{2}$ and quartz-sand, which was constantly stirred and kept on ice. The mixture was poured into a cold potassium hydroxide solution. By adding manganese dioxide the hydrogen peroxide, resulting from excess potassium superoxide, decomposed. The solution with peroxynitrite was obtained by filtering off the sand and manganese dioxide. 
The concentration was determined spectroscopically $\left(=302 \mathrm{~nm},=167() \mathrm{cm}^{-1}\right)$.

\section{Synthesis of 3,5,7,3',4'-penta-O-methyl-quercetin (TUM 8437)}

A suspension of quercetin $(27 \mathrm{~g}, 80 \mathrm{mmol})$, iodomethane $(62.5 \mathrm{~g}, 440 \mathrm{mmol})$ and potassium carbonate $(120 \mathrm{~g}, 870 \mathrm{mmol})$ was heated in dimethylformamide $(240 \mathrm{ml})$ at $65^{\circ} \mathrm{C}$ for $5 \mathrm{~h}$. The reaction mixture was poured into acidic water ( $\mathrm{pH} 3$ ). The yellow precipitate was filtered and washed with $\mathrm{H}_{2} \mathrm{O}$ for 3 times. The product $\left(3,5,7,3^{\prime}, 4^{\prime}\right.$-penta-O-methyl-quercetin) was recrystallised from ethanol to give the pure compound $(16.8 \mathrm{~g}, 50.5 \%)$.

$\left(\mathrm{Mp} 150-5 \mathrm{C},{ }^{\mathrm{j}} \mathrm{H} \mathrm{NMR}\left(\mathrm{CDCl}_{3}\right) \delta: 7.70(2 \mathrm{H}, \mathrm{s}+\mathrm{d}, J=9 \mathrm{~Hz}), 6.97(1 \mathrm{H}, \mathrm{d}, J=2\right.$ $\mathrm{Hz}), 6.50(1 \mathrm{H}, \mathrm{s}), 6.30(1 \mathrm{H}, \mathrm{s}), 3.96(9 \mathrm{H}, 3 \mathrm{~s}), 3.90(3 \mathrm{H}, \mathrm{s}), 3.88(3 \mathrm{H}, \mathrm{s}), 1.95(\mathrm{~s}$, $2 \mathrm{H})$ )

Analysis: $\mathrm{C}_{20} \mathrm{H}_{20} \mathrm{O}_{7} \cdot \mathrm{H}_{2} \mathrm{O}$ : MW 390.40 calcd: $61.53 \% \mathrm{C}$; $5.68 \% \mathrm{H}$. Found: $61.79 \% \mathrm{C}$; $5.63 \% \mathrm{H}$.

\section{Synthesis of 5,7,3',4'-tetra-O-methyl quercetin (TUM 8436)}

$3,5,7,3^{\prime}, 4^{\prime}$-Penta-O-methyl-quercetin (372 $\mathrm{mg}, 0.9 \mathrm{mmol}$ ) heated under reflux with a solution of $5 \mathrm{~g} \mathrm{AlCl}_{3}(5 \mathrm{~g}, 38 \mathrm{mmol})$ in dry ether $(20 \mathrm{ml})$ for $12 \mathrm{~h}$ at $60 \mathrm{C}$. The reaction mixture was poured into water. The yellow precipitate was filtered and boiled for $25 \mathrm{~min}$ in a mixture of acetic acid $(25 \mathrm{ml})$ and hydrochloric acid (12.5 $\mathrm{ml}$ ), resulting in a deep orange solution. When the solution was poured into water $(200 \mathrm{ml})$ the precipitate was filtered and washed with water $(60 \mathrm{ml})$. The product $\left(5,7,3^{\prime}, 4^{\prime}\right.$-tetra-O-methyl quercetin) was recrystallised from ethanol to give pure compound

(200 mg, $55.87 \%)$.

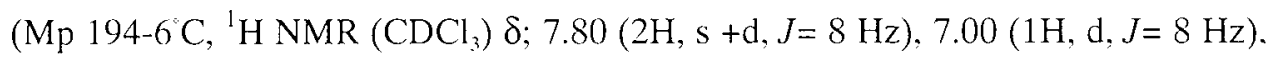
$6.55(1 \mathrm{H}, \mathrm{s}), 6.35(1 \mathrm{H}, \mathrm{s}), 3.9-4.0(12 \mathrm{H}, 4 \mathrm{~s}))$

Analysis: $\mathrm{C}_{19} \mathrm{H}_{18} \mathrm{O}_{7}$ (MW 358.35) calcd: $63.58 \% \mathrm{C} ; 5.06 \% \mathrm{H}$. Found: $63.01 \% \mathrm{C}$ : $5.10 \% \mathrm{H}$. 


\section{Peroxynitrite scavenging}

Peroxynitrite scavenging was measured by the oxidation of DHR, as described by Kooy et al. (1994). Fluorescence measurements were performed at $37 \mathrm{C}$ on a SPF-500C ${ }^{\mathrm{TM}}$ spectrofluorometer (SLM AMINCO) with excitation and emission wavelengths of 500 and $536 \mathrm{~nm}$, respectively. The effects are expressed as the concentration giving 50\% inhibition of the oxidation of DHR $\left(\mathrm{IC}_{51}\right)$.

\section{HyperChem 5.0}

The energy of the highest occupied molecular orbital $\left(E_{\text {เоммо }}\right)$ was calculated with HyperChem 6.0 molecular modelling software after performing geometry optimisation and energy minimisation using AM1 semi-empirical method. The AM1 was chosen because of its reliable accuracy (Dewar, et al., 1985).

\section{Statistical analysis}

The $\mathrm{IC}_{51}$ is expressed as mean $\pm \mathrm{SD}$. The correlation coefficient has been calculated with Sigmaplot.

\subsection{Results and discussion}

\section{Phenols}

This study on the SAR of the scavenging of peroxynitrite by flavonols was started by characterising the scavenging activity of substituted phenols. Phenolic moieties are key groups of flavonols. The concentration of phenol to inhibit half of the peroxynitrite mediated DHR oxidation $\left(\mathrm{IC}_{50}\right)$ is $263 \mu \mathrm{M}$. Methylation of the $\mathrm{OH}$ group of phenol, giving anisole, drastically increases the $\mathrm{IC}_{50}(>5000 \mu \mathrm{M})$ indicating that the $\mathrm{OH}$ group of phenols is indeed responsible for the peroxynitrite scavenging. Catechol, resorcinol and hydroquinone were tested to determine the effect of $\mathrm{OH}$-substituents on the activity of phenol (Figure 1). Substitution with an $\mathrm{OH}$ group increases the activity $\left(1 / \mathrm{IC}_{50}\right)$ of phenol, which is in line with the theory of Cao et al. that increasing the number of OH groups increases the activity (Cao, et al.. 1997). 
In addition, Figure 1 shows that the influence of an $\mathrm{OH}$ group is dependent on the position of substitution. An extra $\mathrm{OH}$ group at the 3-position (resorcinol) only slightly increases the activity $\left(1 / \mathrm{IC}_{50}\right)$ of phenol (ICso phenol $=263$ and resorcinol $=$ $42.5 \mu \mathrm{M})$. An extra $\mathrm{OH}$ group at the 2 or 4 position drastically increases the activity $\left(\mathrm{IC}_{50}\right.$ phenol $=263$, catechol $=2.7$ and hydroquinone $\left.=1.8 \mu \mathrm{M}\right)$. A similar effect of the position of the substituent is also shown with other compounds, i.e. coumaric acid, hydroxybenzoic acid and methoxyphenol (Table 1). Compounds in these series that have a substituent at position 2 or 4 are better peroxynitrite scavengers than compounds substituted at the 3 position.

The effect of various substituents and the position of substitution on the peroxynitrite scavenging of phenol.

\begin{tabular}{lll}
\hline compound & substituent & $\mathrm{IC}_{50}(\mu \mathrm{M})$ \\
\hline 2-coumaric acid & $2-\mathrm{C}_{2} \mathrm{H}_{2} \mathrm{COOH}$ & $27.7 \pm 4.1$ \\
3-coumaric acid & $3-\mathrm{C}_{2} \mathrm{H}_{2} \mathrm{COOH}$ & $4080 \pm 390$ \\
4-coumaric acid & $4-\mathrm{C}_{2} \mathrm{H}_{2} \mathrm{COOH}$ & $8.3 \pm 1.8$ \\
salicylic acid & 2- $\mathrm{COOH}$ & $10330 \pm 590$ \\
3-hydroxy-benzoic acid & $3-\mathrm{COOH}$ & $36340 \pm 490$ \\
4-hydroxy-benzoic acid & 4-COOH & $26800 \pm 6400$ \\
2-methoxyphenol & 2-OCH & $12.6 \pm 2.0$ \\
3-methoxyphenol & 3-OCH & $24.7 \pm 7.1$ \\
4-methoxyphenol & 4-OCH & $6.66 \pm 0.63$ \\
\hline
\end{tabular}


Figure 1 Peroxynitrite scavenging activity $\left(1 / / C_{50}\right)$ of phenol and 2-, 3-, and 4-OH substituted phenol.

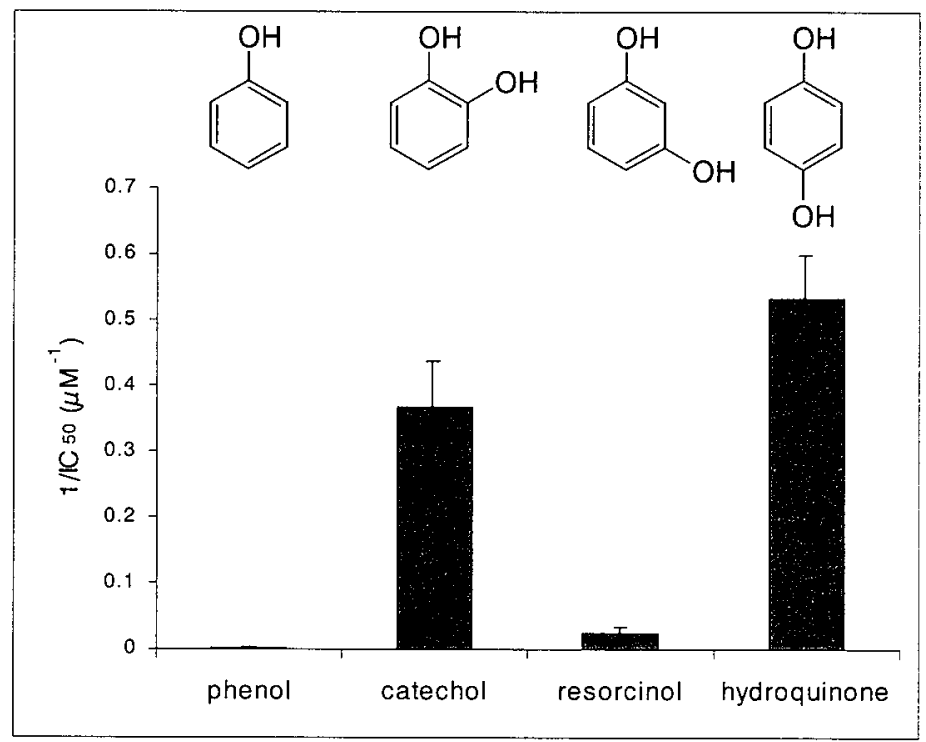

This dissimilarity in influence of the same substituent at different positions can be explained by an electronic effect. An $\mathrm{OH}$ group in a conjugated system has an electron donating effect to the ring. This electron donation from the substituent to the oxygen of the active $\mathrm{OH}$ group weakens the $\mathrm{O}-\mathrm{H}$ bond, making it easier to release an $\mathrm{H}^{\bullet}$. The Hammett $\sigma$ gives the electron donating (negative value) or withdrawing (positive value) effect of a substituent (Hansch, et al., 1995). As can be seen in Figure 2, the Hammett $\sigma$ of the $\mathrm{OH}$ group depends on the relative position of the $\mathrm{OH}$ substitution at the ring compared to the active centre. The maximal electron donating effect, i.e. the most negative $\sigma$, is observed when the $\mathrm{OH}$ is at the ortho or para position. An electron withdrawing effect is seen at the meta position. This nicely fits with the rank order of potency observed for the catechol, resorcinol and hydroquinone. This SAR is further confirmed by the excellent correlation of the peroxynitrite scavenging activity of other tested substituted phenols $\left(\ln \left(1 / \mathrm{IC}_{50}\right)\right)$ and the Hammett $\sigma$ (Figure 3, Eq. (1)). 
Figure 2

The electronic influence (Hammett $\sigma$ ) of substitution of an $\mathrm{OH}$ group in an aromatic ring. The more negative the $\sigma$ is, the greater the electron donating effect. The effect at the ortho and para position is electron donating and at the meta position electron withdrawing.<smiles>Oc1ccccc1O</smiles><smiles>Oc1cccc(O)c1</smiles><smiles>Oc1ccc(O)cc1</smiles>

$\sigma=-0.37$ $\sigma=0.12$ $\sigma=-0.37$

$\ln \left(1 / \mathrm{IC}_{50}\right)=-8.26 \sigma-4.50$

$(\mathrm{R}=0.94 \mathrm{p}=0.00018)$

Figure 3 Correlation between the Hammett sigma of substituents and the $\ln \left(1 / I C_{50}\right)$ of substituted phenols.

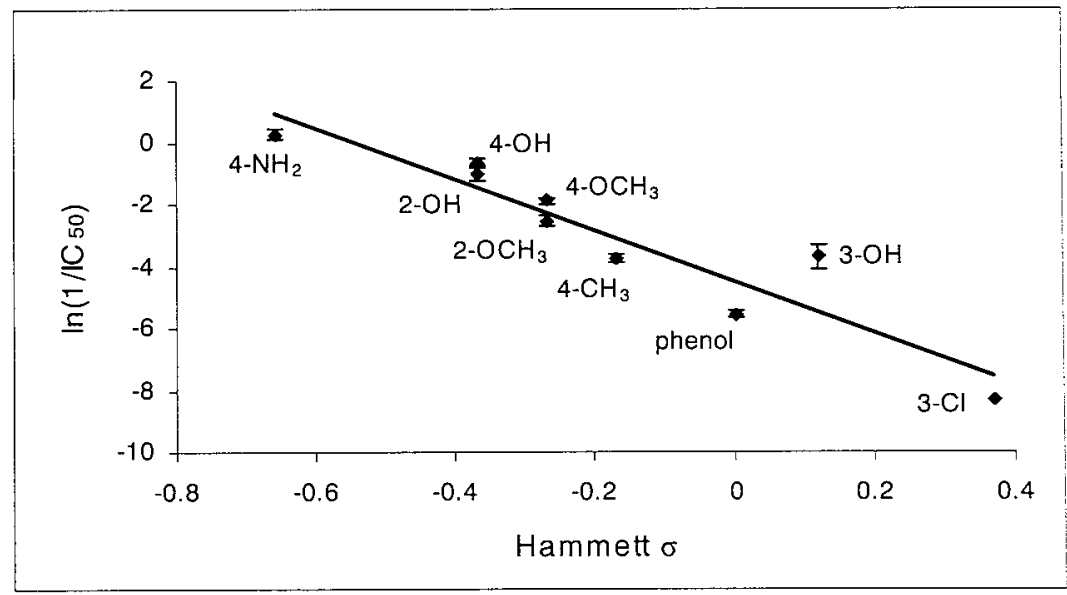

$$
\begin{aligned}
& \ln \left(1 / \mathrm{IC}_{50}\right)=9.77 \mathrm{HOMO}+83.63 \\
& (\mathrm{R}=0.87 \mathrm{p}=0.005)
\end{aligned}
$$




\section{flavonols}

As shown in Figure 4, quercetin $\left(3,5,7,3^{\prime}, 4^{\prime}\right.$-penta-hydroxyflavone), is a very good scavenger of peroxynitrite $\left(\mathrm{IC}_{50}=0.53 \mu \mathrm{M}\right)$. When all the $\mathrm{OH}$ moieties of quercetin are methylated, giving 3,5,7,3',4'-penta-O-methyl-quercetin, the peroxynitrite scavenging activity is drastically decreased $\left(\mathrm{IC}_{50}=216 \mu \mathrm{M}\right)$. Similar to the $\mathrm{OH}$ group in the substituted phenol, the $\mathrm{OH}$ groups in the flavonoids are important for peroxynitrite scavenging activity.

To determine the relative importance of the different $\mathrm{OH}$ groups in flavones in the peroxynitrite scavenging process, the compounds depicted in Figure 4 were tested. The compounds in which ring $B$ is a catechol (ring denomination as shown for quercetin in Figure 4) all have a high activity that is in the same order of magnitude $\left(\mathrm{IC}_{50}\right.$ quercetin $=0.53 \mu \mathrm{M}$, rutin $=0.468 \mu \mathrm{M}$ and monoHER $\left.=0.295 \mu \mathrm{M}\right)$, irrespective of the number of free aromatic $\mathrm{OH}$ groups in the $\mathrm{AC}$ ring. This indicates that in these compounds the catechol in ring $\mathrm{B}$ is the pharmacophore responsible for peroxynitrite scavenging. This is in line with the high activity of 6 catechol we found in the series of substituted phenols (Figure 1). Galangin, kaempferol, and triHEQ $\left(\mathrm{IC}_{50}=1.02,0.35\right.$ and $0.580 \mu \mathrm{M}$ respectively, Figure 5) showed remarkably high activity. In these compounds ring $\mathrm{B}$ is not a catechol, indicating that the high peroxynitrite scavenging activity of these molecules resides in another part of the molecule i.e. the $\mathrm{AC}$ ring. A striking difference in activity is seen when these three compounds are compared to chrysin, apigenin and triHER $\left(\mathrm{IC}_{50}=295,199\right.$ and $162 \mu \mathrm{M}$ respectively, Figure 5), compounds where the $3-\mathrm{OH}$ group is either substituted or missing. This indicates that in the $\mathrm{AC}$ ring the $3-\mathrm{OH}$ is responsible for the peroxynitrite scavenging. This prompted us to test a flavone with an $\mathrm{OH}$ group at the 3 position and no $\mathrm{OH}$ groups at position 5 and 7 and 3' and 4'. Surprisingly this compound, 3-hydroxyflavone, displays a very poor peroxynitrite scavenging activity $\left(\mathrm{IC}_{50}>200 \mu \mathrm{M}\right.$, Fig. 6). Also 5-hydroxyflavone and 7-hydroxyflavone display virtually no scavenging activity $\left(\mathrm{IC}_{50}>300 \mu \mathrm{M}\right.$, Figure 6). These results indicate that none of the three $\mathrm{OH}$ groups of the $\mathrm{AC}$ ring provides the peroxynitrite scavenging activity by themselves. Nevertheless galangin, a compound that only possesses these three $\mathrm{OH}$ groups, at the 3, 5, 7 position, is an excellent scavenger. The explanation for this apparent contradiction can be found in the structure activity relationship of phenol, described above. 
Figure $4 \quad$ The peroxynitrite scavenging activity $\left(I C_{50}\right)$ of the different $\mathrm{OH}$ groups in quercetin (central compound). When all the $\mathrm{OH}$ groups of quercetin are methylated the activity is drastically decreased. When the flavone has a catechol group in ring $B$, as in rutin and monoHER, the activity is in the same order of magnitude. But also the $\mathrm{OH}$ groups in the AC ring give a high activity (galangin).
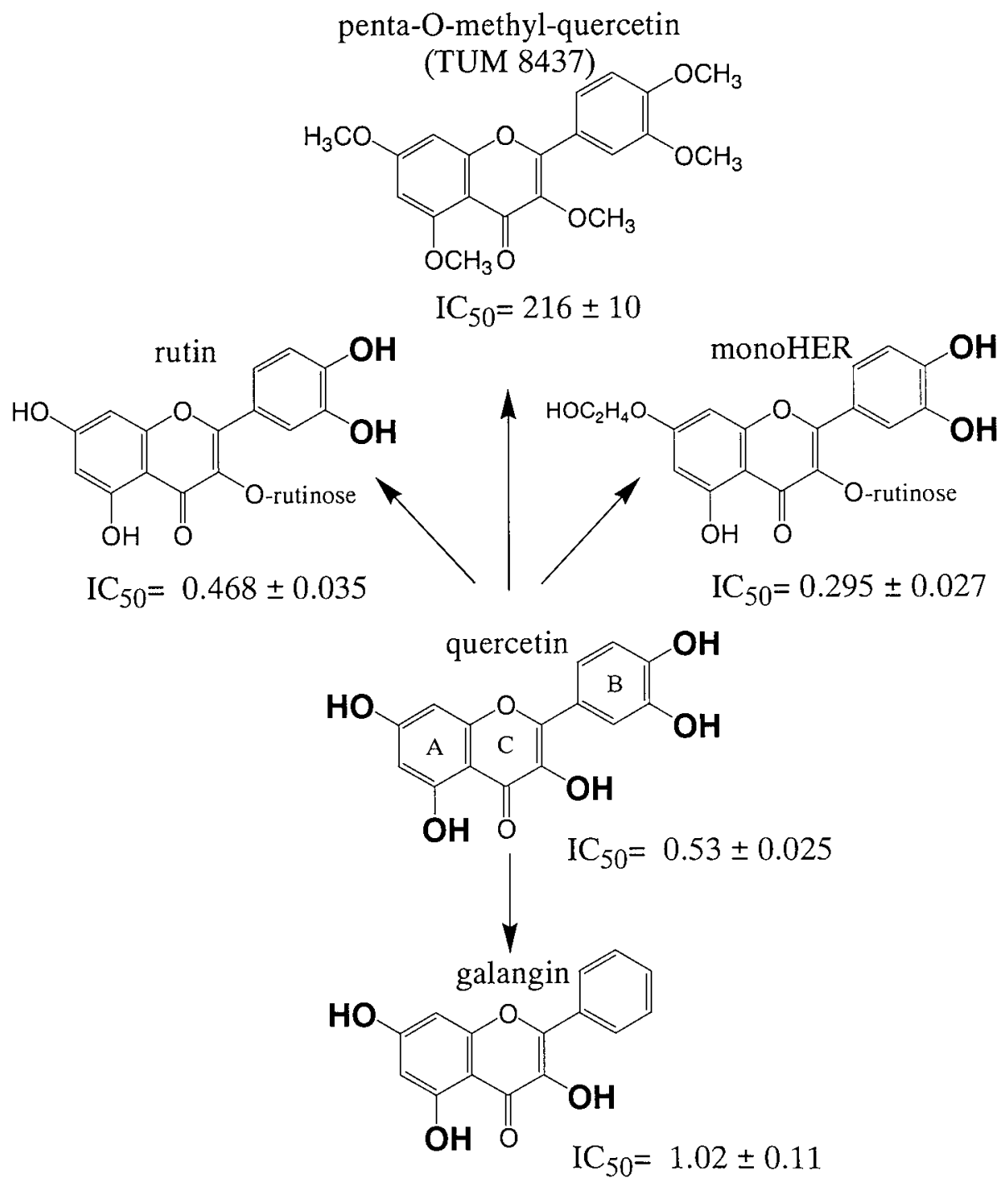
The activity of an aromatic $\mathrm{OH}$ group is positively influenced by electron-donating substituents. The activity of phenol is drastically increased by substitution of an $\mathrm{OH}$ group at the 2 or 4 position (Figure 1). A similar attenuation of the activity of one of the $\mathrm{OH}$ groups in galangin by the other $\mathrm{OH}$ groups may explain the high potency of this compound. A clue for the question, which $\mathrm{OH}$ group in the $\mathrm{AC}$ ring the most reactive one is can be found in the relative activity of the monohydroxyflavones. At a concentration of $80 \mu \mathrm{M}$ the inhibition of the rhodamine-123 production by 3-hydroxyflavone was $29.7 \%$ whereas that of 5-hydroxyflavone and 7 -hydroxyflavone was $9.4 \%$ and $0 \%$ respectively.

Figure 5 The activity of the $\mathrm{OH}$ group in flavanols at the 3 position. Galangin, kaempferol and triHEQ all have a high activity. When the 3-OH group is lacking, as in chrysin, apigenin and triHER, the activity is relatively low.<smiles>O=c1c(O)c(-c2ccccc2)oc2cc(O)cc(O)c12</smiles>

$\mathrm{IC}_{50}=1.02 \pm 0.11$<smiles>O=c1c(O)c(-c2ccc(O)cc2)oc2cc(O)cc(O)c12</smiles>

$\mathrm{IC}_{50}=0.35 \pm 0.020$<smiles>O=c1cc(-c2ccccc2)oc2cc(O)cc(O)c12</smiles>

$\mathrm{IC}_{50}=295 \pm 26$<smiles>O=c1cc(-c2ccc(O)cc2)oc2cc(O)cc(O)c12</smiles>

$\mathrm{IC}_{50}=199 \pm 37$

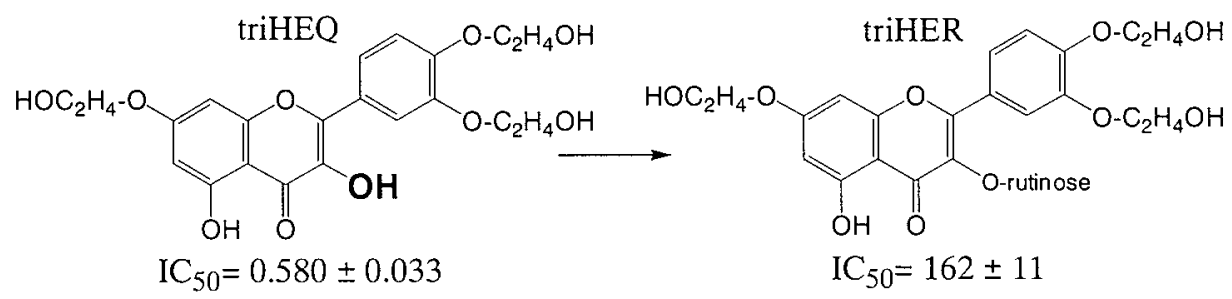


The low activity of triHER $\left(\mathrm{IC}_{50}=162 \mu \mathrm{M}\right)$ also shows a low reactivity of the 5-OH group. The other substituents $\left(-\mathrm{OC}_{2} \mathrm{H}_{4} \mathrm{OH}\right.$ moieties) in triHER have an electron-donating effect but do not stimulate the activity.

TetraHER $\left(5,7,3^{\prime}, 4^{\prime}\right.$ '-hydroxyethyl-rutin, $\left.\mathrm{IC}_{50}=225 \mu \mathrm{M}\right)$ has a very low activity which indicates that the $\mathrm{OC}_{2} \mathrm{H}_{4} \mathrm{OH}$ substituent is not active by itself.

5,7-Dihydroxyflavone also displays a low activity. These results led us to the conclude that the 3-OH group in galangin is the most reactive one and that the $\mathrm{OH}$ groups at positions 5 and 7 enhance the reactivity of this group.

To test this hypothesis we synthesised TUM 8436 (5,7,3', 4'-tetra-O-methyl-quercetine) (Figure 6). This molecule is derived from quercetin, the $\mathrm{OH}$ groups at position 5, 7, 3', and 4' are replaced by $\mathrm{OCH}_{3}$ groups. The $\mathrm{OCH}_{3}$ group was chosen because it has a comparable electronic donating effect as the $\mathrm{OH}$ group (Hammett $\sigma 4-\mathrm{OCH}_{3}$ $=-0.27,4-\mathrm{OH}=-0.37$ ). Moreover, as shown above, the $\mathrm{OCH}_{3}$ group has no peroxynitrite scavenging activity itself. The only free hydroxyl group in TUM 8436 is located at position 3. TUM $8436\left(\mathrm{IC}_{50}=6.10 \mu \mathrm{M}\right)$ proved to be a potent scavenger of peroxynitrite although its activity was somewhat lower than that of galangin. This can be explained by the slightly lower electron-donating effect of the $\mathrm{OCH}_{3}$ group compared to the $\mathrm{OH}$ group. The high activity of TUM 8436 confirms that the $\mathrm{OH}$ moiety at the 3 position is the reactive centre of the $\mathrm{AC}$ ring of a flavonol, e.g. galangin. In the substituted phenols it was shown that the influence of the meta substituent was weaker than the ortho and para substituent, e.g. catechol and hydroquinone are better peroxynitrite scavengers than resorcinol (Figure 1). This was also shown in the series of methoxyphenol, hydroxybenzoic acid and coumaric acid (Table 1). This means that between the substituent and the active $\mathrm{OH}$ group, there has to be an even number of C-atoms to give an optimal influence. Applying this to the flavonols (Figure 7), the 5 and the 7 position give an optimal contribution to the activity of peroxynitrite scavenging influencing the $3-\mathrm{OH}$ moiety. The oxygen in ring $\mathrm{C}$ also has a positive influence an even number of $\mathrm{C}$-atoms away from the active $3-\mathrm{OH}$ group. The effect of the 4-ketogroup may influence the 3-OH moiety. The oxygen in ring $\mathrm{C}$ also has a positive influence an even number of $\mathrm{C}$-atoms away from the active 3-OH group. The effect of the 4-ketogroup may be found in an intramolecular hydrogen bridge with the 3-OH group, resulting in a weakening of the $\mathrm{O}-\mathrm{H}$ bond. 
Figure 6 The peroxynitrite scavenging activity $\left(I C_{50}\right)$ of the different $\mathrm{OH}$ groups in galangin (centre compound). When only one of the $\mathrm{OH}$ groups of galangin is present (3-, 5- and 7-hydroxyflavone) the compound shows a very low activity. Also the 5,7-dihydroxyflavone (chrysin) appears to have a low activity. The compound with a 3-OH group and electron donating substituents in the AC ring at the 5 and 7 position appears to be a potent scavenger.

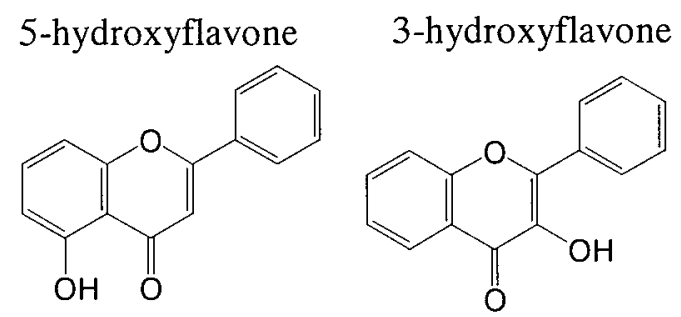<smiles>O=c1cc(-c2ccccc2)oc2cc(O)ccc12</smiles>

$$
\mathrm{IC}_{50}>300
$$$$
\mathrm{IC}_{50}>200
$$

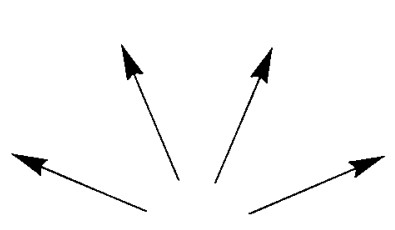

$\mathrm{IC}_{50}>300$<smiles>O=c1c(O)c(-c2ccccc2)oc2cc(O)cc(O)c12</smiles>

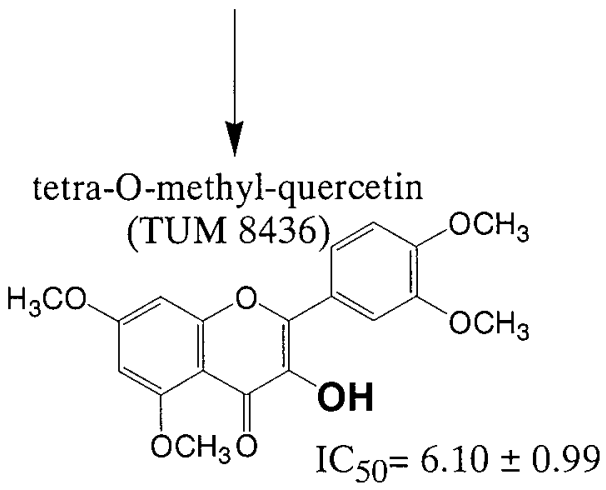


This means that all the influencing groups are optimal for the reactivity of the $3-\mathrm{OH}$ group. The activity of the 5- or 7-OH is only positively influenced by a substituent at the 3 position (Fig. 7). The influence of the 5- and 7-OH groups on each other and the influence that both $\mathrm{OH}$ groups receive from the ring oxygen are suboptimal. This also supports our hypothesis that the $3-\mathrm{OH}$ group displays a prominent peroxynitrite scavenging activity but its reactivity has to be boosted by the electron-donating substituents at position 5 and 7 and the double bonded oxygen substituent at position 4 and the oxygen at position 1 . These results lend further support to the notion that a potent pharmacophore in the flavonols in the AC ring exists, next to the catechol in ring $\mathrm{B}$.

Figure 7

The stimulating electronic influence on the 3-, 5- or 7-OH group in galangin. The activity of an $\mathrm{OH}$ group can be positively influenced by other electron donating groups when there is an even number of $\mathrm{C}$-atoms between the active and stimulating group. The 3-OH group is stimulated by the $\mathrm{OH}$ groups at the 5 and 7 position and also by the oxygen atoms at position 1 and 4. The $O H$ groups at position 5 and 7 are only stimulated by the 3-OH group.

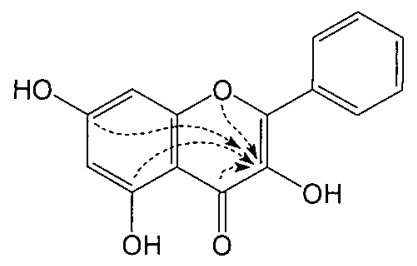

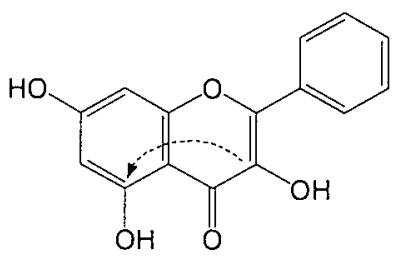<smiles></smiles>

According to the SAR of the substituted phenols there is a possibility that the two pharmacophores can influence each other. The 4'-OH (in for example kaempferol) can in theory affect the activity of the 3-OH group, because of the negative $\sigma$ of the $\mathrm{OH}$ substituent and the even number of $\mathrm{C}$-atoms in a conjugated structure between the 3-OH and the 4'-OH, enabling conjugation. This influence can be evaluated by comparing the peroxynitrite scavenging activity of kaempferol and galangin. The 
peroxynitrite scavenging activity of kaempferol $\left(\mathrm{IC}_{50}=0.35\right)$ is slightly better than that of galangin $\left(\mathrm{IC}_{50}=1.02\right)$ indicating that ring $\mathrm{B}$ has only a minor influence on the pharmacophore in the AC-ring. It has been calculated that when oxidation of quercetin takes place in ring $\mathrm{B}$ almost all spin of the quercetin radical remains in ring $\mathrm{B}$. Surprisingly, less than $1 \%$ of all spin density is delocalised to the $\mathrm{AC}$-ring (van Acker, et al., 1996a). This indicates that the AC-ring only has a minor influence on the pharmacophore in ring B. It should be noted however that the peroxynitrite scavenging effect of flavones containing a catechol group in ring $\mathrm{B}$ is somewhat better than that of catechol. This indicates that there is some effect of the AC ring on the pharmacophore in ring $B$.

Based on this SAR we can predict the reactive centre present in the different flavones. For example, the OH group in diHER (3',5-dihydroxy-4',7-dihydroyethyl-rutin, $\left.\mathrm{IC}_{50}=2.49 \mu \mathrm{M}\right)$ at the 5 position is hardly active, because of the low activity of triHER $\left(\mathrm{IC}_{50}=162 \mu \mathrm{M}\right)$. The major peroxynitrite scavenging activity resides in the $\mathrm{B}$ ring. The electron donating activity of the hydroxyethylgroup at position 4' will enhance the activity of the $\mathrm{OH}$ group at the 3 ' position. This indicates that the high activity in diHER is caused by the activity of the 3'-OH. The $\sigma$ of the hydroxyethylgroup is expected to be somewhat less negative than the $\sigma$ of an $\mathrm{OH}$ group. This explains the lower activity of diHER $\left(\mathrm{IC}_{50}=2.49\right)$ compared to monoHER $\left(\mathrm{IC}_{50}=\right.$ 0.295).

Also in other phenolic compounds the active centre can now be pinpointed and their potency can be predicted (Table 2). For example, ferulic acid $\left(\mathrm{IC}_{50}=1.41 \mu \mathrm{M}\right)$ is expected to be a potent peroxynitrite scavenger since the activity of its $\mathrm{OH}$ group is enhanced by an electron-donating substituent, an $\mathrm{OCH}_{3}$ moiety, at the ortho position. The same active centre is shown in vanillic acid and eugenol $\left(\mathrm{IC}_{50}=7.54 \mu \mathrm{M}\right.$ and $4.88 \mu \mathrm{M})$. However the activity of this pharmacophore is negatively influenced by the electron-withdrawing substituent at position 4 , i.e. $\mathrm{COOH}$ and $\mathrm{C}_{3} \mathrm{H}_{5}$ (a positive $\sigma$ ). Syringic acid is expected to have a higher activity as ferulic acid, i.e. an $\mathrm{OH}$ group with two ortho $\mathrm{OCH}_{3}$ substituents, but its activity appeared to be less than ferulic acid. This can be explained by a steric effect by the subtituents at position 2, 4 and 6 . Steric hindrance also rationalises the high $\mathrm{IC}_{50}$ for butylated hydroxytoluene. 
Table 2 The peroxynitrite scavenging activity of several phenolic compounds.

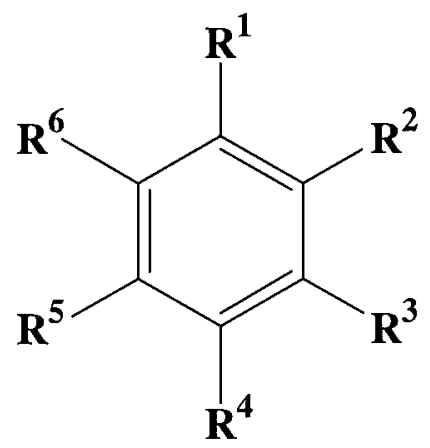

\begin{tabular}{llllllll}
\hline compound & $\mathrm{R}^{*}$ & $\mathrm{R}^{2}$ & $\mathrm{R}^{3}$ & $\mathrm{R}^{4}$ & $\mathrm{R}^{5}$ & $\mathrm{R}^{6}$ & $\mathrm{IC}_{50}(\mu \mathrm{M})$ \\
\hline gallic acid & $\mathrm{OH}$ & $\mathrm{OH}$ & $\mathrm{H}$ & $\mathrm{COOH}$ & $\mathrm{H}$ & $\mathrm{OH}$ & $1.51 \pm 0.24$ \\
gentisic acid & $\mathrm{OH}$ & $\mathrm{H}$ & $\mathrm{H}$ & $\mathrm{OH}$ & $\mathrm{H}$ & $\mathrm{COOH}$ & $125 \pm 0.28$ \\
vanillic acid & $\mathrm{OH}$ & $\mathrm{OCH}_{3}$ & $\mathrm{H}$ & $\mathrm{COOH}$ & $\mathrm{H}$ & $\mathrm{H}$ & $7.54 \pm 0.36$ \\
caffeic acid & $\mathrm{OH}$ & $\mathrm{H}$ & $\mathrm{H}$ & $\mathrm{C}_{2} \mathrm{H}_{2} \mathrm{COOH}$ & $\mathrm{H}$ & $\mathrm{OH}$ & $1.13 \pm 0.08$ \\
ferulic acid & $\mathrm{OH}$ & $\mathrm{OCH}_{2}$ & $\mathrm{H}$ & $\mathrm{C}_{2} \mathrm{H}_{2} \mathrm{COOH}$ & $\mathrm{H}$ & $\mathrm{H}$ & $1.41 \pm 0.50$ \\
syringic acid & $\mathrm{OH}$ & $\mathrm{OCH}_{2}$ & $\mathrm{H}$ & $\mathrm{C}_{2} \mathrm{H}_{2} \mathrm{COOH}$ & $\mathrm{H}$ & $\mathrm{OCH}_{3}$ & $283 \pm 0.12$ \\
eugenol & $\mathrm{OH}$ & $\mathrm{OCH}_{2}$ & $\mathrm{H}$ & $\mathrm{C}_{3} \mathrm{H}_{5}$ & $\mathrm{H}$ & $\mathrm{H}$ & $4.88 \pm 0.92$ \\
p-hydroxy & $\mathrm{OH}$ & $\mathrm{H}$ & $\mathrm{H}$ & $\mathrm{CHO}_{2}$ & $\mathrm{H}$ & $\mathrm{H}$ & $15800 \pm 2400$ \\
BHTaldehyde & $\mathrm{OH}$ & $\mathrm{tC}_{4} \mathrm{H}_{9}$ & $\mathrm{H}$ & $\mathrm{CH}_{3}$ & $\mathrm{H}$ & $\mathrm{tC}_{4} \mathrm{H}_{9}$ & $72.4 \pm 10$ \\
L-tyrosine & $\mathrm{OH}$ & $\mathrm{H}$ & $\mathrm{H}$ & $\mathrm{H}_{2} \mathrm{NC}_{2} \mathrm{H}_{3} \mathrm{COOH}$ & $\mathrm{H}$ & $\mathrm{H}$ & $162 \pm 48$ \\
cinnamic acid & $\mathrm{C}_{2} \mathrm{H}_{2} \mathrm{COOH}$ & $\mathrm{H}$ & $\mathrm{H}$ & $\mathrm{H}$ & $\mathrm{H}$ & $\mathrm{H}$ & $38800 \pm 2100$ \\
\hline
\end{tabular}

The active centre of gallic acid is the $\mathrm{OH}$ group at position 1, because of the positive influence of the two $\mathrm{OH}$ neighbours. Gentisic acid has an $\mathrm{OH}$ group at positions 1 and 4 , which positively influence each other. The most reactive one is probably the $\mathrm{OH}$ moiety at position 1 . This is deduced from the series of hydroxybenzoic acids, when salicylic acid was more active than 3-hydroxybenzoic acid. Tyrosine is supposed to be the primary target for peroxynitrite damage in vivo but 
had a surprisingly low peroxynitrite scavenging activity. The activity of tyrosine is in the same order of magnitude as that of phenol. The $\mathrm{OH}$ group at position 1 is the reactive group but its activity is apparently not positively influenced by the large substituent at position 4.

In conclusion, the aromatic $\mathrm{OH}$ groups are the reactive centres in the peroxynitrite scavenging activity of flavonols. As demonstrated by numerous examples provided in the present study, the activity of these aromatic $\mathrm{OH}$ groups can be enhanced by electron donating effects of other substituents. Two relatively independent pharmacophores can be identified, located on either the B-ring or the AC-ring. In naturally occuring flavones a high activity is seen when the B-ring is a catechol or when the $\mathrm{AC}$-ring has aromatic $\mathrm{OH}$ groups at position 3,5, and 7. There are indications that the $\mathrm{OH}$ group at position 3 is the most reactive one and that its activity is enhanced by the $\mathrm{OH}$ groups at position 5 and 7 and the double bonded oxygen at position 4 and the ring oxygen at position 1.

The activity of the pharmacophore in the AC-ring is in the same order of magnitude as that of the B-ring. Flavonoids with a catechol structure in ring $\mathrm{B}$ display prominent prooxidant properties (van Acker, et al., 1998). It is expected that the pharmacophore in ring $\mathrm{AC}$ does not have such a prooxidant effect. This is based on the negative correlation between $E \mathrm{p} / 2$ (half peak oxidation potential $(\mathrm{mV})$ ) and prooxidant effect and the high $E \mathrm{p} / 2$ of galangin (3,5,7-trihydroxyflavone, $E \mathrm{p} / 2=320 \mathrm{~V}$ ) compared to the $E \mathrm{p} / 2$ of catechol containing flavones, e.g. quercetin $(E \mathrm{p} / 2=30 \mathrm{~V})$. Based on this knowledge it may be possible to develop better and safer flavonoids. This will improve our therapeutic arsenal and strengthen our defence against pathophysiological processes where free radicals show such devastating effects. 


\subsection{References}

Beckman, J.S., (1996) Oxidative damage and tyrosine nitration from peroxynitrite. Chemical Research in Toxicology 9 (5), 836-844.

Cao, G., Sofic, E. and Prior, R.L., (1997) Antioxidant and prooxidant behavior of flavonoids: structure-activity relationships.

Free Radical Biology and Medicine 22 (5), 749-760.

Crow, J.P., Ye, Y.Z., Strong, M., Kirk, M., Barnes, S. and Beckman, J.S., (1997)

Superoxide dismutase catalyzes nitration of tyrosines by peroxynitrite in the rod and head domains of neurofilament-L.

J Neurochem 69 (5), 1945-1953.

Dewar, M.J.S., Zoebisch, E.G., Healy, E.F. and Stewart, J.J.P., (1985) AM1:

a new general purpose quantum mechanical molecular model.

Journal of American Chemical Society 107 3902-3909.

Digerness, S.B., Harris, K.D., Kirklin, J.W., Urthaler, F., Viera, L., Beckman, J.S. and Darley Usmar, V., (1999) Peroxynitrite irreversibly decreases diastolic and systolic function in cardiac muscle.

Free Radical Biology and Medicine 27 (11-12), 1386-1392.

Diplock, A.T., Charleux, J.L., Crozier-Willi, G., Kok, F.J., Rice-Evans, C., Roberfroid, M., Stahl, W. and Vina-Ribes, J., (1998) Functional food science and defence against reactive oxidative species.

British Journal of Nutrition 80 (Suppl 1), S77-S112.

Duarte, J., Perez-Vizcaino, F., Utrilla, P., Jiménez, J., Tamargo, J. and Zarzuelo, A., (1993) Vasodilatory effects of flavonoids in rat aortic smooth muscle.

Structure-activity relationships. General Pharmacology 24 (4), 857-862.

Estévez, A.G., Crow, J.P., Sampson, J.B., Reiter, C., Zhuang, Y., Richardson, G.J., Tarpey, M.M., Barbeito, L. and Beckman, J.S., (1999) Induction of nitric oxide-dependent apoptosis in motor neurons by zinc-deficient superoxide dismutase. Science 286 2498-2500.

Haenen, G.R.M.M., Paquay, J.B.G., Korthouwer, R.E.M. and Bast, A., (1997)

Peroxynitrite scavenging by flavonoids.

Biochemical and Biophysical Research Communications 236 591-593. 
Heijnen, C.G.M., Haenen, G.R.M.M., van Acker, F.A.A., van der Vijgh, W.J.F. and Bast, A., (2001) Flavonoids as peroxynitrite scavengers: the role of the hydroxyl groups. Toxicology in Vitro 15 (1), 3-6.

Heijnen, C.G.M., Haenen, G.R.M.M., Wiseman, S.A., Tijburg, L.B.M. and Bast, A., (2000) The interaction of tea flavonoids with the $\mathrm{NO}^{\circ}$-system:

discrimination between good and bad $\mathrm{NO}^{\circ}$.

Food Chemistry 70 (3), 365-370.

Hertog, M.G.L., Feskens, E.J.M., Hollman, P.C.H., Katan, M.B. and Kromhout, D., (1993) Dietary antioxidant flavonoids and risk of coronary heart disease: the Zutphen Elderly Study. Lancet 342 1007-1011.

Ischiropoulos, H. and Al-Mehdi, A.B., (1995) Peroxynitrite-mediated oxidative protein modifications. FEBS Lett 364 (3), 279-282.

Kerry, N. and Rice-Evans, C.A., (1998) Peroxynitrite oxidises catechols to o-quinines. FEBS Letters 437 167-171.

Kerry, N. and Rice-Evans, C.A., (1999) Inhibition of peroxynitrite-mediated oxidation of dopamine by flavonoid and phenolic antioxidants and their structural relationships. Journal of Neurochemistry 73 247-253.

Kooy, N.W., Royall, J.A., Ischiropoulos, H. and Beckman, J.S., (1994)

Peroxynitrite-mediated oxidation of dihydrorhodamine 123.

Free Radical Biology and Medicine 16 (2), 149-156.

Koppenol, W.H., Kissner, R. and Beckman, J.S., (1996) Syntheses of peroxynitrite:

To go with the flow or on solid grounds?

Methods of Enzymology 269 296-302.

Paquay, J.B.G., Haenen, G.R.M.M., Stender, G., Wiseman, S.A., Tijburg, L.B.M. and Bast, A., (2000) Protection against nitric oxide toxicity by tea.

Journal of Agricultural and Food Chemistry 48 (11), 5768-5772.

Rice-Evans, C.A., Miller, N.J. and Paganga, G., (1996) Structure-antioxidant activity relationships of flavonoids and phenolic acids.

Free Radical Biology and Medicine 20 933-956.

Rubbo, H., Darley-Usmar, V. and Freeman, B.A., (1996) Nitric oxide regulation of tissue free radical injury.

Chemical Research in Toxicology 9 809-820. 
Sadeghi Hashjin, G., Folkerts, G., Henricks, P.A., Muijsers, R.B. and Nijkamp, F.P., (1998) Peroxynitrite in airway diseases.

Clinical and Experimental Allergy 28 (12), 1464-1473.

van Acker, S.A.B.E., de Groot, M.J., van den Berg, D.-J., Tromp, M.N.J.L.,

Donné-op den Kelder, G., van der Vijgh, W.J.F. and Bast, A., (1996a)

A quantum chemical explanation of the antioxidant activity of flavonoids.

Chemical Research in Toxicology 9 1305-1312.

van Acker, S.A.B.E., Plemper van Balen, G., van de Berg, D.-J., Bast, A. and van der

Vijgh, W.J.F., (1998) Influence of iron chelation on the antioxidant activity of flavonoids. Biochemical Pharmacology 56 935-943.

van Acker, S.A.B.E., van den Berg, D.-J., Tromp, M.N.J.L., Griffioen, D.H., van Bennekom, W.P., van der Vijgh, W.J.F. and Bast, A., (1996b) Structural aspects of the antioxidant activity of flavonoids.

Free Radical Biology and Medicine 20 331-342.

Wattanapitayakul, S.K., Weinstein, D.M., Holycross, B.J. and Bauer, J.A., (2000) Endothelial dysfunction and peroxynitrite formation are early events in angiotensin-induced cardiovascular disorders.

FASEB Journal 14 (2), 271-278. 


\section{Chapter 5}

\section{Protection of flavonoids against lipid peroxidation: The structure activity relationship revisited}

Chantal G.M. Heijnen, Guido R.M.M. Haenen, R. Minou Oostveen, Eva M. Stalpers, and Aalt Bast.

Free Radical research 36, 5 (2002) 575-581 



\subsection{Abstract}

The inhibition of the lipid peroxidation, induced by iron and ascorbate in rat liver microsomes, by phenols and flavones was studied. The activity of phenol was enhanced by electron donating substituents, denoted by the Hammett sigma $(\sigma)$. The concentration of the substituted phenols giving 50\% inhibition $\left(\mathrm{IC}_{50}\right)$ of lipid peroxidation gave a good correlation with the $\sigma$ of the substituent $\left(\ln \left(1 / \mathrm{IC}_{50}\right)=-8.92 \sigma+\right.$ $5.80(\mathrm{R}=0.94, \mathrm{p}<0.05))$. In flavones two pharmacophores for the protection against lipid peroxidation were pinpointed: (i) a catechol moiety as ring B and (ii) an $\mathrm{OH}$-group at the 3 position with electron donating groups at the 5 and / or 7 position in the AC-ring. An example of a flavone with the latter pharmacophore is galangin (3,5,7-trihydroxyflavone) where the reactivity of the 3-OH-group is enhanced by the electron donating effect of the 5- and 7-OH-groups. This is comparable to the effect of electron donating substituents on the activity of phenol.

The prooxidant activity of flavones has been related to a low half peak oxidation potential $(E \mathrm{p} / 2)$. All flavones with a catechol as ring $\mathrm{B}$ have very low $E \mathrm{p} / 2$, suggesting that they display a prominent prooxidant activity. In contrast, the $E \mathrm{p} / 2$ varies within the group of flavones with a 3-OH e.g. TUM 8436 (5,7,3',4'-tetra-O-methylquercetin) has a relatively high $E \mathrm{p} / 2$ and is an excellent protector against lipid peroxidation. Apparently amongst the flavones with the pharmacophore in the ACring there are good antioxidants that are expected to display no or limited prooxidant properties. 


\subsection{Introduction}

Flavonoids are a large heterogenic group of benzo- $\gamma$-pyron derivatives, which are abundantly present in our diet, e.g. in fruits and vegetables. Positive health effects of these compounds have been described in several diseases, such as pulmonary and cardiovascular diseases, and cancer (Duarte, et al., 1993, Hertog, et al., 1993). In several food products flavonoids are the major antioxidants (Paquay, et al., 1997, Rice Evans, et al., 1995). The antioxidant activity of flavonoids, reflected in e.g. the protection of polyunsaturated fatty acids against free radical damage (Afanas'ev, et al., 1989, Frankel, et al., 1993, Haenen, et al., 1993), may explain their proclaimed health effects (Heller, et al., 1998, Massaeli, et al., 1999).

Many structure activity relationships (SARs) have been proposed for the antioxidant activity of flavonoids (Arora, et al., 1998, Cao, et al., 1997, Mora, et al., 1990, Ratty, and Das, 1988). In all these SARs the aromatic $\mathrm{OH}$-groups play a pivotal role. It even has been suggested that the potency of a flavonoid correlates with the number of OH-groups (Cao, et al., 1997). Tentatively, this SAR is expected to be imprecise e.g. it does not take the position of the OH-group in the molecule into account. Moreover, a SAR for an antioxidant can be complex since frequently several properties of a compound are involved. For example, in lipid peroxidation not purely the lipidperoxyl radical scavenging activity is studied. Also other properties such as lipophilicity, iron-chelation and pro-oxidant effects come into the equation. Thus the SAR for protection against lipid peroxidation is expected to be composed of the SARs of the different processes.

The aim of this study is to refine the SAR of a selected group of flavonoids, i.e. the flavonols, for the inhibition of lipid peroxidation. Firstly, a series of simple phenols was tested to elucidate the influence of substituents. Subsequently, several flavones were evaluated. 


\subsection{Materials and methods}

\section{Chemicals}

Phenol, catechol, hydroquinone, resorcinol, aminophenol, 2- and 4-methoxyphenol, 4-methylphenol, 3-hydroxyflavone, 5-hydroxyflavone, 7-hydroxyflavone, galangin and chrysin were purchased from Sigma (St. Louis, USA). TUM 8436 (5,7,3', '4'-tetra-O-methyl-quercetin) and TUM 8437 (penta-O-methyl-quercetin) were synthesized as previously described (Heijnen, et al., 2001b). All other chemicals were of analytical grade.

\section{Preparation of Microsomes}

Microsomes were prepared from male Wistar rats, 200-250 g. After decapitation, the livers were removed and homogenized $(1: 2, \mathrm{w} / \mathrm{v})$ in ice cold sodium phosphate buffer (50 mM, pH 7.4) containing 0.1 mM EDTA. The homogenate was centrifuged at $10000 \times \mathrm{g}\left(20 \mathrm{~min}\right.$ at $\left.4^{\circ} \mathrm{C}\right)$. Subsequently the supernatant was centrifuged at $10000 \mathrm{x}$ $g\left(20 \mathrm{~min}\right.$ at $\left.4^{\circ} \mathrm{C}\right)$ and again at $65000 \times \mathrm{g}\left(60 \mathrm{~min}\right.$ at $\left.4^{\circ} \mathrm{C}\right)$. The microsomal pellet was resuspended in the phosphate buffer $(2 \mathrm{~g}$ liver $/ \mathrm{ml})$ and stored at $-80^{\circ} \mathrm{C}$. Before use the control microsomes were thawed and washed twice, with ice cold Tris- $\mathrm{HCl}$ buffer (50 mM, pH 7.4) containing $150 \mathrm{mM} \mathrm{KCl}$.

\section{Lipid Peroxidation}

Microsomes (final concentration approximately $1 \mathrm{mg}$ protein $/ \mathrm{ml}$ ) were incubated at $37^{\circ} \mathrm{C}$, in a shaking water bath, with air being freely admitted in Tris- $\mathrm{HCl} / \mathrm{KCl}$ $(50 \mathrm{mM} / 150 \mathrm{mM}, \mathrm{pH} 7.4)$. Ascorbic acid $(0.2 \mathrm{mM})$ was neutralised with $\mathrm{KOH}$ before addition. Reactions were started by adding a freshly prepared $\mathrm{FeSO}_{4}$ solution $(10 \mu \mathrm{M})$. Lipid peroxidation was assayed by measuring thiobarbituric acid (TBA)reactive material (Haenen, and Bast, 1983). The reaction in an aliquot of the incubation mixture $(0.3 \mathrm{ml})$ was stopped by mixing with ice cold TBA-trichloroacetic acid (TCA) - $\mathrm{HCl}$ - butylhydroxytoluene (BHT) solution (2 ml). After heating (15 min, $80^{\circ} \mathrm{C}$ ) and centrifugation ( $5 \mathrm{~min}$ ) the absorbance at $535 \mathrm{vs.} 600 \mathrm{~nm}$ was determined. The TBA-TCA-HCl solution was prepared by dissolving $1.68 \mathrm{~g}$ TCA and $41.6 \mathrm{mg}$ TBA in $10 \mathrm{ml} 0.125 \mathrm{M} \mathrm{HCl}$. 
BHT was dissolved in ethanol $(1.5 \mathrm{mg} / \mathrm{ml})$ and $1 \mathrm{ml}$ of this solution was added to $10 \mathrm{ml}$ TBA-TCA-HCl. The added chemicals did not interfere with the assay in the concentrations used. Results are expressed as mean \pm SEM.

\section{Half Peak Oxidation Potential}

Flavonoids were dissolved in DMSO (final concentration $2.5 \mathrm{v} / \mathrm{v} \%$ ), diluted $1: 1$ with nanopure water and further diluted in a $50 \mathrm{mM}$ phosphate buffer, reaching a final concentration of $100 \mu \mathrm{M}$. Before starting the measurement, this buffer solution was purged with oxygen free nitrogen for 5 minutes after which the nitrogen was led over the solution.

Figure1

Protection against lipid peroxidation by several phenolic compounds.

The activity is expressed as the natural logarithm of concentration of the compound that gives $50 \%$ inhibition of the lipid peroxidation $\left(\ln I C_{50}\right)$ mean $\pm S E M, n=3$.

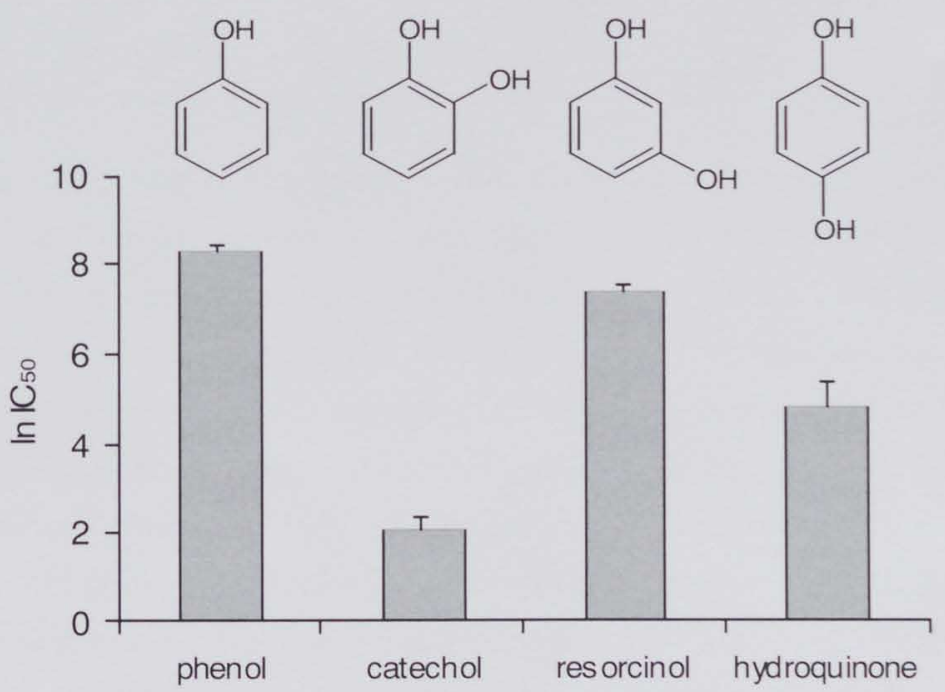


The measurements were performed with a platinum working electrode, a platinum counter electrode and a saturated calomel reference electrode (SCE). After each run the glassy carbon electrode was polished very thoroughly with $6 \mu$ diamond spray on a polishing cloth and sonicated in ethanol, because of possible film formation and memory effects. A scan was made from $-0.2 \mathrm{~V}$ to $0.6 \mathrm{~V}$ with a scanning speed of $20 \mathrm{mV} / \mathrm{s}$ on a PSTAT 10 potentiostat connected to an Autolab (Eco Chemie, Utrecht, The Netherlands) and controlled by the program General Purpose Electrochemical System 3.0 (Eco Chemie, Utrecht, The Netherlands).

When the flavonoid could not be oxidized between $-0.2 \mathrm{~V}$ and $0.6 \mathrm{~V}$, a glassy carbon electrode was used as a working electrode in the range of $-1 \mathrm{~V}$ and $1 \mathrm{~V}$.

\subsection{Results}

phenols

Phenol itself is a poor inhibitor of lipid peroxidation. The concentration of phenol needed to inhibit $50 \%$ of the lipid peroxidation $\left(\mathrm{IC}_{50}\right)$ is $4050 \mu \mathrm{M}$. When the $\mathrm{OH}$ group of phenol is methylated, the activity is extinguished ( $\mathrm{IC}_{50}$ anisole $>7 \mathrm{mM}$ ). Hydroxylation of phenol (giving catechol, resorcinol or hydroquinone) leads to more active compounds (Figure 1). OH-substitution at the 2 and 4 position of phenol increases the activity of phenol $\left(\mathrm{IC}_{50}\right.$ catechol $=10 \mu \mathrm{M}$ and hydroquinone $=156 \mu \mathrm{M})$. Hydroxylation at the 3 position of phenol also increases the activity, but this increase is much lower compared to substitution at position 2 or $4\left(\mathrm{IC}_{50}\right.$ resorcinol $=1800 \pm 337 \mu \mathrm{M})$.

In the series of phenols containing various substituents a clear correlation between the $\mathrm{IC}_{50}$ and the Hammett $\sigma$ is found (Figure 2 and equation 1). 
Figure 2 Correlation between Hammett $\sigma$ and the protection of lipid peroxidation by substituted phenols $\left(\ln \left(1 / I C_{50}\right)\right)$. The activity is expressed as the natural logarithm of $1 /$ concentration of the compound that gives $50 \%$ inhibition of the lipid peroxidation ( $\left.\ln 1 / I C_{50}\right)$ mean $\pm S E M, n=3$. The equation of the fitted line is: $\ln \left(1 / I C_{50}\right)=-8.92$ Hammett $\sigma+5.80(R=0.94, p<0.05)$ Catechol, para- $\mathrm{NH}_{2}$-phenol and resorcinol were not included in the linear regression for the reasons described in the text.

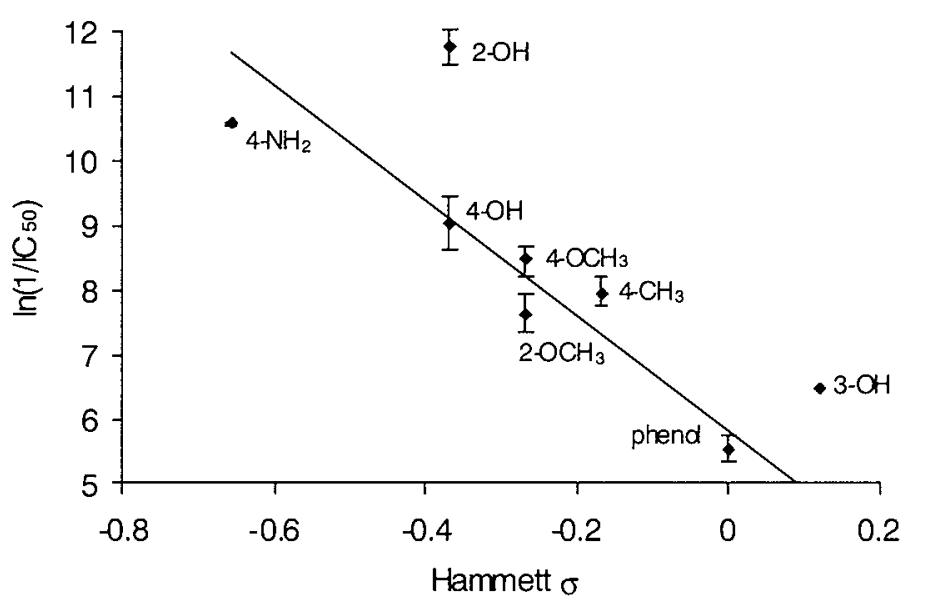

$$
\begin{aligned}
& \ln \left(1 / \mathrm{IC}_{50}\right)=-8.92 \text { Hammett } \sigma+5.80 \\
& (\mathrm{R}=0.94, \mathrm{p}<0.05)
\end{aligned}
$$

(Equation 1)

flavonols

Quercetin has a very high activity (figure 3 ). This activity is drastically decreased when all five $\mathrm{OH}$-groups are methylated (TUM 8437, $\mathrm{IC}_{50}>2 \mathrm{mM}$ ). Flavones with a catechol structure as ring $B$ are also good protectors (rutin and monoHER, figure 3 ). But without a catechol structure as ring B (e.g. galangin) there also can be a high activity. In figure 4 several flavones not containing a catechol group are compared. 
Figure $3 \quad$ Protection against lipid peroxidation by several flavones. The activity is expressed as the concentration of the compound that gives $50 \%$ inhibition of the lipid peroxidation $\left(I C_{50}\right)$. When all $\mathrm{OH}$-groups of quercetin are methylated, the activity is drastically decreased. A flavone with a catechol group as ring $B$ has high activity (rutin and monoHER). Galangin that only has $\mathrm{OH}$-groups in the $\mathrm{AC}$-ring also has a high activity in the inhibition of the lipid peroxidation. $\left({ }^{a}\right.$ data taken from van Acker et al. (1996))<smiles>COc1cc(OC)c2c(=O)c(OC)c(-c3ccc(OC)c(OC)c3)oc2c1</smiles>

\section{TUM 8437}

$\mathrm{IC}_{50}>2 \mathrm{mM}$

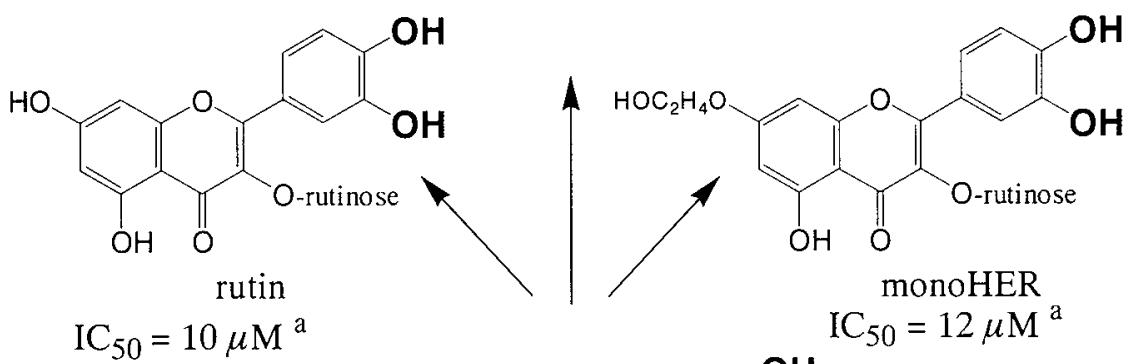<smiles>[M]OC1=C(O)C(c2ccc(O)c(O)c2)Oc2cc(O)cc(O)c21</smiles> 
Figure $4 \quad$ Protection against lipid peroxidation by several flavones. The activity is expressed as the concentration of the compound that gives $50 \%$ inhibition of the lipid peroxidation $\left(I C_{50}\right)$. Galangin, kaempferol and triHEQ all have a high activity. When the 3-OH group is lacking, as in chrysin and apigenin or substituted as in triHER, the activity is diminished.

" data taken from Mora et al. (Mora, et al., 1990)

${ }^{b}$ data taken from van Acker et al. (van Acker, et al., 1996)

${ }^{c}$ data taken from Haenen et al. (Haenen, et al., 1993)<smiles>O=c1c(O)c(-c2ccccc2)oc2cc(O)cc(O)c12</smiles>

galangin $\mathrm{IC}_{50}=1.7 \pm 0.12 \mu \mathrm{M}$<smiles>O=c1c(O)c(-c2ccc(O)cc2)oc2cc(O)cc(O)c12</smiles>

kaempferol $\mathrm{IC}_{50}=23.8 \mu \mathrm{M}^{\mathrm{a}}$ $\mathrm{IC}_{50}=6 \mu \mathrm{M}^{\mathrm{b}}$<smiles>O=c1cc(-c2ccccc2)oc2cc(O)cc(O)c12</smiles>

chrysin $\mathrm{IC}_{50}=29 \pm 0.95 \mu \mathrm{M}$

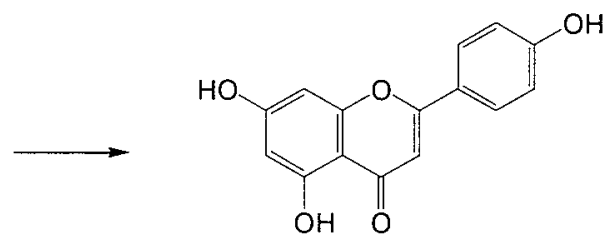

apigenin $\mathrm{IC}_{50}=55.2 \mu \mathrm{M}^{\mathrm{a}}$ $\mathrm{IC}_{50}=2754 \mu \mathrm{M}^{\mathrm{b}}$<smiles></smiles>

triHEQ $\mathrm{IC}_{50}=13 \mu \mathrm{M}^{\mathrm{c}}$

triHER $\mathrm{IC}_{50}=290 \mu \mathrm{M}^{\mathrm{c}}$ 
Figure 5 Protection against lipid peroxidation by several flavones. The activity is expressed as the concentration of the compound that gives $50 \%$ inhibition of the lipid peroxidation $\left(I C_{50}\right)$. A compound with only one of the $\mathrm{OH}$-groups of galangin has a poor activity. The rank order of activity is 3-OH-flavone > 5-OH-flavone > 7-OH-flavone. When 3-OH-flavone is substituted with electron donating groups, the activity is increased.<smiles>O=c1cc(-c2ccccc2)oc2cc(O)ccc12</smiles>

7-hydroxyflavone $\mathrm{IC}_{50}>2 \mathrm{mM}$<smiles>O=c1cc(-c2ccccc2)oc2cccc(O)c12</smiles>

5-hydroxyflavone $\mathrm{IC}_{50}>0.5 \mathrm{mM}$
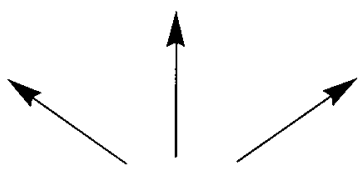

3-hydroxyflavone $\mathrm{IC}_{50}=22.8 \pm 1.9 \mu \mathrm{M}$

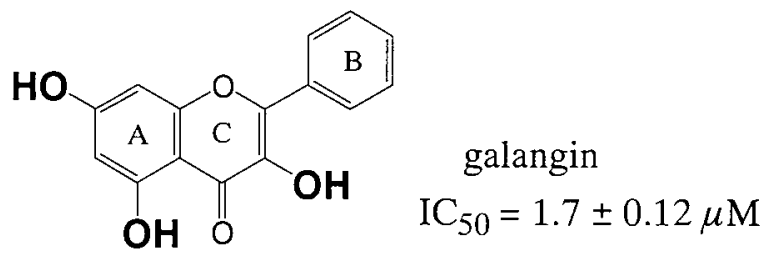<smiles>COc1cc(OC)c2c(=O)c(O)c(-c3ccc(OC)c(OC)c3)oc2c1</smiles> 
Flavones containing the 3-OH group (galangin, kaempferol and triHEQ) were found to be better protectors compared to the corresponding compounds not containing this group (respectively chrysin, apigenin and triHER).

Of the flavones containing only one $\mathrm{OH}$-group in the $\mathrm{AC}$-ring (figure 5)

3-OH-flavone $\left(\mathrm{IC}_{50}=22.8 \mu \mathrm{M}\right)$ was found to be the best protector.

$\left(\mathrm{IC}_{50}\right.$ 5-OH-flavone $>0.5 \mathrm{mM}, 7-\mathrm{OH}$-flavone $>2 \mathrm{mM}$ ). TUM 8436, a compound possessing only a free $\mathrm{OH}$-group at the 3 position, is also very active $\left(\mathrm{IC}_{5_{0}}=13.5 \mu \mathrm{M}\right)$. The activity of several flavones is correlated to the half peak oxidation potential $(E \mathrm{p} / 2)$ (figure 6). The group without the catechol and without the pharmacophore in ring $\mathrm{AC}$ has a relatively high $E \mathrm{p} / 2$, the group of flavones with a catechol-group in ring $\mathrm{B}$ has a very low $E \mathrm{p} / 2$. The group of flavones with only the pharmacophore in ring $\mathrm{AC}$ has a wide range of $E \mathrm{p} / 2$.

\subsection{Discussion}

This study on the structure activity relationship (SAR) of the inhibition of lipid peroxidation by flavonols was started by characterizing the influence of substituents on the activity of phenol. It was found that the nature of the substituent as well as its position determines the activity of phenol. This influence can be explained by the different electron-donating effect of the various substituents at different positions. The Hammett $\sigma$ denotes the electron donating $(-\sigma)$ or withdrawing $(+\sigma)$ effect of a certain substituent at a certain position. A clear correlation between the concentration needed to inhibit the lipid peroxidation for $50 \%\left(\mathrm{IC}_{50}\right)$ and the $\sigma$ is found in the series of substituted phenols (figure 2 and equation 1 ).

The higher the electron-donating effect of a substituent, the higher the protection of the substituted phenol against lipid peroxidation is. Electron-donation weakens the $\mathrm{O}-\mathrm{H}$ bond making it easier to transfer an $\mathrm{H}^{-}$to a lipidperoxyl radical, thus breaking the chain process of lipid peroxidation. The good correlation indicates that in this series of compounds the electron donating effect is the predominant factor for the protection against lipid peroxidation.

According to its $\sigma$, resorcinol is expected to be less active than phenol because of 
the electron withdrawing effect of an OH-group at the 3-position. Surprisingly, resorcinol was found to be more protective than phenol $\left(\mathrm{IC}_{50}\right.$ phenol $=4050 \mu \mathrm{M}$ and resorcinol $=1800 \mu \mathrm{M})$. Apparently other factors than the electron-donating effect play a role in the inhibition of lipid peroxidation, e.g. lipophilicity, iron chelation, and location within the membrane.

Lipid peroxidation takes place in membranes and the scavenging of lipidperoxyl radicals can only be accomplished by the fraction of antioxidants that is present in the membrane. The lipophilicity of resorcinol $(\log \mathrm{P}=0.80)$ is lower than that of phenol $(\log \mathrm{P}=1.46)$, which means that a smaller fraction of resorcinol is present in the membrane compared to phenol. The relative high activity of resorcinol can therefore not be attributed to accumulation in the membrane. Multiple regression analyses did show no significant contribution of the lipophilicity on the activity in the series of substituted phenols. In the difference between the measured activity of 4- $\mathrm{NH}_{2}$-phenol $\left(\mathrm{IC}_{50}=25.6 \mu \mathrm{M}\right)$ and the calculated activity based on the electron donating effect of a 4- $\mathrm{NH}_{2}$-group $\left(\mathrm{IC}_{50}=8.4 \mu \mathrm{M}\right)$ lipophilicity is probably involved. 4- $\mathrm{NH}_{2}$ - phenol is a relatively hydrophilic compound with a $\log \mathrm{P}$ of 0.04 versus $\log \mathrm{P} 1.46$ of phenol. This indicates that lipophilicity might play a role in lipid peroxidation. Secondly, iron chelation can reduce radical generation in iron-ascorbate induced lipid peroxidation. This plays a pivotal role in the antioxidant effect of flavonoids (Cheng, and Breen, 2000, Haenen, et al., 1993). Iron chelation has also been reported for catechol (van Acker, et al., 1996), but has not been described for resorcinol. The higher protection against lipid peroxidation of catechol compared to its predicted activity based on the $\sigma$ of an ortho $\mathrm{OH}$-group (Figure 2 and Equation 1) might be due to its iron chelating ability.

A third possibility for the relatively good activity of resorcinol might be found in the actual location of resorcinol within the membrane. For example, the chroman head of tocopherol, that is responsible for the actual antioxidant effect, is located in the membrane very near the lipid-water interface (Perly, et al., 1985). Also for other antioxidants, such as carotenoids and 5-aminosalicylic acid, the position within the membrane is suggested to greatly influence their activity (Pearson, et al., 1996, Woodall, et al., 1997). Resorcinol might have the structural elements that direct it to a position within the membrane where it can effectively protect against lipid 
peroxidation. Although this has not been studied, it might explain the higher activity of resorcinol.

In conclusion, in the series of the substituted phenols the electron-donating effect of the substituent appeared to be the most denominating factor in the inhibition of lipid peroxidation. Other factors including lipophilicity, iron chelation and location within the membrane probably are also involved in the final antioxidant effect, however, their exact role has not been elucidated.

Similar to phenol, the free OH-groups of flavonoids appear to be responsible for the activity. Polyphenols, such as quercetin are also reported to be good inhibitors of lipid peroxidation (Afanas'ev, et al., 1989, Ratty, and Das, 1988, van Acker, et al., 1996). When all the OH-groups of quercetin are methylated, giving TUM 8437 (penta-O-methyl quercetin), the activity is drastically decreased (figure $3, \mathrm{IC}_{50}>2 \mathrm{mM}$ ).

Flavonoids have been tested in many different antioxidant assays, e.g. TEAC and lipid peroxidation. Several SARs have been constructed. In these SARs the catechol moiety as ring B has been addressed as a pivotal group (Arora, et al., 1998, Bors, and Michel, 1999, Cao, et al., 1997, Sekher Pannala, et al., 2001, van Acker, et al., 2000). Indeed in all these studies, flavones with a catechol moiety in ring $B$ were very good inhibitors of lipid peroxidation ( $\mathrm{IC}_{50}$ is approximately $10 \mu \mathrm{M}$, figure 3 ) (Arora, et al., 1998, Bors, and Michel, 1999, Cao, et al., 1997, Mora, et al., 1990, Sekher Pannala, et al., 2001, van Acker, et al., 2000, van Acker, et al., 1996). We recently synthesized a series of 20 different flavones all containing a catechol group as ring B. Also these compounds appeared to be excellent protectors against lipid peroxidation, irrespective of the number and nature of the substituents at the AC-ring (van Acker, et al., 2000). This denotes that the presence of a catechol group as ring $\mathrm{B}$ is indeed important. This is in line with the high activity of catechol we found in the series of substituted phenols.

Recently Pannala et al. (2001) concluded that only the catechol moiety as ring B is important in the reactions of the ABTS ${ }^{\circ}$ with flavonoids. They found that also kaempferol, a compound having a phenol group as ring $\mathrm{B}$, had an activity comparable to catechol containing compounds. The high potency of kaempferol was explained 
by the potential for conjugation between the 4'-OH-group in the B-ring and the 3$\mathrm{OH}$-group through the conjugated $\mathrm{C}$-ring. In our study we found that besides kaempferol, galangin (a flavonol lacking the 4'-OH-group of kaempferol) appeared also to be a potent protector against lipid peroxidation. Apparently the high activity of kaempferol and galangin does not reside in ring $\mathrm{B}$ but in another part of the molecule, i.e. the $\mathrm{AC}$-ring.

To determine which OH-group in the AC-ring is the most important, 3-, 5- and 7monohydroxyflavone were tested (figure 5). 3-Hydroxyflavone appears to be the most potent compound pointing to a pivotal role of the 3-OH-group. This is in line with the much higher potency of galangin, kaempferol and triHEQ $\left(\mathrm{IC}_{50}=1.7,23.8\right.$, and $13 \mu \mathrm{M}$ respectively, figure 4) compared to the corresponding compounds lacking a free 3-OH-group (i.e. chrysin, apigenin and triHER, $\mathrm{IC}_{50}=29,55.2$, and $290 \mu \mathrm{M}$ respectively, figure 4)

Although 3-hydroxyflavone is a good protector against lipid peroxidation, its effectiveness is exceeded by galangin $\left(\mathrm{IC}_{50}=1.7 \mu \mathrm{M}\right)$ more than 10 times. The explanation for the high activity of galangin can be found in the SAR of substituted phenols, described above. The activity of an aromatic $\mathrm{OH}$-group is positively influenced by electron-donating substituents, e.g. the activity of phenol is drastically increased by substitution of an OH-group at the 2 or 4 position. The introduction of a 3-OH-group in phenol only results in a slight increase of the activity (figure 1). An even number of $\mathrm{C}$-atoms between the electron donating group and the reactive $\mathrm{OH}$-group appears to be optimal to increase the activity. An uneven number of $\mathrm{C}$-atoms gives a suboptimal stimulation. This dependency on the number of $\mathrm{C}$-atoms in-between is characteristic for an electron donating effect. In galangin there is an even number of $\mathrm{C}$-atoms between the 3-OH-group and the 5-and 7-OH-groups. The interaction of the 5- and 7-OH-group on each other is suboptimal since they are separated by an uneven number of C-atoms. Moreover, the activity of the 3-monohydroxyflavone exceeds that of the 5- and 7-monohydroxyflavone. This indicates that the 3-OH-group in galangin is the most reactive one and that the $\mathrm{OH}$-groups at the 5 and 7 position boost the reactivity of the 3-OH-group.

To examine this hypothesis the newly synthesized compound TUM 8436 $\left(5,7,3^{\prime}, 4^{\prime}\right.$-tetra-O-methyl-quercetin) was tested. This compound has only one free 
$\mathrm{OH}$-group at the 3 position. At the 5, 7, 3', and 4' position the flavone is substituted with an electron donating group, i.e. an $\mathrm{OCH}_{3}$-group. The $\mathrm{OCH}_{3}$-group was chosen because it has an electron donating effect comparable to the OH-group, although this effect is somewhat smaller (Hammett $\sigma 4-\mathrm{OCH}_{3}=-0.27,4-\mathrm{OH}=-0.37$ ). Moreover an $\mathrm{OCH}_{3}$-group itself provides no protective effect against the lipid peroxidation, as shown by the high $\mathrm{IC}_{50}$ of TUM $8437\left(\mathrm{IC}_{50}>2 \mathrm{mM}\right.$, fig 3). TUM $8436\left(\mathrm{IC}_{50}=\right.$ $13.5 \mu \mathrm{M})$ proved to be a good inhibitor of lipid peroxidation, better than the $3-\mathrm{OH}$ flavone $\left(\mathrm{IC}_{50}=22.8\right)$ (Figure 5). This demonstrates that in the $\mathrm{AC}$-ring the 3-OH is important for the antioxidant activity, and that the activity can be boosted by electron donating substituents (e.g. $\mathrm{OH}$ - or $\mathrm{OCH}_{3}$-group) at the 5 and 7 position. In the present study it is shown that besides a catechol group as ring $\mathrm{B}$ another pharmacophore can be pinpointed i.e. the 3-OH-group in the AC-ring in combination with electron donating groups. The SAR for the protection against lipid peroxidation is identical to the SAR for scavenging of peroxynitrite by flavones, where also these two pharmacophores have been identified (Haenen, et al., 1997, Heijnen, et al., 2001a, Heijnen, et al., 2001b). In peroxynitrite scavenging it has also been shown that both pharmacophores can influence each other (Heijnen, et al., 2001b). There are some striking differences in potency of some compounds in the protection against lipid peroxidation and peroxynitrite induced damage. Chrysin (5,7-hydroxyflavone) is practically inactive in peroxynitrite scavenging whereas it is a good protector against lipid peroxidation $\left(\mathrm{IC}_{50}=29.3 \mu \mathrm{M}\right)$. Peroxynitrite scavenging, where only one activity is examined, is less complex than lipid peroxidation. As discussed above, the SAR for protection against lipid peroxidation is a combined SAR and several processes other than $\mathrm{H}^{\cdot}$ donation come into the equation. Based on structural similarity, i.e. the structure in ring A resembles resorcinol, the same molecular mechanism responsible for the relative high potency of resorcinol might be involved in the unexpected high potency of chrysin.

Paradoxically, several flavones, e.g. quercetin, with an excellent antioxidant activity also display a prominent prooxidant activity. Several attempts were made by us using different types of assays, e.g. deoxyribose breakdown, coumarin hydroxylation, and capturing radicals with spintraps, to unravel radical formation and antioxidant effects. The net effect measured appeared to depend greatly on experimental 
conditions such as concentration of the compounds and the duration of the incubation. Apparently a straightforward quantification of the prooxidant activity of these compounds is hampered by interfering processes such as, the potent radical scavenging activity, iron chelation and the formation of active oxidation products from the flavones.

Figure 6

The correlation between the half peak oxidation potential (Ep/2) and the natural logarithm of the concentration that gives $50 \%$ inhibition of lipid peroxidation ( $\left.\ln I C_{50}\right)$. The flavonoids with a catechol group as ring $B(\square)$ are good inhibitors of lipid peroxidation and have a very low Ep/2. The flavonoids with the 3-OH group and electron donating substituents at position 5 and 7 have a high activity and a variable Ep/2. The flavonoids without both pharmacophores $(\Delta)$ are poor inhibitors and have a high Ep/2. The compounds are $1=$ quercetin, $2=$ fisetin, $3=$ rutin, $4=$ luteolin, $5=$ monoHER, $6=$ kaempferol, $7=$ galangin, $8=$ triHEQ, $9=$ TUM 8436, $10=$ diHER, $11=$ TUM 8437, $12=$ triHER and $13=$ apigenin.

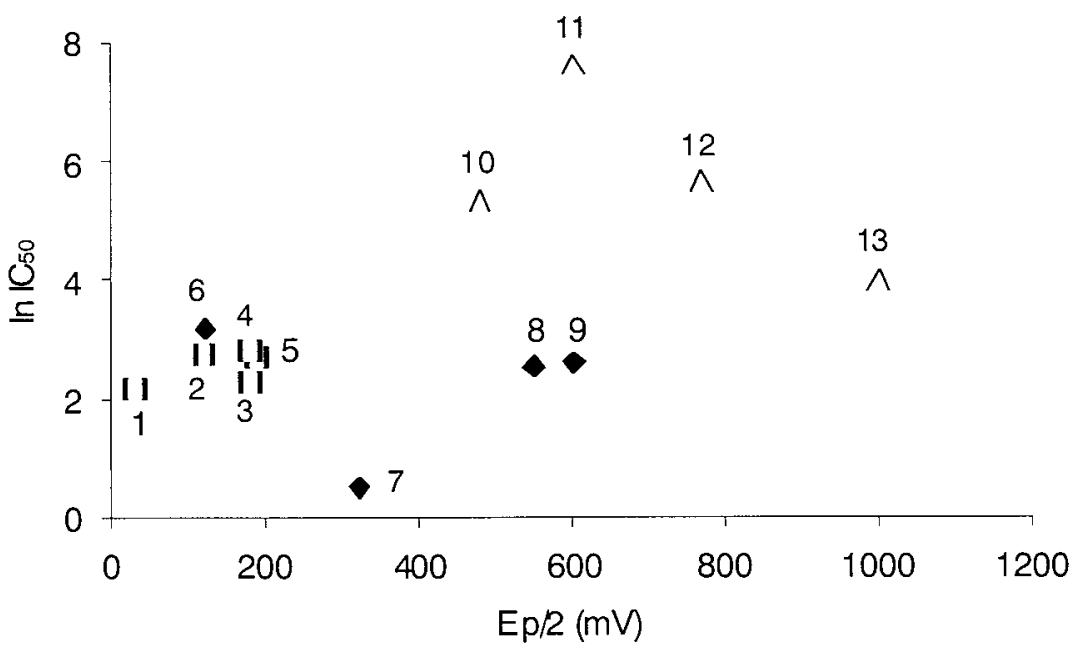




\section{Chapter 5}

Therefore it was decided to evaluate a crucial step prior to radical formation, i.e. the ability to act as a reductant to reduce transition metals like iron. This is an essential step in formation of radicals by e.g. the Fenton reaction. The reducing ability of a compound is reflected by its $E \mathrm{p} / 2$. Indeed a negative correlation between the prooxidant activity and the $E \mathrm{p} / 2$ has been reported (Dickancaite, et al., 1998, Sergediene, et al., 1999). In figure 6 the relation is shown between the concentration that gives $50 \%$ inhibition of the lipid peroxidation $\left(\mathrm{IC}_{50}\right)$ and the $E \mathrm{p} / 2$. This figure shows three groups. The flavones without the two pharmacophores are poor inhibitors of lipid peroxidation and have a high $E \mathrm{p} / 2$. The flavones with a catechol moiety as ring $\mathrm{B}$ are very good inhibitors of lipid peroxidation and have a very low $E \mathrm{p} / 2$, and thus are expected to be prooxidants. The flavones without the pharmacophore in ring B but with a 3-OH-group and electron limited prooxidant properties. The independence of the activity and the $E \mathrm{p} / 2$ of the latter group versus the low $E \mathrm{p} / 2$ of all the flavones containing a catechol as ring B suggests that the two different pharmacophores act with a different mechanism to inhibit lipid peroxidation. This also means that it might be possible to unravel the pro- and antioxidant effects and to select good antioxidants which are expected to display no prooxidant effect, e.g. the semi-synthetic compound TUM 8436.

Acknowledgements: The authors like to thank Paul van Hal, Karlijn Gijzen and Julian Ramakers for their work on the prooxidant properties of flavonoids. 


\subsection{References}

Afanas'ev, I.B., Dorozhko, A.I., Brodskii, A.V., Kostyuk, V.A. and Potapovitch, A.I., (1989) Chelating and free radical scavenging mechanisms of inhibitory action of rutin and quercetin in lipid peroxidation.

Biochem Pharmacol 38 (11), 1763-1769.

Arora, A., Nair, M.G. and Strasburg, G.M., (1998) Structure-activity relationships for antioxidant activities of a series of flavonoids in a liposomal system. Free Radical Biology and Medicine 24 (9), 1355-1363.

Bors, W. and Michel, C., (1999) Antioxidant capacity of flavanols and gallate esters: pulse radiolysis studies. Free Radic Biol Med 27 (11-12), 1413-1426. Cao, G., Sofic, E. and Prior, R.L., (1997) Antioxidant and prooxidant behavior of flavonoids: structure-activity relationships.

Free Radical Biology and Medicine 22 (5), 749-760.

Cheng, I.F. and Breen, K., (2000) On the ability of four flavonoids, baicilein, luteolin, naringenin, and quercetin, to suppress the Fenton reaction of the iron-ATP complex. Biometals 13 (1), 77-83.

Dickancaite, E., Nemeikaite, A., Kalvelyte, A. and Cenas, N., (1998) Prooxidant character of flavonoid cytotoxicity: structure-activity relationships. Biochemistry and Molecular Biology International 45 (5), 923-930.

Duarte, J., Perez-Vizcaino, F., Utrilla, P., Jiménez, J., Tamargo, J. and Zarzuelo, A., (1993) Vasodilatory effects of flavonoids in rat aortic smooth muscle. Structure-activity relationships. General Pharmacology 24 (4), 857-862.

Frankel, E.N., Kanner, J., German, J.B., Parks, E. and Kinsella, J.E., (1993) Inhibition of oxidation of human low-density lipoprotein by phenolic substances in red wine. Lancet 341 454-457.

Haenen, G.R.M.M. and Bast, A., (1983) Protection against lipid peroxidation by a microsomal glutathione-dependent labile factor.

FEBS Lett 159 (1-2), 24-28.

Haenen, G.R.M.M., Jansen, F.P. and Bast, A., (1993) The antioxidant properties of five O-(B-hydroxyethyl)-rutinosides of the flavonoid mixture Venoruton. Phlebology Suppl 1 10-17. 
Haenen, G.R.M.M., Paquay, J.B.G., Korthouwer, R.E.M. and Bast, A., (1997)

Peroxynitrite scavenging by flavonoids.

Biochemical and Biophysical Research Communications 236 591-593.

Heijnen, C.G.M., Haenen, G.R.M.M., van Acker, F.A.A., van der Vijgh, W.J.F. and

Bast, A., (2001a) Flavonoids as peroxynitrite scavengers:

the role of the hydroxyl groups. Toxicology in Vitro 15 (1), 3-6.

Heijnen, C.G.M., Haenen, G.R.M.M., Vekemans, J.A.J.M. and Bast, A., (2001b)

Peroxynitrite scavenging of flavonoids: Structure activity relationship.

Environmental Toxicology and Pharmacology 10 (4), 199-206.

Heller, F.R., Descamps, O. and Hondekijn, J.-C., (1998) LDL oxidation:

therapeutic perspectives. Atherosclerosis 137 Suppl S25-31.

Hertog, M.G.L., Feskens, E.J.M., Hollman, P.C.H., Katan, M.B. and Kromhout, D., (1993) Dietary antioxidant flavonoids and risk of coronary heart disease:

the Zutphen Elderly Study. Lancet 342 1007-1011.

Massaeli, H., Sobrattee, S. and Pierce, G.N., (1999) The importance of lipid solubility in antioxidants and free radical generating systems for determining lipoprotein proxidation. Free Radic Biol Med 26 (11-12), 1524-1530.

Mora, A., Paya, M., Rios, J.L. and Alcaraz, M.J., (1990) Structure-activity relationships of polymethoxyflavones and other flavonoids as inhibitors of non-enzymic lipid peroxidation.

Biochemical Pharmacology 40 (4), 793-797.

Paquay, J.B.G., Haenen, G.R.M.M., Korthouwer, R.E.M. and Bast, A., (1997)

Peroxynitrite scavenging by wines.

Journal of Agricultural and Food Chemistry 45 3357-3358.

Pearson, D.C., Jourd'heuil, D. and Meddings, J.B., (1996) The anti-oxidant properties of 5-aminosalicylic acid. Free Radic Biol Med 21 (3), 367-373.

Perly, B., Smith, I.C.P., Hughes, L., Burton, G.W. and Ingold, K.U., (1985)

Estimation of the location of natural alpha-tocopherol in lipid bilayers by 13C-NMR spectroscopy. Biochimica et Biophysica Acta 819 (1), 131-135.

Ratty, A.K. and Das, N.P., (1988) Effects of flavonoids on nonenzymatic lipid peroxidation: structure-activity relationship.

Biochemical Medicine and Metabolic Biology 39 (1), 69-79. 
Rice Evans, C.A., Miller, N.J., Bolwell, P.G., Bramley, P.M. and Pridham, J.B., (1995) The relative antioxidant activities of plant-derived polyphenolic flavonoids. Free Radic Res 22 (4), 375-383.

Sekher Pannala, A., Chan, T.S., O'Brien, P.J. and Rice Evans, C.A., (2001)

Flavonoid B-ring chemistry and antioxidant activity: fast reaction kinetics.

Biochem Biophys Res Commun 282 (5), 1161-1168.

Sergediene, E., Jönsson, K., Szymusiak, H., Tyrakowska, B., Rietjens, I.M.C.M. and Cenas, N., (1999) Prooxidant toxicity of polyphenolic antioxidants to HL-60 cells: description of quantitative structure-activity relationships.

FEBS Letters 462 392-396.

van Acker, F.A.A., Hageman, J.A., Haenen, G.R.M.M., van der Vijgh, W.J.F., Bast, A. and Menge, W.M.P.B., (2000) Synthesis of novel 3,7-substituted-2-(3',4'dihydroxyphenyl) flavones with improved antioxidant activity.

Journal of Medicinal Chemistry 43 3752-3760.

van Acker, S.A.B.E., van den Berg, D.-J., Tromp, M.N.J.L., Griffioen, D.H., van Bennekom, W.P., van der Vijgh, W.J.F. and Bast, A., (1996) Structural aspects of the antioxidant activity of flavonoids.

Free Radical Biology and Medicine 20 331-342.

Woodall, A.A., Britton, G. and Jackson, M.J., (1997) Carotenoids and protection of phospholipids in solution or in liposomes against oxidation by peroxyl radicals: relationship between carotenoid structure and protective ability. Biochim Biophys Acta 1336 (3), 575-586. 



\section{Chapter 6}

\section{The effect of flavonol-enriched tomato paste on blood pressure in spontaneously hypertensive rats}

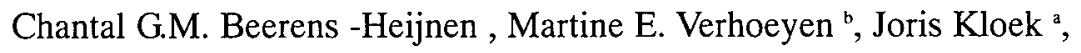

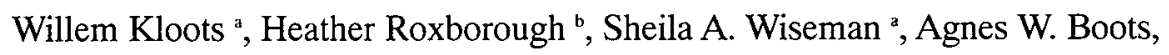
Gertjan J.M. den Hartog, Guido R.M.M. Haenen, and Aalt Bast

a Unilever R\&D Vlaardingen, Unilever Health Institute, P.O.Box 114, 313 AC Vlaardingen, The Netherlands

' Unilever R\&D Colworth, Colworth House, Sharnbrook, MK44 1LQ, UK

Submitted 



\subsection{Abstract}

The aim in this study was to investigate the effect of a flavonol-enriched tomato paste on hypertension. The blood pressure of spontaneously hypertensive rats (SHR) was measured by telemetry, a non-invasive measurement in conscious, freely moving, non-stressed rats. According to an incomplete block design the rats were fed with 2 out of 4 diets: basic diet, basic diet containing quercetin aglycone, tomato paste or flavonol-enriched tomato paste (diets $\mathrm{B}, \mathrm{BQ}, \mathrm{T}$, or $\mathrm{TQ}$ respectively) for 5 weeks. No statistically significant differences were seen between the diet groups after the intervention (at $\mathrm{P}=0.05$ level). Relaxation of the isolated aorta measured in vitro was also not affected by the diets. However, the increase in mean blood pressure, as seen in group $B$, tends to be less in the rats receiving a flavonoid rich diet $\mathrm{BQ}$ and $\mathrm{T}$. This increase appeared to be absent in the group TQ. A small reduction in blood pressure is already expected to lower the risk of developing cardiovascular diseases substantially. The subtle effect of flavonol-enriched tomato paste on blood pressure, as shown in the present study, might therefore be of general importance for public health. 


\subsection{Introduction}

The heterogeneous group of dietary antioxidants is extensively studied in relation to human health. The Mediterranean diet, which contains large amounts of antioxidants, is considered to be healthy (Formica and Regelson, 1995, Nijveldt, et al., 2001, Trichopoulou and Vasilopoulou, 2000). A large part of these dietary antioxidants are flavonoids, polyphenolic compounds ubiquitous in fruits, vegetables and beverages, such as tea, wine and beer. Positive health effects of the flavonoids have been demonstrated in epidemiological studies regarding several diseases, including cancer, osteoporosis, and cardiovascular diseases (Hegarty, et al., 2000, Hollman and Katan, 1997, Knekt, et al., 1996). In fundamental research, regarding these diseases, flavonoids have been described as vasoprotective, anti-carcinogenic and anti-inflammatory (Bravo, 1998, Heo, et al., 2001, Hollman and Katan, 1999).

When processes, which play a role in the etiology of cardiovascular diseases, are studied in isolation, protective effects of flavonoids have been reported. Flavonoids protect against in vitro membrane lipid peroxidation, LDL-oxidation, and damage by peroxynitrite (Cherubini, et al., 1999, Grinberg, et al., 1997, Heijnen, et al., 2002, Heijnen, et al., 2001, Kono, et al., 1997). Some experiments on experimental animals have shown that flavonoids, such as the flavonol quercetin, have a positive effect on arterial blood pressure, an important factor in cardiovascular disease (Duarte, et al., 2002, Duarte, et al., 2001, Jouad, et al., 2001). Also clinical studies suggest a protective effect of a flavonoid-rich diet against cardiovascular diseases (Chopra, et al., 2000, Hollman and Katan, 1997, Knekt, et al., 1996).

To increase the antioxidant level in the western diet, large amounts of fruit and vegetables should be consumed daily or new products enriched in antioxidants, eg. flavonoids, should be made available. A major fruit that is consumed all over the world is the tomato (Bugianesi, et al., 2002, Willcox, et al., 2003). It contains modest levels of flavonoids in the peel of its fruit. This level is elevated in the high-flavonol tomato (Muir, et al., 2001). In the peel of these tomatoes the overexpression of a petunia chalcone isomerase gene causes an up to 78-fold increased level of flavonols, mainly quercetin-rutinoside (rutin) and quercetin-glucoside (isoquercitrin). Consumption of this fruit increases the flavonoid content of the diet and is expected to have a 
beneficial effect on hypertension.

Hypertension has been established as an independent risk factor for coronary heart disease, kidney and heart failure and stroke and may lead to disability and premature death. Hypertension has a prevalence of about $15 \%$ in the western population and is increasing in developing countries. Above the age of 65 , the incidence in the western population increases to approximately $35 \%$. Lowering blood pressure in hypertensive subjects is effective in reducing the risk of associated diseases, and from an economical point of view this can lower the cost of health care (World Health Organisation, 2003). A frequently used animal model to study human essential hypertension is the spontaneously hypertensive rat (SHR). In the present study, the blood pressure of the SHR is measured using telemetry. This technique enables the measurement of blood pressure in freely moving, non-stressed rats. Handling of the rat during the actual measurement, which will affect blood pressure, is absent (Irvine, et al., 1997, Van Vliet, et al., 2000). Using telemetry the blood pressure can be followed continuously for long periods, up to months. The aim of our study was to study the effects of a high-flavonol tomato paste on blood pressure of SHR.

\subsection{Methods and Materials}

\section{Chemicals}

$\mathrm{N}_{2} \mathrm{O}_{2}$ and $\mathrm{O}_{2}$ gas were purchased from Hoekloos (the Netherlands) and halothane from Zeneca (the Netherlands). Phenylephrine, metacholine and nitro-L-arginine methylester (L-NAME) were obtained from Sigma-Aldrich (St. Louis, USA). Sodium nitroprusside was obtained from Fluka (Buchs, Switzerland).

\section{Animals and experimental protocol}

Thirteen to sixteen-week-old (249-388 g), male spontaneously hypertensive rats were obtained from Harlan Laboratories (Horst, The Netherlands). The rats were housed individually in a room with a 12 -h reversed dark/light cycle (dark: $8 \mathrm{pm}-8 \mathrm{am}$ and light $8 \mathrm{am}-8 \mathrm{pm})$. Water was available ad libitum all the time and standard semisynthetic food was available ad libitum from 9:00 AM till 4:30 PM. The experimental 
food was fed from 8:00 AM till 9:00 AM. The set-up of the experiment was an incomplete block design wherein every rat received two out of four diets. After surgery to implant the telemetry device, 24 Spontaneously Hypertensive rats (SHR) were randomly assigned to one of the four diets for 5 weeks ( 6 rats per group). After a 4-week washout period, the rats received another diet for 5 weeks. The randomisation took into account that a rat did not receive the same diet as in the first intervention and that all combinations of diets given to an animal are equally present in the study. The protocol was approved by the Animal Ethics Committee of the University of Maastricht.

\section{Diet}

The ad libitum available semi-synthetic food was a balanced food low in antioxidants, especially flavonoids. The composition of this diet is given in table 1 . This diet also served as the control diet (diet B). Diet BQ is the semi-synthetic diet (diet B) with quercetin-aglycone added $(1 \mathrm{~g} / \mathrm{kg} \operatorname{diet} \mathrm{B})$. Via diet BQ the rats received approximately $10 \mathrm{mg}$ quercetin-aglycone / $\mathrm{kg}$ body weight daily with the diet.

Portions of the semi-synthetic powder diets B and BQ were prepared prior to each 45 weeks feeding period and stored vacuum at $-20^{\circ} \mathrm{C}$. Each day the powder was mixed with water ( $1.5 \mathrm{~g}$ tap water per $1 \mathrm{~g}$ powder) just before feeding. Diet $\mathrm{T}$ was a paste made from normal tomatoes, in which the level of quercetin, mainly present as rutin, was $1.73 \mathrm{mg}$ quercetin aglycone / $100 \mathrm{~g}$ wet weight (measured in hydrolysed samples). The tomato paste of diet $\mathrm{TQ}$ was derived from genetically modified tomatoes with enhanced levels of quercetin, mainly present as rutin and isoquercitrin (Muir, et al., 2001). The level of quercetin-glycosides in this paste was $48.8 \mathrm{mg}$ quercetin aglycone / $100 \mathrm{~g}$ tomato paste wet weight (measured in hydrolysed samples). The daily amount of quercetin-glycosides received by the rats via diet TQ was equivalent to approximately $10 \mathrm{mg}$ quercetin aglycone / $\mathrm{kg}$ body weight. The amount of flavonoid in diet $\mathrm{T}$ and TQ was checked semi-quantitatively by TLC every time a new can of paste was opened. 
Table 1 Composition of the diet

ingredient $\quad \mathrm{kJ} / \mathrm{g} \quad \mathrm{g} / \mathrm{kg} \quad \mathrm{en} \% \quad \mathrm{~kJ}$

Calcium-caseinate

$\begin{array}{llll}15.7 & 150.5 & 16 & 2357.7\end{array}$

Vitamin-mixture

10.7

Mineral-mixture

36.7

Arbocel BC-200

52.5

Fat blend (SUFA:MUFA:PUFA = 1:1:1)

$\begin{array}{lll}37.7 & 78.3 \quad 20\end{array}$

2947.1

Choline Bitartrate

2.6

L-cysteine hydrochloride

1.9

Maize starch

$\begin{array}{llll}13.7 & 667.0 & 64 & 9430.6\end{array}$

total

$1000 \quad 100 \quad 14735.4$

\section{Surgery}

Implants (PA-C40, Data Sciences International, St Paul (MN) USA) were inserted as described by Data Science. The telemetry device was inserted in the peritoneal cavity under aseptic conditions. Briefly, the animal was anaesthetized with a mixture of $\mathrm{O}_{2} / \mathrm{N}_{2} \mathrm{O} /$ halothane. The catheter with fluid-filled tip was inserted in the abdominal aorta with the tip just caudal of the renal arteries; it was fixed with a cellulose-patch and tissue adhesive. The body of the implant was immobilized by suturing it to the ventral abdominal wall with a nonresorbable suture. The derma was closed with a resorbable suture. The animals were allowed to recover for at least 10 days before blood pressure measurements and start of the dietary interventions.

\section{Blood pressure measurements}

The blood pressure of each rat was measured by telemetry. Periods of $10 \mathrm{sec}$ duration were stored every five minutes for 3 days per week. During these periods heart rate, pulse pressure, systolic, diastolic and mean arterial blood pressure were derived from the waveforms of the blood pressure measurements (Dataquest ${ }^{\mathrm{TM}}$ A.R.T. for Windows, Data Science, St Paul MN USA). 


\section{Vascular function ex vivo}

At the end of the telemetry experiment 12 SHR were used to study the response of the isolated aorta to phernylephrine and metacholine. After the rats were anaesthetized with a mixture of $\mathrm{O}_{2} / \mathrm{N}_{2} \mathrm{O} /$ halothane, their aorta was rapidly excised, and 4 small rings per rat $\left(1 \mathrm{~mm}\right.$ thick) were mounted in a thermostated organ bath $\left(37^{\circ} \mathrm{C}\right)$ containing a Krebs buffer gassed with a mixture of $95 \% \mathrm{O}_{2}$ and $5 \% \mathrm{CO}_{2} ; \mathrm{pH}$ 7.4. The composition of the Krebs buffer was (mM): $\mathrm{NaCl}(117.5), \mathrm{KCl}(5.6), \mathrm{MgSO}_{4}$ $(1,18), \mathrm{CaCl}_{2}(2.5), \mathrm{NaHPO}_{4}(1.28), \mathrm{NaHCO}_{3}(25)$ and glucose (5.5). The contraction of the aorta rings was determined isometrically under a preload set to $0.2 \mathrm{~g}$ after a stabilisation period of $1 \mathrm{hr}$. During the stabilisation periods the Krebs buffer was refreshed every $10 \mathrm{~min}$. To determine the acetylcholine-receptor mediated relaxation, the aorta rings were first pre-contracted using phenylephrine. A concentration response curve $\left(10^{-9}-10^{-5} \mathrm{M}\right.$ phenylephrine) was constructed. Subsequently, the concentration-dependent relaxation mediated by the acetylcholine-receptor (muscarine) was determined in the aorta contracted by $10^{-5} \mathrm{M}$ phenylephrine. Metacholine $\left(10^{-9}-10^{-5} \mathrm{M}\right)$, a enzymatically more stable agonist than acetylcholine, was used for this purpose. In half of the aorta rings maximal relaxation was elicited by sodium nitroprusside. The other half of the rings were washed and incubated for 30 min with L-NAME $\left(10^{-4} \mathrm{M}\right)$. After this period, a second concentration-response curve of metacholine was established, the maximal contraction is elicited by $80 \mathrm{mM}$ $\mathrm{KCl}$. The $\mathrm{pD}_{2}$ values (-log of the molar concentration that produces half maximal effect) of the compounds were calculated.

\section{Data handling and statistics}

The 10-second blood pressure recordings were stored every 5 minutes for 3 days per week. For every $10 \mathrm{sec}$-measurement a data point is saved per rat, this is considered the raw data. All data points (10-second measurements) are averaged per rat per week. Week 0 is the baseline, the results are expressed as increase or decrease compared to the baseline per rat. These results of rats receiving the same diet are compared to those of the rats receiving another diet. The results are expressed as mean \pm SEM and statistically tested in ANCOVA, with treatment period as a factor, (SAS 8), or in a one-tailed t-test (SPSS 10.1) $\mathrm{p}=0.05$. 


\subsection{Results}

The average change in mean blood pressure per week relative to the baseline is given for each diet group in figure 1 . No statistically significant differences between the diet-groups during the 5-week-intervention are seen. In figure 2 the change in mean, systolic and diastolic blood pressure and heart rate relative to the baseline is given after five weeks of intervention. There are no statistically significant differences between the diet groups in any of the parameters, with every rat receiving 2 out of 4 diets. The rats, which received diet B, show an increase in mean and diastolic blood pressure after 5 weeks relative to the baseline (figure 2) (respectively $\mathrm{p}=0.044$ and 0.034 ). The increase in systolic blood pressure relative to the baseline of the rats, which received diet $B$ for 5 weeks, has a p-value of 0.065 . This increase in blood pressure is not seen in the rats, which received diet TQ for 5 weeks ( $p$-values $0.355,0.471,0.388$, for the change in respectively mean, systolic and diastolic blood pressure). The heart rate is decreased in all diet groups, and no differences in heart rate between the diet groups after 5 weeks of experimental feeding are found.

Experiments performed on the aorta, isolated from the rats after the last 5-weeks feeding period, showed no differences between the diet groups in either contraction of the aorta to phenylephrine (figure $3 \mathrm{~A}$ ) or relaxation to metacholine (figure $3 \mathrm{~B}$ ) or to nitroprusside (data not shown). In the presence of L-NAME, metacholine as a vasoconstrictor showed no difference between the diet groups (figure $3 \mathrm{C}$ ).

\subsection{Discussion}

The aim of our study was to test the effects of a tomato paste enriched in flavonolglycosides (mainly quercetin-glycosides) in SHR, an animal model for human essential hypertension. The rats, receiving the control diet (diet B) for 5 weeks, show a timedependent increase in mean arterial blood pressure (figure 1). Although blood pressure levels should have levelled off at the age of the rats in the experiment (data animal supplier), the blood pressure still rose during the feeding experiment. Significant differences in blood pressure between the diet groups, B, BQ, T and TQ are not found 
during a 5-week-intervention by the ANCOVA-test. Although a trend of a blood lowering effect in rats recieving TQ is seen in week 5 . Notably, in rats that have been fed the TQ diet for 5 weeks, the increase in mean arterial blood pressure is absent. In addition, the systolic and diastolic pressure are unchanged (figure 2, panel $\mathrm{A}, \mathrm{B}$, and C). Statistical analysis showed no increase in mean, systolic and diastolic blood pressure of the rats that received diet TQ for 5 weeks, whereas these parameters are increased in rats receiving diet $\mathrm{B}$. This indicates that the flavonol-glycoside enriched tomato paste inhibits the increase in blood pressure in SHR. The average of the blood pressure obtained in rats receiving diet $\mathrm{BQ}$ or diet $\mathrm{T}$ was in between that of $\operatorname{diet} \mathrm{B}$ and $\operatorname{diet} \mathrm{TQ}$.

Figure $1 \quad$ The change in mean arterial blood pressure in rats recieving a different diet in time. The diets are: $B$ (control diet), $B Q$ (control diet plus quercetin), $T$ (control tomato paste) and TQ (quercetinglycoside enriched tomato paste). All values are expressed as mean \pm SEM. No significant differences have been found between the diet groups during 5 weeks intervention.

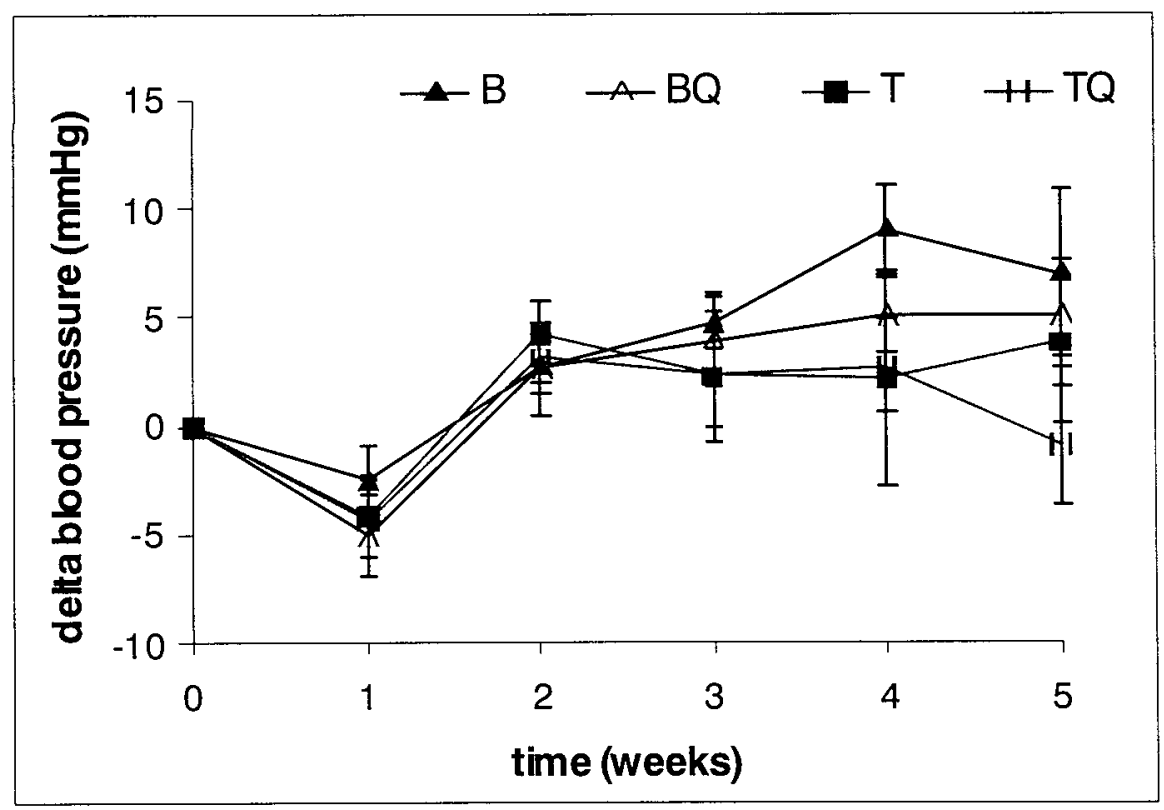


Diet BQ contains the same amount of quercetin as diet TQ, however, it is present in diet $\mathrm{BQ}$ as quercetin-aglycon and as quercetin-glycoside in diet TQ. Quercetin aglycon is reported to have a lower bioavailability than quercetine glucosides (Hollman and Katan, 1997) and this may have resulted in the smaller effect of diet BQ on blood pressure compared to that of diet TQ. Diet $T$ contains quercetin-glycosides but much less than diet $\mathrm{TQ}$, explaining the smaller effect of diet $\mathrm{T}$ compared to that of diet TQ. The heart rate is decreased in all diet groups after 5 weeks. The decrease in heart rate can be explained by the growth and ageing of the animals and is apparently not affected by the diets.

In our study no effect of the diet on the ex vivo contraction or endothelium dependent relaxation of the isolated aorta is found. In several other studies it is reported that flavonoids do enhance vasorelaxation ex vivo (Duarte, et al., 1993a, Duarte, et al., 1993b, Flesch, et al., 1998). An acute effect of the flavonoid, measured in these ex vivo studies, is not expected in our study, because in our study the flavonoid is administered to the rat and not added directly to the isolated aorta in the organ bath. Another reason may be the fact that the isolated aorta is washed in our study for $1 \mathrm{hr}$ before the contraction and relaxation is measured. This is performed to wash out vasoactive mediators, elicited by the excision and preparation. This procedure might also wash out quercetin and diminish a possible direct effect of the flavonoid. Differences in washing procedure might be responsible for the reported discrepancy between our and the ex vivo study of Duarte (2001). However next to the studies, reporting a vasorelaxative effect of quercetin, there are also studies describing results in line with our study (Chiesi and Schwaller, 1995, Cishek, et al., 1997, Heijnen, et al., 2000). In the isolated aorta of SHR Duarte et al. (Duarte, et al., 2001) reported a vasoconstricting effect of a relatively high concentration of acetylcholine when the NOS-inhibitor L-NAME is present. This effect of acetylcholine was almost not observed in normotensive rats. Although, the vasoconstrictor effect illustrated in our study by metacholine (+L-NAME) was slightly less than Duarte found in SHRs, both studies showed no difference between treatment groups.

In the study of Duarte et al. (2001) the administration of $10 \mathrm{mg}$ quercetin aglycon per $\mathrm{kg}$ body weight per day to SHRs for 5 weeks resulted in a dramatic decrease of mean $(-21 \%)$, systolic $(-18 \%)$, and diastolic $(-23 \%)$ blood pressure. 
Figure 2 The change in mean arterial blood pressure $(A)$, systolic $(B)$, and diastolic blood pressure $(C)$ and heart rate $(D)$ in week 5 of the rats receiving diet $B$ (control diet), $B Q$ (control diet plus quercetin), $T$ (control tomato paste) or TQ (quercetin-glycoside enriched tomato paste) for five weeks, relative to the baseline, is given. All values are expressed as mean $\pm S E M$, * is a significant increase, in a $t$-test $p<0.10$.

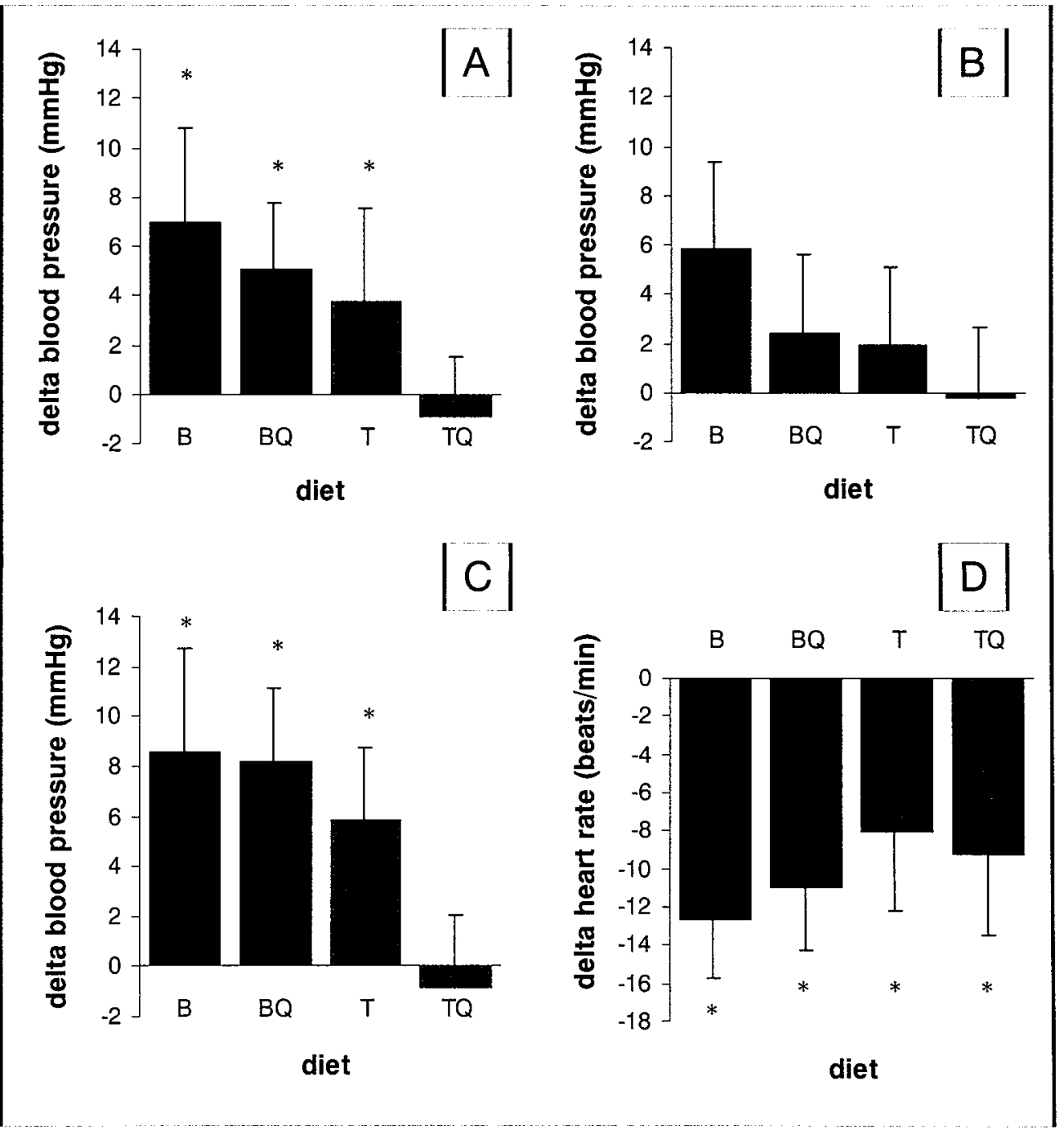


Figure 3 The endothelium dependent vascular
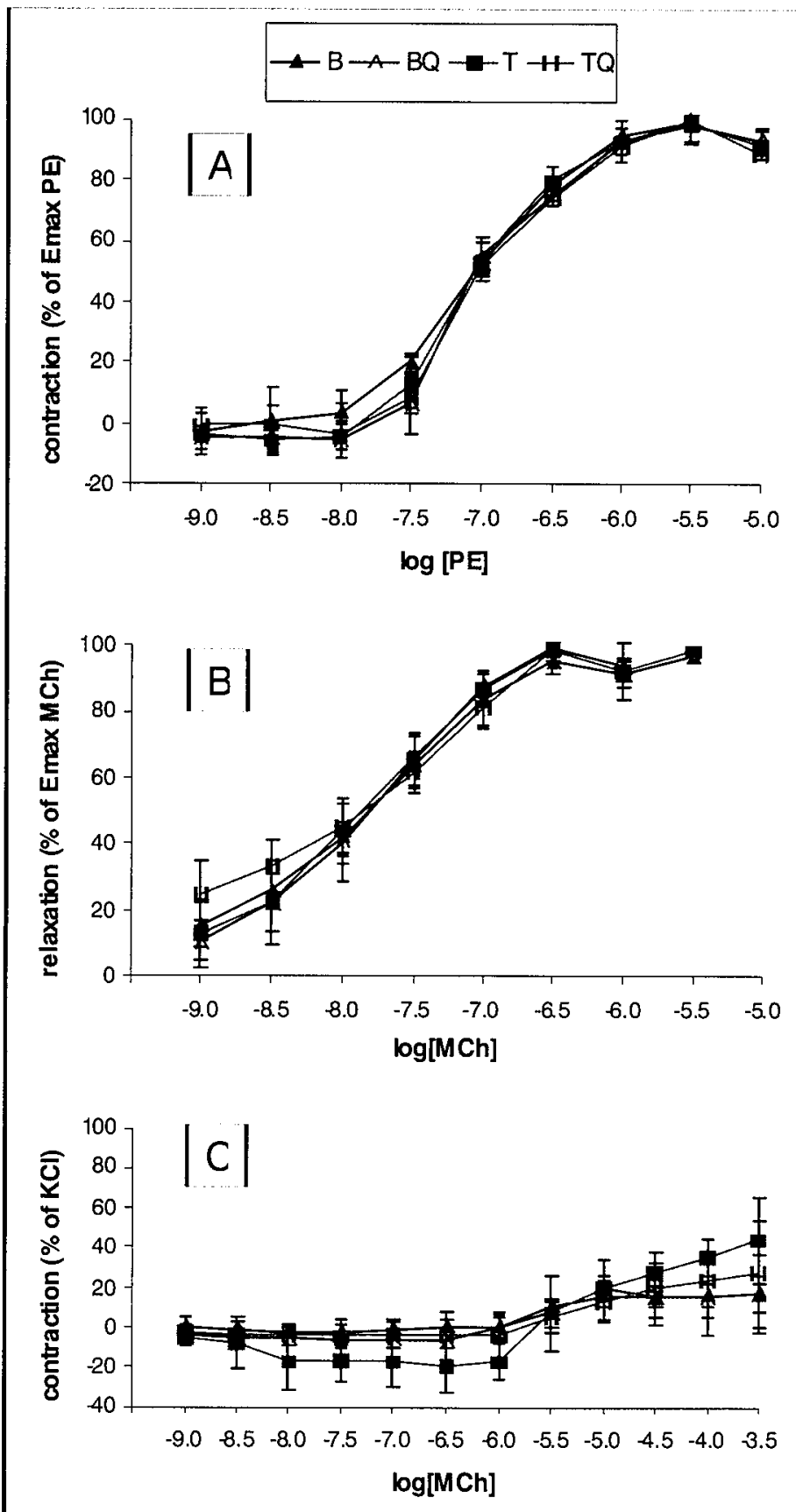

function of the isolated aorta of rats receiving a different diet: Panel $A$ is the contraction by (PE) $\left(10^{-9}-10^{-5} \mathrm{MPE}\right)$ as a percentage of the maximal contraction by $P E$. The $p D_{2}$ values are (diet $B, B Q, T$ and $T Q$, respectively): $7.04 \pm 0.03,7.04 \pm 0.08$, $7.04 \pm 0.10$ and $6.68 \pm$ 0.06 for $P E$. There are no significant differences between the diet groups. $P$ anel $B$ is the relaxation by metacholine $(\mathrm{MCh})$ $\left(10^{-9}-10^{-5} \mathrm{M} M \mathrm{Ch}\right)$ after contraction by $P E$ given as a percentage of the maximal relaxation by MCh. Panel $C$ is contraction by $M C h$ after incubation with L-NAME $\left(10^{-4} \mathrm{M}\right)$ for 30 min as a percentage of the maximal contraction by $\mathrm{KCl}(80 \mathrm{mM})$.

When the concentration of MCh exceeds $10^{-5} \mathrm{M}$ a minor (no receptorspecific) contraction is measured. All values are expressed as mean $\pm S D$. 
The large decrease in blood pressure Duarte et al. reported is not observed in our rats despite feeding them equivalent amounts of quercetin either as aglycon (diet $B Q$ ) or glycosides (diet TQ). In our study, only the increase in blood pressure, compared to baseline, is absent in the rats fed with the diet TQ (figure 2). This difference in the effect of the same dose of quercetin between the study of Duarte and our study might be explained by several differences in experimental procedure. The major differences are (i) the matrix and the chemical form of quercetin, (ii) the method for blood pressure measurements of the rats, and (iii) the baseline values of the blood pressure of the SHRs in our study were much lower than the blood pressure of the SHRs in the study of Duarte et al.

In the study of Duarte quercetin-aglycon was administered to the rats by gavage every day in a solution of $1 \%$ methylcellulose. In our study quercetin was incorporated in the diet (diet BQ and TQ). Quercetin was added as quercetin-aglycon to a flavonoid low diet (diet BQ), or was present as rutin and isoquercitrin in the GM tomato paste (diet TQ). The difference in matrix and chemical form might result in a different bioavailability of quercetin. The diet might reduce bioavailability by an interaction with different components in the semi-synthetic diet (Arts, et al., 2002). This can hamper the uptake of quercetin. In addition quercetin-glucosides (of which isoquercitrin is an example) present in diet $\mathrm{TQ}$ are suggested to have a better bioavailability than the aglycone, present in diet BQ and in the diet applied by Duarte et al.(Hollman, et al., 1997, Hollman and Katan, 1999, Shimoi, et al., 2003). The rationale for the manner of flavonoid administration we have chosen in our study is that enhancing the quercetin-glucoside content of the diet is the most practical and realistic way to increase the flavonoid intake of humans. In fruit and vegetables, flavonoids are predominantly present as glycosides.

Another fundamental difference between the study of Duarte and our study is found in the method applied to determine blood pressure. In the study of Duarte blood pressure was measured once a week with the tail-cuff method. The tail cuff measurement requires restraining of the rat, which causes stress. Stress is a factor that greatly influences the blood pressure. The telemetry method, applied by us, induces no stress in animals during the blood pressure measurement. In the experiment of Duarte et al. stress is also induced when the test compound is given by gavage in 
contrast to the stress free administration via a meal, as in our study.

The height of the baseline blood pressure might determine the magnitude of the lowering effect. The higher the hypertension the higher the absolute blood pressure lowering effect can be. Duarte et al. (2001) showed that normotensive rats do not show any blood pressure lowering effect due to administration of quercetin for 5-weeks. Although our rats were hypertensive (systolic blood pressure $\sim 180 \mathrm{mmHg}$ ), the rats in the study of Duarte had a higher blood pressure $(220 \mathrm{mmHg})$. The relatively low blood pressure in our study might be responsible for the much smaller effect observed in our study compared to that of the study of Duarte et al. A large observational study during 6-months with 690 subjects showed that the reduction in systolic and diastolic blood pressure induced by a high fruit and vegetables intake was merely 4 and $1.5 \mathrm{mmHg}$ (John, et al., 2002). This small reduction, however, is predicted to result in a decrease of about $17 \%$ in the incidence of hypertension, $6 \%$ in the risk of coronary heart disease, and $15 \%$ in the risk of stroke and transient ischaemic attack (Cook, et al., 1995). Thus, a subtle effect on blood pressure may have a drastic impact on health. The subtle effect of quercetin-glycoside enriched tomato paste on blood pressure observed in our study might therefore be of general importance for public health.

Acknowledgements: The authors like to thank the animal department team (CPV) of Maastricht University (Maastricht, The Netherlands) for all the technical support in this study, as well as Peter Murray (Unilever R\&D Colworth) for statistical support. 


\subsection{References}

Arts, M.J.T.J., Haenen, G.R.M.M., Wilms, L.C., Beetstra, S.A.J.N., Heijnen, C.G.M., Voss, H.P. and Bast, A., (2002) Interactions between flavonoids and proteins: effect on the total antioxidant capacity.

Journal of Agricultural and Food Chemistry 50 1184-1187.

Bravo, L., (1998) Polyphenols: chemistry, dietary sources, metabolism, and nutritional significance.

Nutrition Reviews 56 (11), 317-333.

Bugianesi, R., Catasta, G., Spigno, P., D’Uva, A. and Maiani, G., (2002) Naringenin from cooked tomato paste is bioavailable in men.

Journal of Nutrition 132 3349-3352.

Cherubini, A., Beal, M.F. and Frei, B., (1999) Black tea increases the resistance of human plasma to lipid peroxidation in vitro, but not ex vivo.

Free Radical Biology and Medicine 27 (3/4), 381-387.

Chiesi, M. and Schwaller, R., (1995) Inhibition of constitutive endothelial $\mathrm{NO}^{\bullet}$ synthase activity by tannin and Quercetin.

Biochemical Pharmacology 49 (4), 495-501.

Chopra, M., Fitzsimons, P.E., Strain, J.J., Thurnham, D.I. and Howard, A.N., (2000) Nonalcoholic red wine extract and quercetin inhibit LDL oxidation without affecting plasma antioxidant vitamin and carotenoid concentrations. Clinical Chemistry 46 (8 Pt 1), 1162-1170.

Cishek, M.B., Galloway, M.T., Karim, M., German, J.B. and Kappagoda, C.T., (1997) Effect of red wine on endothelium-dependent relaxation in rabbits. Clinical Science 93 507-511.

Cook, N.R., Cohen, J., Hebert, P.R., Taylor, J.O. and Hennekens, C.H., (1995) Implications of small reductions in diastolic pressure for primary prevention. Archives of Internal Medicin 155 701-709.

Duarte, J., Jimenez, R., O’Valle, F., Galisteo, M., Perez-Palencia, R., Vargas, F., Perez-Vizcaino, F., Zarzuelo, A. and Tamargo, J., (2002) Protective effects of the flavonoid quercetin in chronic nitric oxide deficient rats. Journal of Hypertension 20 (9), 1843-1854. 
Duarte, J., Pérez-Palencia, R., Vargas, F., Angeles Ocete, M., Pérez-Vizcaino, F., Zarzuelo, A. and Tamargo, J., (2001) Antihypertensive effects of the flavonoid quercetin in spontaneously hypertensive rats.

British Journal of Pharmacology 133 117-124.

Duarte, J., Perez-Vizcaino, F., Utrilla, P., Jiménez, J., Tamargo, J. and Zarzuelo, A., (1993a) Vasodilatory effects of flavonoids in rat aortic smooth muscle. Structure-activity relationships. General Pharmacology 24 (4), 857-862. Duarte, J., Perez-Vizcaino, F., Zarzuelo, A., Jimenez, J. and Tamargo, J., (1993b) Vasodilator effects of quercetin in isolated rat vascular smooth muscle. European Journal of Pharmacology 239 (1-3), 1-7.

Flesch, M., Schwarz, A. and Böhm, M., (1998) Effects of red and white wine on endothelium-dependent vasorelaxation of rat aorta and human coronary arteries. American Journal of Physiology 275 H1183-H1190.

Formica, J.V. and Regelson, W., (1995) Review of the biology of Quercetin and related bioflavonoids. Food and Chemical Toxicology 33 (12), 1061-1080.

Grinberg, L., Newmark, H., Kitrossky, N., Rahamim, E., Chevion, M. and Rachmilewitz, E., (1997) protective effects of tea polyphenols against oxidative damage to red blood cells.

Biochemical Pharmacology 54 973-978.

Hegarty, V.M., May, H.M. and Khaw, K.T., (2000) Tea drinking and bone mineral density in older women.

American Journal of Clinical Nutrition 71 (1003-1007),

Heijnen, C.G., Haenen, G.R., Oostveen, R.M., Stalpers, E.M. and Bast, A., (2002) Protection of flavonoids against lipid peroxidation: the structure activity relationship revisited. Free Radical Research 36 (5), 575-581.

Heijnen, C.G.M., Haenen, G.R.M.M., Vekemans, J.A.J.M. and Bast, A., (2001) Peroxynitrite scavenging of flavonoids: Structure activity relationship. Environmental Toxicology and Pharmacology 10 (4), 199-206.

Heijnen, C.G.M., Haenen, G.R.M.M., Wiseman, S.A., Tijburg, L.B.M. and Bast, A., (2000) The interaction of tea flavonoids with the NO ${ }^{\circ}$-system:

discrimination between good and bad $\mathrm{NO}^{\circ}$.

Food Chemistry 70 (3), 365-370. 
Heo, M.Y., Sohn, S.J. and Au, W.W., (2001) Anti-genotoxicity of galangin as a cancer chemopreventive agent candidate.

Mutation Research 488 (2), 135-150.

Hollman, P.C. and Katan, M.B., (1997) Absorption, metabolism and health effects of dietary flavonoids in man. Biomedical Pharmacotherapy 51 (8), 305-310.

Hollman, P.C., van Trijp, J.M., Buysman, M.N., van der Gaag, M.S., Mengelers, M.J., de Vries, J.H. and Katan, M.B., (1997) Relative bioavailability of the antioxidant flavonoid quercetin from various foods in man. FEBS Letters 418 (1-2), 152-156.

Hollman, P.C.H. and Katan, M.B., (1999) Dietary flavonoids: Intake, health effects and bioavailability. Food and Chemical Toxicology 37 (9-10)), 937-942.

Irvine, R.J., White, J. and Chan, R., (1997) The influence of restraint on blood pressure in the rat. Journal of Pharmacological and Toxicological Methods 38 (3), 157-162.

John, J.H., Ziebland, S., Yudkin, P., Roe, L. and Neil, H., (2002) Effects of fruit and vegetable consumption on plasma antioxidant concentrations and blood pressure: a randomised controlled trail. Lancet 359 1969-1974.

Jouad, H., Lacaille-Dubois, M.A., Lyoussi, B. and Eddouks, M., (2001) Effects of the flavonoids extracted from Spergularia purpurea Pers. on arterial blood pressure and renal function in normal and hypertensive rats. Journal of Ethnopharmacology 76 159-163.

Knekt, P., Jarvinen, R., Reunanen, A. and Maatela, J., (1996) Flavonoid intake and coronary mortality in Finland: a cohort study.

British Medical Journal 312 (7029), 478-481.

Kono, Y., Kobayashi, K., Tagawa, S., Adachi, K., Ueda, A., Sawa, Y. and Shibata, H., (1997) Antioxidant activity of polyphenolics in diets. Rate constants of reactions of chlorogenic acid and caffeic acid with reactive species of oxygen and nitrogen. Biochimica et Biophysica Acta 1335 (3), 335-342.

Muir, S.R., Collins, G.J., Robinson, S., Hughes, S., Bovy, A., Vos, C.H.D., Tunen, A.J.v. and Verhoeyen, M.E., (2001) Overexpression of petunia chalcone isomerase in tomato results in fruit containing increased levels of flavonols. Nature Biotechnology 19 470-474. 
Nijveldt, R.J., van Nood, E., van Hoorn, D.E., Boelens, P.G., van Norren, K. and van Leeuwen, P.A., (2001) Flavonoids: a review of probable mechanisms of action and potential applications.

American Journal of Clinical Nutrition 74 (4), 418-425.

Shimoi, K., Yoshizumi, K., Kido, T., Usui, Y. and Yumoto, T., (2003) Absorption and Urinary Excretion of Quercetin, Rutin, and alphaG-Rutin, a Water Soluble Flavonoid, in Rats.

Journal of Agricultural and Food Chemistry 51 (9), 2785-2789.

Trichopoulou, A. and Vasilopoulou, E., (2000) Mediterranean diet and longevity. British Journal of Nutrition 84 Suppl 2 S205-209.

Van Vliet, B.N., Chafe, L.L., Antic, V., Schnyder-Candrian, S. and Montani, J.P., (2000) Direct and indirect methods used to study arterial blood pressure. Journal of Pharmacological and Toxicological Methods 44 (2), 361-373.

Willcox, J.K., Catignani, G.L. and Lazarus, S., (2003) Tomatoes and cardiovascular health. Critical Reviews in Food Science and Nutrition 43 (1), 1-18.

World Health Organisation, I.S.o.H.W.G., (2003) 2003 World Health Organisation (WHO) / International Society of Hypertension (ISH) statement on management of hypertension. Journal of Hypertension 21 (11), 1983-1992. 



\section{Chapter 7}

Summary and general discussion 



\subsection{Summary and general discussion}

Fat, carbohydrate, and protein are the established nutrients in our food. Next to these nutrients other bioactive compounds can be found in our diet. Flavonoids form a large group of these bioactive ingredients, which have gained much attention lately. Approximately 4000 chemically different structures have been identified within this group. They can be divided in several subgroups according to their backbone: flavones, flavonols, flavanones, flavanols, anthocyanidins, chalcones and isoflavonoids. The daily intake of flavones and flavonols is estimated to be approximately 20-28 mg.

Flavonoids are considered to protect against several diseases, including cardiovascular diseases. In cardiovascular disorders, as hypertension and atherosclerosis, oxidative stress plays a pivotal role in the etiology of the disorders. In the cardiovascular system $\mathrm{NO}^{\circ}$ and $\mathrm{NO}^{\circ}$-related processes ( $\mathrm{NO}^{\circ}$-system) can, next to their regulatory role, disturb the homeostasis because it might be involved in oxidative metabolism. In many studies the heterogeneous group of flavonoids has been studied in relation to $\mathrm{NO}^{\circ}$ and the detrimental effects of the $\mathrm{NO}^{\circ}$-system. It is generally accepted that the antioxidant properties of flavonoids are involved in their protective effects. The protective ability of a flavonoid can be determined by measuring the activity of the flavonoid in isolated processes, such as the modulation of $\mathrm{NO}^{\circ}$-production, $\mathrm{NO}^{\circ}$ scavenging, $\mathrm{O}_{2}{ }^{\bullet-}$ scavenging, peroxynitrite scavenging, and inhibition of lipid peroxidation. The antioxidant properties, within the $\mathrm{NO}^{-}$-system, of specific flavonoids are investigated in this thesis.

Tea is a flavonoid-rich product commonly consumed all over the world. In some countries, tea is a large source for the daily flavonoid intake (61\% of the flavonoid intake). Black and green tea were tested for their ability to discriminate between good and bad $\mathrm{NO}^{\circ}$ (chapter 2 ). $\mathrm{NO}^{\circ}$ can react with $\mathrm{O}_{2}{ }^{--}$to form the cytotoxic compound peroxynitrite (bad $\mathrm{NO}^{\circ}$ ). Both black and green tea appeared to be good scavengers of peroxynitrite. Green tea was a slightly better scavenger. $\mathrm{NO}^{\bullet}$ itself is also scavenged by the flavonoids from both teas. $\mathrm{NO}^{\circ}$ can elict vasorelaxation in the aorta. However, no enhancement of the vasorelaxation was seen in the isolated aorta 
by flavonoids from tea. The maximal $\mathrm{NO}^{\circ}$-dependent relaxation was not influenced by flavonoids, because the response to the $\mathrm{NO}^{\circ}$-donor (sodium nitroprusside) was not affected in the presence of these flavonoids.

Various studies in literature (Benito, et al., 2002, Duarte, et al., 1993) report on a vasorelaxing activity of flavonoids and flavonoid containing products like tea and wine, although also other effects have been reported (Chiesi and Schwaller, 1995, Heijnen, et al., 2000). Apparently, the results seem to be contradictory and inconclusive. It should be noted that even in an in vitro experiment on a well defined organ as the aorta a very large variability between different laboratories is expected due to differences in e.g. age, strain, feeding and handling of the animal the organ is obtained from, the procedure used to isolate and prepare the organ and the conditions of the experimental set-up. In addition, a relatively high concentration of flavonoid is needed to elicit effects in contraction and relaxation. This can lead to non-physiological reactions in the organ bath, e.g. flavonoids are known to bind aspecifically to proteins. Furthermore, when a mixture of several flavonoids is tested (as tea and wine), different compounds might have simultaneously positive or negative effects on vasorelaxation. This may be a reason for contradicting results obtained in studies on the protective role of flavonoids on vasorelaxation in in vitro experiments.

Flavones are a subgroup of flavonoids with potent antioxidant activity. They are abundantly present in the diet. The activity of several flavones and flavonols to scavenge peroxynitrite is determined (chapter 3). By relating chemical structure to activity, structural elements are recognized that are important in peroxynitrite scavenging. The $\mathrm{OH}$ group at the 3-position appeared to play an important role. However 3-hydroxy-flavone and TUM 9761, a compound with only an OH group at the 3 position, were only slightly active. It was suggested that next to the $3-\mathrm{OH}$ group, the $\mathrm{OH}$ groups at the 5 and 7 position are important because they enhance the peroxynitrite scavenging activity of the $3-\mathrm{OH}$ group.

To further investigate the structure activity relationship of peroxynitrite scavenging by flavones (chapter 4), the backbone was first simplified to a simple phenol. The Topliss-approach was used to check for lipophilic, electronic and steric effects of 
substituents on peroxynitrite scavenging activity. The electronic parameter appeared to be the most important one. An excellent correlation between the Hammett sigma (a parameter expressing the electron donating effect) of the substituent and the peroxynitrite scavenging activity was found. This structure activity relationship was translated to the flavones. It was concluded that within the flavones two relatively independent centres with peroxynitrite scavenging activity occur. One pharmacophore is the catechol moiety in ring $\mathrm{B}$ and the second pharmacophore is the $3-\mathrm{OH}$ in ring $\mathrm{C}$ with the presence of electron donating groups at the 5- and/ or 7-position. To investigate whether this structure-activity relationship of peroxynitrite scavenging by flavones is predictive for other antioxidant activities, the inhibition of lipid peroxidation by phenols and flavones was determined (chapter 5). Although lipophilicity was expected to be involved in this antioxidant activity, it appeared to play an insignificant role. The structure-activity relationship of the protection against lipid peroxidation by phenols or flavones is similar to that of peroxynitrite scavenging. With these structure-activity relationships it is possible to identify the active centre in phenolic compounds. Furthermore, the revealed characteristics of structural elements can give information to unravel molecular mechanism of the tested activities. In both processes, inhibition of lipid peroxidation and peroxynitrite scavenging, electron or proton donation by flavonoids is important in the mechanism of action. Moreover the structure-activity relationships might be important in the development of new active compounds in peroxynitrite scavenging or inhibition of lipid peroxidation. Tetra-O-methyl-quercetin was designed according to the structure-activity relationship conducted in chapter 4 . In both tested activities this compound had the expected activity.

From these structure-activity relationship studies, it is deduced that the antioxidant activity of flavonoids is directed to a special moiety of the molecule. In flavones and flavonols two antioxidant moieties can be discerned, firstly the catechol moiety in ring $\mathrm{B}$ and secondly the $3-\mathrm{OH}$ in ring $\mathrm{C}$ with the presence of electron donating groups at the 5- and / or 7-position. The pharmacophores can be separately present in different molecules, such as rutin (first pharmacophore) or galangin (second pharmacophore). Also both active centres can exist in one molecule, such as quercetine. 
The presence of more than one pharmacophore in flavonoids is probably the reason why structure-activity relationships described earlier are ambiguous. It should be noted that these pharmacophores are intertwined.

In pharmacology, a moiety in a drug that is responsible for its biological activity is labelled as "pharmacophore". Several drugs are known to contain more than one pharmacophore. In analogy to pharmacology, we have called the active antioxidant moieties we discovered in flavones and flavonols also "pharmacophores". However, a flavonoid is not a drug, it is an ingredient of our diet. It would therefore be more appropriate to use another label in nutrition as "pharmacophore". We would, therefore, like to introduce the term "nutricophore" to describe the bioactive part of the molecule responsible for the positive health effect of a specific nutrient. Compared to the label "pharmacophore", "nutricophore" more accurately reflects the nature of such a bioactive moiety i.e. the nutricophore mediates the beneficial health effect of a specific nutrient.

In the last chapter, a flavonoid-enriched product, tomato paste, is investigated for its beneficial health effect in a model for essential hypertension (chapter 6). The overexpression of the chalcone isomerase gene in the tomato fruits used in this study has led to a 78-fold increased production of quercetin glucosides in the peel. After 5 weeks of feeding a genetically modified tomato paste or one of the control diets (normal tomato paste, semi-synthetic low-flavonoid diet, or semi-synthetic with added quercetine) the blood pressure lowering effect of flavonoid enriched tomato paste was not statistically significant in an overall test. However, the data per diet group show a significant increase $(7 \mathrm{mmHg})$ in blood pressure in the rats consuming the semi-synthetic low-flavonoid diet after 5 weeks. This increase was not observed in the rats receiving the flavonoid-enriched diet the blood pressure was stable during 5 weeks.

Thus a small positive effect of flavonoids on blood pressure appears to be present in this rat study. A high flavonoid intake can be reached by the high intake of fruit and vegetables via our diet. In a large observational study during 6-months with 690 subjects a high fruit and vegetables intake induced a reduction in systolic and diastolic 
blood pressure of merely 4 and $1.5 \mathrm{mmHg}$ (John, et al., 2002). Such a small reduction of blood pressure already has a substantial positive impact on several cardiovascular conditions. A reduction of only $2 \mathrm{mmHg}$ results in a decrease of about $17 \%$ in the incidence of hypertension, $6 \%$ in the risk of coronary heart disease, and $15 \%$ in the risk of stroke and transient ischaemic attack (Cook, et al., 1995). Therefore a highflavonoid tomato will contribute to a healthy diet. A limited reduction in blood pressure by a flavonoid rich diet, as shown in this study, might be of general importance for public health.

\subsection{Conclusions}

* Flavonoids can protect efficiently against peroxynitrite in vitro.

* Tea, containing several flavonoids, does not enhance the $\mathrm{NO}^{\circ}$-dependent relaxation of the rat aorta in vitro.

* Two nutricophores in peroxynitrite scavenging activity can be pointed out in flavones and flavonols: the catechol moiety in ring $\mathrm{B}$ and the 3-OH with electron donating substituents at position 5 and /or 7 .

* The same nutricophores as in peroxynitrite scavenging are present in inhibition of lipid peroxidation.

* After 5 weeks of supplementation with flavonol-enriched tomato paste a decreased trend was found in blood pressure of spontaneously hypertensive rats compared to the controls.

\subsection{Implications}

To combine the $\mathrm{NO}^{\circ}$-system with flavonoids is a complex challenge. Firstly, several $\mathrm{NO}^{\circ}$ - related processes are involved in cardiovascular health. Secondly, the flavonoids forma heterogenous group with very different, even some contradictive, activities. The structure-activity relationship of flavones, in peroxynitrite scavenging as well as in inhibition of lipid peroxidation, has led to the identification of two separate nutricophores. The two nutricophores found will help us to better understand and 
predict the biological effects of flavonoids.

In general, a health effect of alimentary compounds is subtle compared to that of drugs. Nevertheless, the final result of dietary compounds might be more important than that of drugs, because the lifetime exposure to nutrients is much longer than the exposure to drugs. Moreover, drugs are usually taken once a pathology has become manifest. Nutrition is better suited to prevent diseases. This means that the prevention by the flavonoid-rich tomato of the increase in blood pressure we observed in spontaneously hypertensive rats might have a substantial impact. Another difference between drugs and nutrients is that of nutrients our knowledge on the molecular mechanism of action usually is limited. The molecular mechanism, including bioavailability and metabolism, has to be studied thoroughly before a drug can be registered for human use. In contrast, for most nutrients this knowledge is almost completely lacking. Nevertheless, nutrients are consumed by a large population and frequently taken in a relatively high dose in supplements. Most of the evidence on the beneficial health effect of food components is derived from epidemiological studies that only relate the effect to the intake of certain types of food. Based on these observations, attempts are being made to increase the content of compounds that are associated with good health in our diet, e.g. by means of genetic manipulation of fruits and vegetables. At the moment the general public is very critical towards these products.

Understanding the molecular mechanisms responsible for the beneficial effects of nutrients and the identification of nutricophores will have several benefits. Firstly, health-promoting ingredients in the diet can be identified and foods that contain these products in a sufficient quantity can be designed. Moreover, knowledge of the general public on how health effects by certain types of nutrients are achieved will increase the acceptance and consumption of products that contain these compounds. In this way knowledge on the molecular mechanism and identification of nutricophores forms the fundament of good health of people. 


\subsection{References}

Benito, S., Lopez, D., Saiz, M.P., Buxaderas, S., Sanchez, J., Puig-Parellada, P. and Mitjavila, M.T., (2002) A flavonoid-rich diet increases nitric oxide production in rat aorta. British Journal of Pharmacology 135 (4), 910-916.

Chiesi, M. and Schwaller, R., (1995) Inhibition of constitutive endothelial $\mathrm{NO}^{\circ}$-synthase activity by tannin and Quercetin.

Biochemical Pharmacology 49 (4), 495-501.

Cook, N.R., Cohen, J., Hebert, P.R., Taylor, J.O. and Hennekens, C.H., (1995)

Implications of small reductions in diastolic pressure for primary prevention. Archives of Internal Medicin 155 701-709.

Duarte, J., Perez-Vizcaino, F., Zarzuelo, A., Jimenez, J. and Tamargo, J., (1993)

Vasodilator effects of quercetin in isolated rat vascular smooth muscle.

European Journal of Pharmacology 239 (1-3), 1-7.

Heijnen, C.G.M., Haenen, G.R.M.M., Wiseman, S.A., Tijburg, L.B.M. and Bast, A., (2000) The interaction of tea flavonoids with the $\mathrm{NO}^{\circ}$-system:

discrimination between good and bad NO ${ }^{\circ}$. Food Chemistry 70 (3), 365-370.

John, J.H., Ziebland, S., Yudkin, P., Roe, L. and Neil, H., (2002) Effects of fruit and vegetable consumption on plasma antioxidant concentrations and blood pressure: a randomised controlled trail. Lancet 359 1969-1974. 



\section{Chapter 8}

Samenvatting en algemene discussie 



\subsection{Samenvatting en algemene discussie}

Vetten, koolhydraten en eiwitten zijn bekende nutriënten in onze voeding. Naast deze nutriënten bevat onze voeding ook nog andere bioactieve componenten. Een groot aantal van deze bioactieve componenten vormen de groep flavonoïden, waar de laatste tijd veel aandacht op is gericht. Ongeveer 4000 chemisch verschillende structuren zijn geïdentificeerd binnen deze groep. De structuren kunnen onderverdeeld worden afhankelijk van de uitgangsstructuur in enkele subgroepen: flavonen, flavonolen, flavanonen, flavanolen, anthocyanidinen, chalconen en isoflavonoïden. De dagelijkse inname van flavonen en flavonolen is geschat op ongeveer 20 tot 28 mg.

Flavonoïden worden beschouwd als stoffen die bescherming bieden tegen enkele ziektebeelden, zoals cardiovasculaire ziekten. In de etiologie van cardiovasculaire aandoeningen, bijvoorbeeld hypertensie en atherosclerose, speelt oxidatieve stress een belangrijke rol. In het cardiovasculaire systeem spelen $\mathrm{NO}^{\bullet}$ en $\mathrm{NO}^{\bullet}$ - gerelateerde processen ( $=$ het $\mathrm{NO}^{\circ}$-systeem) een sturende rol maar kunnen ook de homeostase verstoren doordat ze betrokken zijn bij de oxidatieve stress.

In vele studies zijn de flavonoïden bestudeerd in relatie tot $\mathrm{NO}^{\bullet}$ en de verstorende effecten van $\mathrm{NO}^{\circ}$. Het is algemeen geaccepteerd dat de antioxidant eigenschappen van flavonoïden een rol spelen in hun beschermende effecten. De mogelijke bescherming door een flavonoïd kan worden bepaald door het meten van de activiteit van de flavonoïd in geïsoleerde processen, zoals moduleren van $\mathrm{NO}^{\circ}$-productie, het wegvangen van $\mathrm{NO}^{\bullet}$ of $\mathrm{O}^{*}$ of peroxynitriet en het remmen van lipide peroxidatie. De antioxidatieve eigenschappen van specifieke flavonoïden in relatie tot het $\mathrm{NO}^{\circ}$ systeem zijn onderzocht in dit proefschrift.

Thee is een flavonoïd-rijk product dat veel gebruikt wordt over de hele wereld. In sommige landen is thee de grootste bron voor de flavonoïden inname (61\% van de totale flavonoïd inname). Zwarte en groene thee zijn getest om na te gaan of dat ze onderscheid konden maken tussen goed en slecht $\mathrm{NO}^{\bullet}$ (Hoofdstuk 2). $\mathrm{NO}^{\bullet}$ kan reageren met $\mathrm{O} 2{ }^{\bullet-}$ en vormt hierbij de cytotoxische component peroxynitriet (slecht $\mathrm{NO}^{\circ}$ ). Beide soorten thee, zwart en groen, bleken peroxynitriet goed weg te vangen. 
Groene thee bleek iets beter te zijn dan zwarte. $\mathrm{NO}^{\bullet}$ zelf wordt ook weggevangen door de flavonoïden in de beide soorten thee. $\mathrm{NO}^{\bullet}$ kan vaso-relaxatie veroorzaken in de aorta. Een stimulatie van de vasorelaxatie door flavonoïden uit thee werd echter niet gevonden in de geïsoleerde aorta. De maximale $\mathrm{NO}^{\circ}$-afhankelijke relaxatie werd niet beïnvloed door flavonoïden, omdat de reactie op de $\mathrm{NO}^{\bullet}$-donor (natrium nitroprusside) niet beïnvloed werd door toevoeging van deze flavonoïden.

Verscheidene studies uit de literatuur (Benito, et al., 2002, Duarte, et al., 1993) rapporteren een vasorelaxerend effect door flavonoïden en producten die flavonoïden bevatten, zoals wijn en thee. Maar er zijn ook studies die andere effecten beschrijven (Chiesi and Schwaller, 1995, Heijnen, et al., 2000). De resultaten lijken elkaar tegen te spreken. Er moet op gewezen worden dat zelfs in een in vitro experiment met een goed gedefinieerd orgaan als de aorta een grote variabiliteit tussen laboratoria wordt verwacht. Deze variabiliteit kan komen door verschillen in o.a. leeftijd, soort, voeding en omgang van / met de dieren waarvan het orgaan wordt genomen. Ook kunnen er verschillen zijn in de procedure om het orgaan te isoleren en te prepareren en de experimentele opzet. Ook is een relatief hoge concentratie van flavonoïden nodig voor effecten op de relaxatie of contractie van de aorta. Dit kan leiden tot niet-fysiologische reacties in het orgaanbad, bijvoorbeeld aspecifieke binding van flavonoïden aan eiwitten. Bovendien kunnen bij het testen van complexe mengsels (zoals thee en wijn) verschillende componenten op hetzelfde moment positieve en negatieve effecten hebben op de vasorelaxatie. Dit alles kunnen redenen zijn voor de tegensprekende resultaten verkregen in studies naar de beschermende rol van flavonoïden in vasorelaxatie in in vitro experimenten.

Flavonen vormen een subgroep van flavonoïden met potente antioxidatieve activiteit. Ze zijn in hoge mate aanwezig in het dagelijkse dieet. De mate waarin verscheidene flavonen en flavolen peroxynitriet wegvangen is bepaald (hoofdstuk 3 ). Door de chemische structuur te relateren aan activiteit kunnen structuurelementen worden herkend die een belangrijke rol spelen in het wegvangen van peroxyniytriet. De OH groep op de 3-positie bleek een belangrijke rol te spelen. De stoffen 3-hydroxy-flavone en TUM 9761, met alleen een OH groep op de 3-positie, hadden echter 
beiden een lage activiteit. Wij suggereerden daarom dat naast de 3-OH groep ook de 5- en 7-OH groep van belang zijn en de activiteit van de 3-OH groep versterken. Om de structuur activiteits relatie van het wegvangen van peroxynitriet door flavonen en flavonolen verder te bestuderen (hoofdstuk 4), werd de uitgangsstructuur vereenvoudigd tot een fenol. De Topliss benadering is gebruikt om lipofiliteits-, electronische en sterische effecten van substituenten op de activiteit te onderzoeken. De electronische parameter bleek het meest bepalend te zijn voor de mate van wegvangen van peroxynitriet. Een zeer goede correlatie werd gevonden tussen de Hammett sigma (een parameter die het electrondonerende effect uitdrukt) van de substituent en de mate van peroxynitriet wegvangen. Hierna werd de structuuractiviteitsrelatie van fenolen vertaald naar de flavonen en flavonolen. Er kon worden geconcludeerd dat binnen de groep van flavonen en flavonolen twee relatief onafhankelijke centra zijn aan te wijzen die zorgen voor het wegvangen van peroxynitriet. De eerste farmacofoor is de catecholgroep in ring $\mathrm{B}$ en de tweede farmacofoor is de $3-\mathrm{OH}$ in ring $\mathrm{C}$ met de aanwezigheid van electrondonerende groepen op de 5- enof 7-positie. Om te onderzoeken of deze structuuractiviteitsrelatie met betrekking tot het wegvangen van peroxynitriet door flavonen en flavonolen ook toe te passen is op andere antioxidatieve activiteiten, werd de remming van de lipideperoxidatie door fenolen en flavonen en flavonolen bepaald (hoofdstuk 5). Alhoewel verwacht werd dat lipofiliteit een belangrijke rol zou spelen in deze remming, is gebleken dat deze parameter een niet-significante bijdrage leverde aan de activiteit. De structuuractiviteitsrelatie met betrekking tot de bescherming tegen lipideperoxidatie door fenolen en flavonen en flavonolen is gelijk aan die met betrekking tot het wegvangen van peroxynitriet. Met deze structuuractiviteitsrelaties is het mogelijk om actieve centra in fenolische moleculen te identificeren. Bovendien kan het inzicht geven in de specifieke eigenschappen van structuurelementen, waardoor de moleculaire mechanismen van de geteste activiteiten kunnen worden ontrafeld. In beide, geteste processen (remming van lipide peroxidatie en wegvangen van peroxynitriet) is electron-, of protondonatie door flavonoïden een belangrijk aspect in het mechanisme. Verder kan een structuuractiviteitsrelatie een belangrijke rol spelen in de ontwikkeling van nieuwe actieve stoffen. Tetra-O-methyl-quercetine is ontworpen naar aanleiding van de structuuractiviteitsrelatie zoals beschreven in hoofstuk 4 . In de beide geteste activiteiten had 
deze stof de verwachte activiteit.

Uit deze studies naar structuuractiviteitsrelaties kan worden opgemaakt dat de antioxidatieve werking van flavonoïden kan worden toegeschreven aan een speciaal element in het molecuul. In flavonen en flavonolen kunnen twee antioxidant elementen onderscheiden worden. Ten eerste de catecholgroep in ring $\mathrm{B}$ en ten tweede de $3-\mathrm{OH}$ in ring $\mathrm{C}$ met de aanwezigheid van electrondonerende groepen op de 5- en/of 7-positie. De farmacoforen kunnen apart aanwezig zijn in een flavonoïd, zoals rutine (eerste farmacofoor) of galangin (tweede farmacofoor). Beide actieve centra kunnen ook tegelijkertijd in een flavonoïd voorkomen, zoals in quercetine. De aanwezigheid van meer dan één farmacofoor is waarschijnlijk de reden dat de eerdere structuuractiviteitsrelaties niet eenduidig zijn. het moet worden opgemerkt dat de twee farmacoforen niet geheel onafhankelijk zijn.

In de farmacologie noemt men een structuurelement in een geneesmiddel, dat verantwoordelijk is voor een biologische activiteit een "famacofoor". Verscheidene medicijnen bevatten meer dan één farmacofoor. In analogie met de farmacologie hebben we de actieve antioxidant centra in de flavonoïden ook farmacoforen genoemd. Een flavonoïd is echter geen geneesmiddel maar een ingrediënt van ons dieet. Het is daarom toepasselijker om een andere term te gebruiken dan farmacofoor. De term "nutricofoor" willen we dan ook introduceren om het bioactieve deel van het molecuul te benoemen, dat verantwoordelijk is voor de positieve gezondheidseffecten. Vergelijkend met het label "farmacofoor" weerspiegelt "nutricofoor" beter de aard van het bioactieve deel van het molecuul: Nutricofoor refereert naar een specifiek structuurelement dat verantwoordelijk is voor een bepaald positief gezondheidseffect van een nutriënt.

In het laatste hoofdstuk wordt een studie beschreven waarin een product, tomatenpuree verrijkt met flavonoïden, onderzocht wordt op een gezondheidseffect in een model voor essentiële hypertensie (hoofdstuk 6). De overexpressie van het gen chalcone isomerase in de tomaten, die gebruikt worden in deze studie, heeft tot een verhoging (78x) van de productie van quercetine glucoside geleid in de schil. De ratten kregen 5 weken genetisch gemodificeerde tomatenpuree of een van de controlediëten 
(normale tomatenpuree, semi-synthetisch laag-flavonoïden dieet of het semi-synthetisch dieet met quercetine). Na deze periode was het bloeddruk verlagend effect van flavonoïd-verrijkte tomatenpuree niet significant in een test met alle groepen. Echter de gegevens per dieet-groep lieten een significante stijging zien $(7 \mathrm{mmHg})$ van de bloeddruk na 5 weken in de ratten die semi-synthetische laag-flavonö̈den dieet kregen. Deze stijging was niet te zien in de ratten die de flavonoïd-verrijkte tomatenpuree aten. In deze groep was de bloeddruk stabiel.

Dus een klein positief effect van flavonoïd-rijk dieet op de bloeddruk is aanwezig in deze rattenstudie. Een hoge inname van flavonoïden kan verkregen worden door een hoge inname van fruit en groente. In een grote 6-maanden observatie studie met 690 personen induceerde een hoge groente en fruit inname een reductie van systolische en diastolische bloeddruk met respectievelijk 4 en $1.5 \mathrm{mmHg}$ (John, et al., 2002).

Deze kleine reductie van bloeddruk kan al een substantiële positieve invloed hebben op cardiovasculaire condities. Een reductie van de bloeddruk van maar $2 \mathrm{mmHg}$ resulteert in een verlaging van de incidentie van hypertensie met $17 \%$ en een verlaging van het risico op coronaire hartschade en $15 \%$ verlaging van risico op ischemie (Cook, et al., 1995). Om deze redenen zal een flavonoïd-verrijkte tomaat een bijdrage kunnen leveren aan een gezonder dieet. Een beperkte reductie van de bloeddruk door een flavonoïd-rijk dieet, zoals beschreven in deze studie, zal van algemeen belang zijn voor de volksgezondheid.

\subsection{Conclusies}

* Flavonoïden kunnen beschermen tegen peroxynitriet in vitro.

* Thee, waarin verscheidene flavonoïden voorkomen, verhoogt niet de $\mathrm{NO}^{*}$-afhankelijke relaxatie van de aorta van de rat in vitro.

* Twee nutricoforen voor het wegvangen van peroxynitriet kunnen worden aangewezen in flavonen en flavonolen: de catecholgroep in ring $\mathrm{B}$ en de 3-OH met electrondonerende groepen op de 5-en/of 7-positie.

* Dezelfde nutricoforen als voor het wegvangen van peroxynitiet zijn aanwezig in de remming van lipideperoxidatie. 
* Na 5 weken van supplemetatic met een flavonol-rijke tomatenpuree, een trend van verlaging werd gezien in de bloeddruk van spontaan hypertensieve ratten vergeleken met de dieren die een controledieet kregen.

\subsection{Implicaties}

Om een $\mathrm{NO}^{\bullet}$-systeem gunstig te beïnvloeden met flavonoïden is een complexe uitdaging. Allereerst zijn er verscheidene $\mathrm{NO}^{\bullet}$-gerelateerde processen betrokken bij de gezondheid van hart en vaten. Verder vormen de flavonoïden een heterogene groep mate vele verschillende, en soms ook tegenwerkende, activiteiten. De structuuractiviteitsrelaties van flavonen en flavonolen met betrekking tot het wegvangen van peroxynitriet en remming van lipideperoxydatie, hebben geleid tot de identificatie van twee aparte nutricoforen. De identificatie van deze twee nutricoforen is van belang voor het begrijpen en voorspellen van biologische effecten van flavonoïden. In het algemeen zijn de gezondheidseffecten van bioactieve stoffen in de voeding subtiel in vergelijking met die van geneesmiddelen. Desalniettemin, zou een eindresultaat van componenten in het dieet wel eens belangrijker kunnen zijn dan het effect van geneesmiddelen, doordat de levenslange blootstelling aan nutriënten langer is dan de blootstelling aan de meeste geneesmiddelen. Bovendien worden geneeesmiddelen pas voor geschreven als een aandoening zich manifesteert. Voeding is een middel om ziekten te voorkomen. Dit betekent dat de preventie van stijging van de bloeddruk door een flavonoïd-rijke tomaat, zoals we gezien hebben in de spontaan hypertensieve ratten, een substantiële invloed heeft. Een ander verschil tussen geneesmiddelen en nutriënten is dat onze kennis over het moleculaire mechanisme van de activiteit van de nutriënt vaak nog beperkt is. Het moleculaire mechanisme, inclusief bio-beschikbaarheid en metabolisme, moeten uitgebreid bestudeerd worden voordat een geneesmiddel kan worden geregistreerd voor humaan gebruik. Voor de meeste nutriënten met een gezondheidsclaim ontbreekt deze kennis. Toch worden deze nutriënten geconsumeerd door een grote populatie en zelfs vaak ingenomen in hoge doseringen via voedingssupplementen. Veelal is het bewijs voor positieve gezondheidseffecten van voedingscomponenten verkregen via 
epidemiologische studies die een effect relateren aan bepaalde typen voeding. Gebaseerd op deze observaties, wordt er geprobeerd om in het dieet de hoeveelheid van stoffen die geassocieerd zijn met goed gezondheid te vergroten, bijvoorbeeld door genetische manipulatie van groente en fruit. Op dit moment is de publiek opinie erg kritisch ten opzichte van deze producten.

Het ophelderen van het moleculair mechanisme dat verantwoordelijk is voor de positieve effecten van nutriënten en identificeren van nutricoforen heeft meerdere voordelen. Ten eerste, kunnen gezondheidsbevorderende ingrediënten in het dieet worden geïdentificeerd en voedingsmiddelen, die deze ingrediënten in voldoende mate bevatten, kunnen worden ontworpen. Bovendien zal acceptatie en consumptie van verrijkte producten toenemen, wanneer het algemene publiek meer kennis heeft over hoe gezondheidseffecten met bepaalde nutriënten bereikt worden. Op deze manier zal kennis over het moleculaire mechanisme en identificatie van nutricoforen het fundament vormen van een goede gezondheid. 


\subsection{Referenties}

Benito, S., Lopez, D., Saiz, M.P., Buxaderas, S., Sanchez, J., Puig-Parellada, P. and Mitjavila, M.T., (2002) A flavonoid-rich diet increases nitric oxide production in rat aorta. British Journal of Pharmacology 135 (4), 910-916.

Chiesi, M. and Schwaller, R., (1995) Inhibition of constitutive endothelial $\mathrm{NO}^{\bullet}$ synthase activity by tannin and Quercetin.

Biochemical Pharmacology 49 (4), 495-501.

Cook, N.R., Cohen, J., Hebert, P.R., Taylor, J.O. and Hennekens, C.H., (1995) Implications of small reductions in diastolic pressure for primary prevention. Archives of Internal Medicin 155 701-709.

Duarte, J., Perez-Vizcaino, F., Zarzuelo, A., Jimenez, J. and Tamargo, J., (1993) Vasodilator effects of quercetin in isolated rat vascular smooth muscle. European Journal of Pharmacology 239 (1-3), 1-7.

Heijnen, C.G.M., Haenen, G.R.M.M., Wiseman, S.A., Tijburg, L.B.M. and Bast, A., (2000) The interaction of tea flavonoids with the $\mathrm{NO}^{\circ}$-system: discrimination between good and bad $\mathrm{NO}^{\circ}$. Food Chemistry 70 (3), 365-370. John, J.H., Ziebland, S., Yudkin, P., Roe, L. and Neil, H., (2002) Effects of fruit and vegetable consumption on plasma antioxidant concentrations and blood pressure: a randomised controlled trail. Lancet 359 1969-1974. 



\section{Dankwoord}

Zonder promotor en co-promotor, geen AIO-project vanaf het allereerste begin tot dit eind. Zonder de gezellige werkomgeving, geen resultaten.

Zonder formele en informele discussies, geen vooruitgang.

Zonder stress-bestendige vrienden, geen relativering.

Zonder een vertrouwd thuisfront, geen proefschrift.

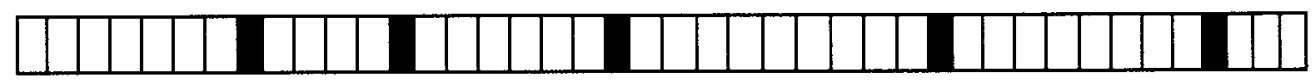

(invullen met de overgebleven letters) 


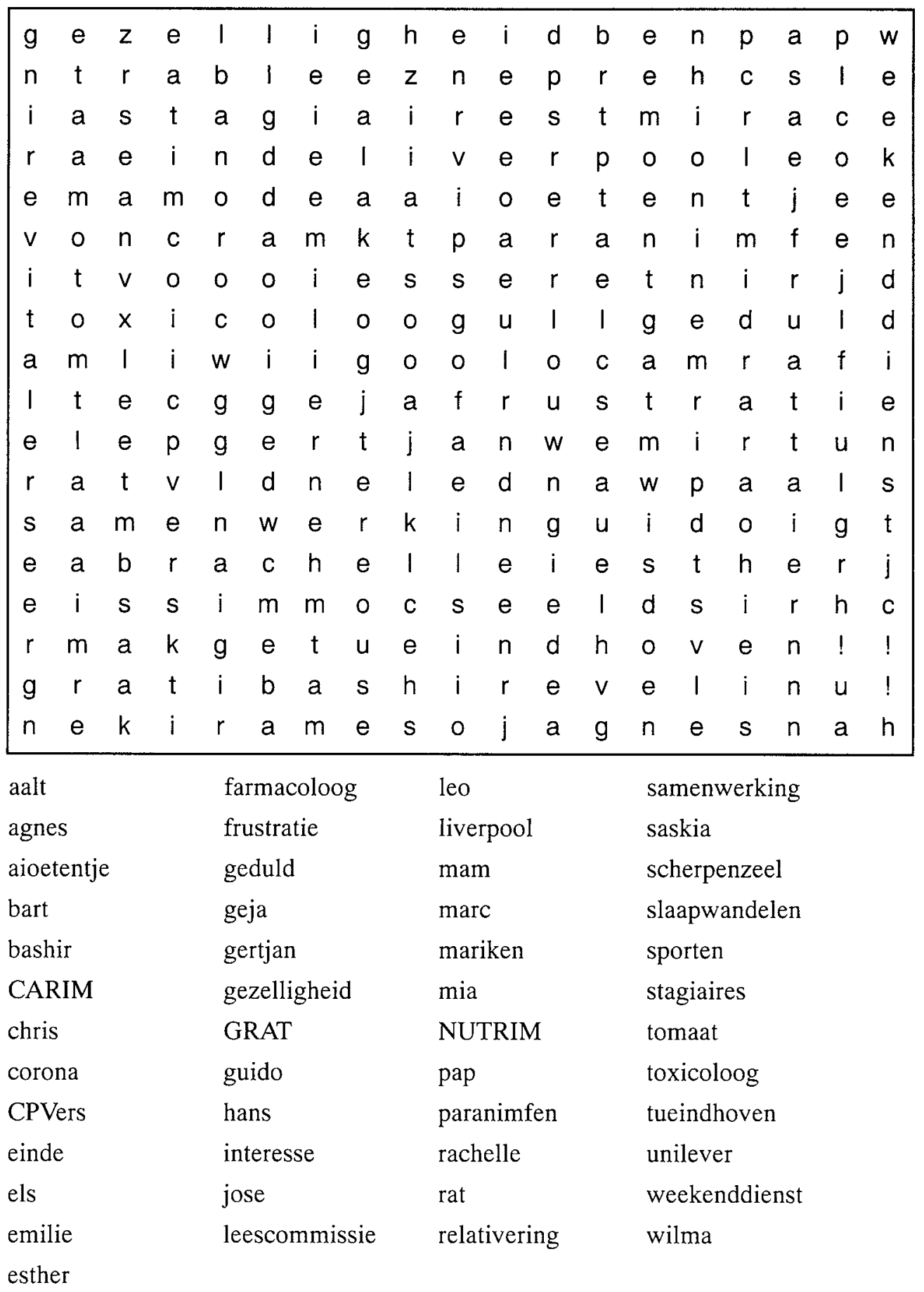





\section{Curriculum Vitae}

Op 15 Oktober 1974 werd Chantal Heijnen geboren te Utrecht. In 1987 begon haar Gymnasium opleiding op het St. Willibrord Gymnasium te Deurne, waar zij in 1994 haar diploma in ontvangst mocht nemen. In datzelfde jaar ging zij naar de Rijksuniversiteit Limburg (tegenwoordig Universiteit Maastricht) om Gezondheidswetenschappen te gaan studeren met als afstudeerrichting Biologische gezondheidskunde. Haar afstudeerstage vond plaats binnen de capaciteitsgroep Neurowetenschappen aan de Universiteit Maastricht, faculteit Geneeskunde onder leiding van Dr. J. De Vente. In 1999 behaalde ze het doctoraaldiploma. Direct na het behalen van het diploma startte ze op 1 Maart 1999 als assistent in opleiding bij de capaciteitsgroep Farmacologie en Toxicologie, sectie Humane toxicologie, aan de Universiteit Maastricht. Het onderzoek werd uitgevoerd onder begeleiding van Dr. G.R.M.M.Haenen en Prof. Dr. A. Bast en staat beschreven in dit proefschrift. Tijdens deze periode voltooide zij tevens de opleiding tot toxicoloog. Van 1 Juni 2003 tot 1 mei 2004 was Chantal Beerens-Heijnen werkzaam als toxicologisch onderzoeker, op de afdeling New Ingredient Discovery van Numico-Research, te Wageningen. Vanaf 1 mei 2004 werkt ze bij haar huidige werkgever, NOTOX Safety and Environmental Research, te 's-Hertogenbosch als studieleider op de afdeling Toxicologie. 


\section{List of publications}

\section{Articles}

C.G.M. Heijnen, G.R.M.M Haenen, S.A. Wiseman, L.B.M. Tijburg and A.Bast. The interaction of tea flavonoids with the $\mathrm{NO}^{\circ}$-system: discrimination between good and bad NO". Food Chemistry 2000, 70(3), 365-370.

C.G.M. Heijnen, G.R.M.M. Haenen, F.A.A. van Acker, W.J.F. van der Vijgh and A. Bast. Flavonoids as peroxynitrite scavengers: the role of the hydroxyl groups. Toxicology In Vitro 2001, 15(1), 3-6.

C.G.M. Heijnen, G.R.M.M Haenen, J.A.J.M. Vekemans, A. Bast Peroxynitrite scavenging of flavonoids: structure activity relationship. Environmental Toxicology and Pharmacology 2001, 10, 199-206.

C.G.M. Heijnen, G.R.M.M. Haenen, R. Minou Oostveen, Eva M. Stalpers and Aalt Bast. Protection of flavonoids against lipid peroxidation: The structure activity relationship revisited. Free Radical Research 2002, 36(5), 575-581.

M.J.T.J. Arts, G.R.M.M Haenen, L.C. Wilms, S.A.J.N. Beetstra, C.G.M. Heijnen, H.P. Voss, A. Bast. Interactions between flavonoids and proteins: effect on the total antioxidant capacity. Journal of Agricultural and Food Chemistry 2002, 50, 1184-1187.

C.G.M. Beerens-Heijnen, M. Verhoeyen, J. Kloek, W. Kloots, H. Roxborough, S.Wiseman, A.W. Boots, G.J.M. den Hartog, G.R.M.M. Haenen, and A. Bast. The effect of flavonol-enriched tomato paste on blood pressure in spontaneously hypertensive rats. (submitted) 


\section{Abstracts}

C.G.M. Heijnen, G.R.M.M. Haenen, A. Bast.The interaction of flavonoids with the $\mathrm{NO}^{\circ}$-system. European Summer Meeting of the Society of Free Radical Research, 20-22 juli 2000 Liverpool

C.G.M. Heijnen, G.R.M.M. Haenen, A. Bast. Flavonoids and the $\mathrm{NO}^{\circ}$-system. FIGON Geneesmiddelendagen, 2-3 oktober 2000 Lunteren.

C.G.M. Heijnen, G.R.M.M. Haenen, A. Bast. Interaction of flavonoids with the $\mathrm{NO}^{\circ}$-system: peroxynitrite scavenging. Proceedings of the scientific meeting of the Netherlands Society of Toxicology 6-7-8 december 2000 Kerkrade.

C.G.M. Heijnen, G.R.M.M. Haenen, A. Bast. The structure activity relationship the peroxynitrite scavenging by flavonols. 2001 World Congres of the Oxygen Club of California and the SFRR International.

7-10 maart 2001 Santa Barbara

C.G.M. Heijnen, G.R.M.M. Haenen, A. Bast. Unraveling the pro- and anti-oxidant activity of flavonoids. Proceedings of the scientific meeting of the Netherlands Society of Toxicology 11-12-13 November 2001 Nijmegen.

C.G.M. Heijnen, G.R.M.M. Haenen, A. Bast. Pro- and anti-oxidant activity of flavonoids. Proceedings of the scientific meeting of the Netherlands Society of Toxicology 14-15 January 2003 Utrecht. 